\title{
National Appropriateness of International Climate Policy Frameworks \\ in India, Brazil, and South Africa
}

\author{
Prabhat Upadhyaya
}

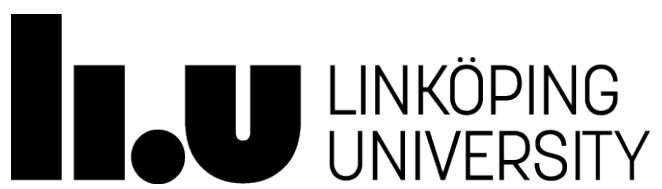

Linköping Studies in Arts and Science No. 708

Faculty of Arts and Sciences

Linköping 2017 
Linköping Studies in Arts and Science $\cdot$ No. 708

At the Faculty of Arts and Sciences at Linköping University, research and doctoral studies are carried out within broad problem areas. Research is organized in interdisciplinary research environments and doctoral studies mainly in graduate schools. Jointly, they publish the series Linköping Studies in arts and Science. This thesis comes from the Department of Thematic Studies - Environmental Change.

Distributed by:

Department of Thematic Studies - Environmental Change Linköping University

58183 Linköping

SWEDEN

Prabhat Upadhyaya

National Appropriateness of International Climate Policy Frameworks

in India, Brazil, and South Africa

Edition 1:1

ISBN 978-91-7685-582-9

ISSN 0282-9800

Cover image: Illustration by Johanna Basford, from Enchanted Forest (Förtrollade skogen), 2015 Cover coloring: Prabhat Upadhyaya

CPrabhat Upadhyaya

The Department of Thematic Studies - Environmental Change 2017

Printed by: LiU-Tryck, Linköping 2017 
For my Parents. 

It is good knowing that glasses are to drink from; the bad thing is not to know what thirst is for.

$\sim$ Antonio Machado, Songs \& Proverbs

If you are irritated by every rub, How will you be polished?

$\sim$ Rumi 



\section{CONTENTS}

SUMMARY

LIST OF APPENDED PAPERS

Author's contributions

ABBREVIATIONS___ iii

ACKNOWLEDGEMENTS ___ iv

1 INTRODUCTION 1

1.1 Aim and Research Questions ___ 3

1.2 Summary of Papers_______ 5

1.3 Structure of the Thesis ___ 6

2 BACKGROUND _ 7

2.1 NAMAs: Definitional Aspects ___ 7

2.2 NAMAs: Institutional Aspects ___ 11

2.3 Climate Policy and Mitigation in Emerging Economies ___ 16

2.4 Climate Policy in India, Brazil, and South Africa ___ 18

3 THEORY AND ANALYTICAL FRAMEWORK 25

3.1 Policy Process Theories___ 25

3.2 Policy Cycle Model used for studying Policy Processes___ 29

3.3 Institutional Perspectives ___ 32

4 METHOD 41

4.1 Mixed-Method Approach ___ 41

4.2 Sequential Explanatory Research Design____ 43

4.3 Empirical Material ___ 46

4.4 Linking Theory and Empirical Material ___ 50

5 RESULTS

5.1 Domestic Policy Responses to Climate Change in Emerging Economies ___ 55

5.2 NAMA Engagements in India ___ 56

5.3 NAMA Engagements in Brazil____ 62

5.4 NAMA Engagements in South Africa_____________ 66

6 DISCUSSION 71

6.1 Comparing NAMAs in IBSA ___ 71

6.2 NAMAs and Climate Governance ___ 77

7 CONCLUSIONS _ 83

7.1 Lessons for Nationally Determined Contributions ___ 88

7.2 Future research areas_____ 91

REFERENCES _ 93

APPENDICES _ 113

Appendix I: Interview Guide ___ 113

Appendix II: Interviewee Descriptions ___ 115 


\section{LIST OF TABLES}

Table 1: National-Level Climate Policy Initiatives in Emerging Economies.___ 17

Table 2: Socio-Economic Parameters, by IBSA countries _ 19

Table 3: GHG Emissions Including LULUCF, by IBSA countries ___________ 20

Table 4: Comparison of Policy Process Theories ____ 28

Table 5: Roles of Different Methods in the Four Papers ____ 44

Table 6: Interviewee Distribution _____ 47

Table 7: Empirical Material ______ 50

Table 8: Key Themes in the South African Climate Policy Process _________ 


\section{SUMMARY}

How does the international climate policy frameworks influence the domestic institutional responses to climate mitigation in emerging economies? And how, in turn, do domestic institutions and politics in emerging economies influence the fate of international climate policy frameworks? The thesis provides answers to these questions by studying domestic engagements with Nationally Appropriate Mitigation Actions in three emerging economies India, Brazil, and South Africa. The thesis specifically studies how these engagements were influenced by the domestic institutional context provided by national climate policy, norms, and institutional capacity in the three countries. Drawing upon the variations in the engagements with nationally appropriate mitigation actions, made visible by use of the policy cycle as a heuristic device, the thesis informs the implementation of another nascent, yet prevalent, international climate policy framework - Nationally Determined Contributions.

The thesis identifies how engagements with nationally appropriate mitigation actions varied in India, Brazil, and South Africa in agenda-setting, policy formulation, decision-making, implementation, and evaluation. In cases where international support is considered crucial for taking mitigation actions, external factors such as lack of clarity on definitional aspects and availability of international support can hamper the prospects of such frameworks at the agenda-setting and policy formulation stages. Efforts to engage with these frameworks under this uncertainty are held back by non-decisions, overriding national climate policy, as well as by uneven inter-ministerial coordination. The thesis argues that successful implementation of upcoming Nationally Determined Contributions will be influenced by a country's ability to align them with its national climate policy, localization of the transnational norms, and the extent to which efforts to enhance institutional capacity for coordinating the implementation of national climate policy are made. In sum, the effective implementation of International Climate Policy Frameworks will be dependent on the willingness of the state to provide oversight and coordination, and clarity on the availability of international support.

Keywords: Policy process, Institutions, Domestic Politics, Nationally Appropriate Mitigation Actions, National, Climate Policy, India, Brazil, South Africa, Institutional Capacity, Norms, Nationally Determined Contributions. 


\section{LIST OF APPENDED PAPERS}

This thesis is based on the following papers. The papers are referred to by their roman numbers in the thesis.

Paper I: Dubash, Navroz K., Markus Hagemann, Niklas Höhne, and Prabhat Upadhyaya. (2013). "Developments in National Climate Change Mitigation Legislation and Strategy”. Climate Policy 13 (6): 649-64.

Paper II: Upadhyaya, Prabhat. (2016). "Aligning Climate Policy with National Interest: Disengagements with Nationally Appropriate Mitigation Actions in South Africa". Journal of Environmental Policy \& Planning 18 (4): 463-481.

Paper III: Upadhyaya, Prabhat, Mathias Fridahl, Björn-Ola Linnér, and Mikael Román. (Manuscript). "Comparing climate policy processes in India, Brazil, and South Africa: the case of domestic engagement with "Nationally Appropriate Mitigation Actions".

Paper IV: Upadhyaya, Prabhat, Mathias Fridahl, and Björn-Ola Linnér. (under review). Institutional Engagements with International Climate Policy Frameworks in India, Brazil, and South Africa. Submitted to International Environmental Agreements: Politics, Law and Economics, published here with kind permission of Springer Science and Business Media.

\section{Author's contributions}

Paper I was co-authored with Navroz K. Dubash, Niklas Höhne, and Markus Hagemann. Prabhat Upadhyaya, the author of this thesis, conducted the background research, codeveloped the methodology, coordinated the data collection and data analysis for the paper, personally collected data for all the countries profiled in Asia and Africa, and construction of the database.

The author is solely responsible for Paper II.

For papers III and IV, the author conducted the empirical work and preliminary analysis, contributed to developing the analytical framework, coded the material, and contributed to the overall writing. 


\section{ABBREVIATIONS}

CDM Clean Development Mechanism

COP Conference of Parties

GDP Gross domestic product

GHG Greenhouse Gas

GIZ Deutsche Gesellschaft für Internationale Zusammenarbeit

IBSA India, Brazil, and South Africa

INDCs Intended Nationally Determined Contributions

LULUCF Land use, land use change, and forestry

MRV Measurable, reportable, and verifiable

NAMAs Nationally Appropriate Mitigation Actions

NDCs Nationally Determined Contributions

NGOs Non-governmental organizations

PPP Purchasing power parity

SARi South African Renewable Initiative

SSF Sustainable Settlement Facility

V-NAMA Vertically-Integrated Nationally Appropriate Mitigation Action

UNFCCC United Nations Framework Convention on Climate Change 


\section{ACKNOWLEDGEMENTS}

This thesis is a product of rendezvous and conversations spanning at least four countries. In our so-called globalised world, few of us are afforded the privilege to engage with such diverse constituencies. Attempting to acknowledge the individuals and institutions that came together in serendipitous ways to afford me this privilege is a tough task, but a task that is most important in the journey that now comes to a close. Safe to surmise, my debts are spread far and wide, in both space and time.

I would like to thank Björn-Ola Linnér, for putting his trust in me all throughout the last four years. I benefitted immensely from his vast repository of knowledge. More importantly, he not only motivated me when I was down but also challenged me whenever I became complacent. To see him push his physical and mental limits outside the academic environment, be it on futsal field or on the treacherous trek to Machu Pichu, made me demand more from my own self. I would also like to thank his family, Monika Linnér and kids for welcoming a stranger on a cold, snowy Swedish night and for letting me be part of their adventures.

Mathias Fridahl, who took on, and juggled with the multiple roles that he had to play as my colleague, friend, co-author and finally, as my supervisor, played the roles of good cop and bad cop with aplomb. He very subtly encouraged me to be more open to the theoretical approach to research and yet remain attentive to the empirical findings. Thanks are also due to Fridahl family who shared with me their love and also flowers from their garden.

I would like to thank Eva Lövbrand for opening me up to explore the world of ideas. Her encouragement to raise my arguments and to see the bigger picture remain an ideal that I continue to strive for. I learned the importance of developing a wider perspective on things from her.

My thesis would have been half its worth, if not for the critical feedback it received from the reviewers at different stages of my work. I received constructive criticism and encouraging feedback for improving my work during 30\%, 60\% and the final seminars. They not only helped me utilise my empirical material better but also encouraged me to make some difficult choices towards the last phase of my writing. I thank each one of them for their suggestions and feedback on improving my work. I have attempted to incorporate as many valuable suggestions as I could. I hope that the thesis now addresses their concerns and inputs.

I would like to thank my funders, the Swedish Energy Agency, which supported my work under the Governing NAMAs project. The state of higher education in Sweden provides a useful model that fosters the spirit of inquiry - a prerequisite for the knowledge economy. I hope that more researchers from developing countries get the opportunity to conduct their research in Swedish environment. As this journey comes to an end, I must also express my gratitude to Michael Mehling and Navroz K. Dubash for supporting my candidature. I would also like to thank my co-authors. In business lexicon, each one of them has been a shareholder 
in this endeavour. Their thoughts and suggestions find expression throughout the thesis. Thanks are also due to Maria Jernaäs and Chahrazad Zahi for their help in transcribing the interviews.

My interest in comparative research was ignited in 2011 when I was visiting the South African Embassy in Berlin, which happens to be beside the Indian Embassy on the Zoologischergatan. Compared to the South African Embassy that had a semi-glass façade and a very basic check for entrants, entering the Indian Embassy - with its iron fences, red sandstone structure and presence of armed security on the main gate - entailed a routine check up of your belongings in order to establish your identity. I am not sure if this is still the same, but at that time, it made me wonder why the two embassies - located not only in the same city, but on the same street, and alongside each other - had so different approaches to national security. Once I travelled to South Africa, I realised that in India, you may get by with just a lock at your property, but in South Africa, raised fences and electric wires around your property is considered normal. This raised my interest in countries domestic realities and their international projections, something that I have tried to explore in this thesis. This and many other such instances keep me enthralled about the peculiarities that countries come to see as normal. The 43 interviewees whom I interviewed, helped me to compare and make sense of these peculiarities in India, Brazil, and South Africa. I would like to thank each one of them for sharing their perspectives with me. Their views have shaped this thesis. In order to maintain confidentiality, they will remain anonymous.

I am assured that in thanking my colleagues and friends in India, Brazil, South Africa, Sweden, and beyond, I will miss many names. My sincere apologies for all those who do not find their names below. Kindly excuse this error as fallibility of a human mind that has been besieged by the weight of finishing the thesis in time.

In South Africa, I would like to begin my thanks by acknowledging the support extended by the Energy Research Centre at the University of Cape Town for hosting me in 2014. At the centre, I would like to thank Prof. Harald Winkler, Kim Coetzee, Anya Boyd and Britta Rennkamp for supporting my research with their valuable inputs. Interactions with Andrew Marquard, Marta Torres Gunfaus, Bram Buijs, Alfred Moyo, Hilton Trollip and Jesse Burton were useful for me to improve my understanding of the South African context. Fazlin Harribi's cheerful disposition made the work environment very hospitable. Most importantly, Late Giesela Prasad and her husband Jamuna Prasad extended their wisdom and support to me during a testing time. Gisela's counsel is sorely missed. Outside the ERC environment, I would like to thank Lesley Masters and Emily Tyler for their inputs at different stages of my work. Charles Roger helped me connect with colleagues in South Africa and gave me sage advice on preparing for my field work.

In Brazil, my research was aided by views shared by Prof. Schaffer, Prof. Viola and Mikael Román. By a stroke of luck, our department's collaboration with Brazilian partners ensured that many Brazilian researchers were based in Linköping. My conversations with Alex Enrich Prast, Angela, Marcelo Côrtes, Roberta Piexoto, Fausto Machado-Silva ensured that I remained informed about the developments in Brazil. Their views were particularly helpful in making me aware of the political dynamics prevalent in Brazil during this time. 
In India, I would like to thank the Climate Initiative at the Centre for Policy Research (CPR) and, The Energy and Resources Institute (TERI) for providing me with platforms to pursue my work. I would also like to thank CPR and the Iora Ecological Solutions Pvt. Ltd. For hosting me in 2015. In particular, I would like to thank Navroz Dubash, Manish K. Shrivastava and Swapan Mehra for providing me feedback and suggestions to improve my research. I would also like to thank all the colleagues who have guided me and invested in me over the years. It has been an immensely enriching experience to work with each one of you. I hope you will share my joy and happiness on reaching a milestone in my professional life. To colleagues who are more of friends, Manish, Swapan, Anupam Badola, Indu Kalpa Saikia, Neha Pahuja, Soumitri Das, I am eagerly looking forward to seeing you again. I don't think you will let me off by just thank you. My personal guides from IIFM days, Jagjeet Singh Sareen, Kanishk Negi, Nirmalya Choudhry and SomShekhar Bhattacharya, words can't begin to express the importance of your counsel. I look forward to thanking you in person. Friends from IIFM, Jyoti, Madhu, Subhro, Paramjyoti, Shashi, Anup, Bhaskar, Parth and Jaspal - I hope that you will keep me grounded as ever. Sanjhi, Aparupa and Nitin were always there when I needed them. To thank them will be to undermine the relationship that I share with them.

I would also like to thank all the colleagues at the department, particularly, Anna Bohman, Mathias Hjerpe, Julie Wilk, Anna Johnson, Madelene Ostwald, Joyanto Routh, Carlo Navarra, Lena Lundman and David Bastviken who shared their experiences over many rounds of fika and uncountable cups of coffee. Thank you, Susanne Eriksson, Ingrid Leo, Carin Ennergård, Ian and Mikael For making life at TEMA-M easier.

This journey would not have been enjoyable without the fellow PhD candidates, both past and present. Erik, Ola, Naghmeh, Martin, Sabine, Therese, Malin, Sepher, Magdalena, Devnita, Sivakiruthika, Vladimir, Luka, Lazare, Eva-Maria, Love-Raoul, Jamshaid, Dennis, Magali, Lotten, Anne, Emelie and Anna- thank you all for helping me to keep going. I made many friends in Sweden from the Indian sub-continent, whom I would have probably never met in India. Rizwan, Tejal, Chanchal, Sathish, Prithvi, Jacob, Meenu, Jonah, Sankar, Jamshed and Rubayat, thank you all for making me feel at home when needed.

I would like to thank my family for believing in me and for making me who I am. My parents for their unconditional love, patience, understanding and blessings; for teaching me to read and write; and infusing in me the confidence to test the unchartered waters. You are the reason this thesis has found its existence. To my brother Prashant and his wife Shruti, thank you for your patience and for putting up with my eccentricities. Thank you Tau ji and Tai ji for paving the way for my generation. Thank you to everyone in my family for having trust in me and cheering for me from afar.

Finally, I would like to thank Meagan, the most important person in my life, who put her life on hold for me. Thank you for believing in me even when we disagreed. Without your support and encouragement on daily basis, this book would not have seen the light of the day. This book is as much yours as it is mine and I can't wait to celebrate its completion with you. More than that, I can't wait for us to come together now. 
Lastly, I would like to remember and thank the part of my family that passed away during this time. Nana ji and Nani ji, I wish I could have started and finished this much sooner. Shirish, mere bhai, wherever you are, I hope you are at peace. 


\section{INTRODUCTION}

Climate change, on account of its scale and complexity, is a policy problem unlike any other. Keeping the atmospheric concentrations of greenhouse gases (GHGs) well below the level commensurate with $2^{\circ} \mathrm{C}$ temperature rise - if not $1.5^{\circ} \mathrm{C}$ - poses a challenge of incomparable proportions. At the $21^{\text {st }}$ Conference of the Parties (COP21) to the United Nations Framework Convention on Climate Change (UNFCCC), the international community agreed by consensus to address climate change through the "Paris Agreement".

The Paris Agreement exemplifies the gradual shift from top-down approaches to addressing climate change - as envisaged under the Kyoto Protocol to the UNFCCC - toward bottom-up approaches. However, it retains some important elements of top-down architecture, for example, oversight of the commensurability of collective efforts in the form of an accounting rulebook, a system for evaluating and reporting progress, and a global stocktaking exercise (UNFCCC, 2015). The result is expected to be a hybrid architecture of governance (Bäckstrand, Kuyper, Linnér, \& Lövbrand, Forthcoming; Bodansky, Hoedl, Metcalf, \& Stavins, 2016) in which implementation by means of Nationally Determined Contributions (NDCs) is bottom-up and the global stocktaking is top-down in nature. The global stocktaking exercise is scheduled every five years to track whether global efforts are commensurate with the pathways required to keep dangerous climate change at bay. The numerous battles to address climate change will be fought under the flags of national determination and are expected to be largely driven at national levels, but the strategy for determining who is expected to lead the charge, who is falling behind, and who is to bear the cost of addressing climate change, will continue to be influenced by international negotiations (Betsill et al., 2015). By studying and comparing domestic engagements with international climate policy frameworks for enhancing mitigation actions, we can be better prepared for the challenges in making this hybrid architecture work (Roger, Hale, \& Andonova, 2017). International climate policy frameworks to reduce GHG emissions are here considered to be a set of guiding principles, institutional conditions, and long-term goals that collectively form the common reference point for policy making across jurisdictions.

In this thesis, I approach Nationally Appropriate Mitigation Actions (NAMAs) as an international climate policy framework. NAMAs emerged as a compromise between developing and developed countries during the COP13 in Bali (Helme, 2009; Rajamani, 2009). The paragraph 1(b)(ii) of the Bali Action Plan, states that, "Nationally appropriate mitigation actions by developing country parties [are to be undertaken] in the context of sustainable development, supported and enabled by technology, financing and capacitybuilding, in a measurable, reportable and verifiable manner;" (UNFCCC, 2007). I use the paragraph 1(b)(ii) of the Bali Action Plan and the decisions related to NAMAs taken subsequently, to approach NAMA as an international climate policy framework, comprising of: 1) guiding principles including that they should be undertaken in context of sustainable development, respect national sovereignty (emanating from nationally appropriate), contribute to mitigation in developing countries, able to receive international support (M. K. Shrivastava \& Upadhyaya, 2014), and ensuring transparency both in terms of support provided and action taken; 2) institutional conditions as the efforts to ensure transparency, accountability, and 
NAMA support, by setting up governance architecture such as the Green Climate Fund, different reporting and verification provisions and bodies, and the NAMA registry, and; 3) a long-term goal that it aims to achieve "a deviation in emissions relative to 'business as usual' emissions in 2020" (UNFCCC, 2011b).

This thesis focuses on the variations in the national interventions. Some of these variations can already be noted. First, national approaches to addressing climate change vary in terms of their legal obligations. While the developed world has largely followed a legislation driven approach to climate change mitigation, developing countries have largely taken strategic approaches. The difference between the two kinds of approaches is that while the former is approved through national parliament or an equivalent body, the latter is not. In a legislative approach, the government is obliged to establish an institutional apparatus by means of governing bodies or coordinating agencies. Strategic approaches, on the other hand, give the government greater flexibility. To account for this variance, I use "climate policy" to refer to both legislative (i.e. hard law or rule based) and strategic (i.e. soft law or planning) approaches undertaken by countries for addressing climate change at the national level.

Second, there is variance in how different governance levels interact in different contextual settings. For example, broader environmental policy in the European Union operates mainly via legislation, can influence national policies in individual European states, and maintains enough flexibility to take the form of multiple policy models at the national level as well as voluntary actions at sub-national levels. In developing countries, the Clean Development Mechanism (CDM) established under the Kyoto Protocol was able to provide a common reference point for project developers in developing countries to undertake project- and programme-level initiatives. CDM governance was varied and reflected general governance differences arising from the varied political-economic contexts of developing countries (Fuhr \& Lederer, 2009; Newell, 2009). There have been instances where in absence of national governments providing clear direction, transnational initiatives have emerged at sub-national levels (Harrison, 2007; Setzer, 2014). Drawing on these developments, efforts to facilitate linkages across regional, national and sub-national climate policies is being proposed (Bodansky et al., 2016; Green, Sterner, \& Wagner, 2014).

Third, there is variance in terms of the policy instruments being deployed. For example, pricing carbon by means of policy instruments, such as carbon tax or cap-and-trade systems, has largely been favoured in high-income countries (Borghesi, Montini, \& Barreca, 2016; Ellerman \& Buchner, 2007; Tuerk, Mehling, Flachsland, \& Sterk, 2009). The actual implementation of such instruments remains limited in developing countries; for example, emissions trading systems and carbon taxes have been adopted in very few developing countries (ICAP, 2016; World Bank \& Ecofys, 2016). Similarly, there is variance in the types of goals and targets defined (CAT, 2016; Nachmany et al., 2015) and in the participation of non-state actors in climate change governance (Nasiritousi, 2016).

However, our understanding of these variances is largely informed by studies based on industrialised countries (Compston \& Bailey, 2008; Harrison \& Sundstrom, 2010). Of late there is a growing emphasis on using customised frameworks to study and compare climate policies in a broader set of developing countries (Held, Roger, \& Nag, 2013a), more 
specifically, in rapidly industrializing countries or emerging economies (Bailey \& Compston, 2012; Fuhr \& Lederer, 2009), also while paying equal attention to cases of climate governance in both developed and developing countries (Bang, Underdal, \& Andresen, 2015; Nachmany et al., 2015). To further develop understanding of climate governance in developing countries, more specifically, in emerging economies (which are also crucial for climate mitigation), I study these variances with respect to India, Brazil, and South Africa's (henceforth, "IBSA") ${ }^{1}$ domestic engagements with the international climate policy framework provided by NAMAs. I use the term engagement as it does not take for granted any particular outcome since it signals openness to whether responses to NAMAs in IBSA are committed or non-committed, facilitative or refraining, affirmative or constricting. By studying NAMA engagements in different country contexts, this thesis emphasises that domestic engagements with international climate policy frameworks will vary and studies how domestic politics in different countries results in variations across these engagements.

\subsection{Aim and Research Questions}

The overarching objective of this thesis is twofold. First, to understand how domestic institutional responses to climate change mitigation in emerging economies get influenced by international climate policy frameworks. Second, to study how these domestic institutions determine the utility of international climate policy frameworks in the domestic arena. More specifically, the thesis aims to identify and account for variations in institutional approaches to addressing GHG emissions through NAMAs, in IBSA.

In attempting to understand the politics along the common international-varying national continuum of contexts, three research questions guide this thesis. These are:

1. What domestic policy responses have been undertaken in emerging economies to mitigate climate change, and what are the historical developments thereof? (Paper I).

2. How have IBSA engaged with the international climate policy framework of NAMAs in terms of agenda-setting, policy formulation, decision-making, implementation, and evaluation? (papers II and III).

3. How and why have national climate policy, ${ }^{2}$ norms, and institutional capacities in IBSA influenced engagements with the international climate policy framework of NAMA? (papers I-IV).

While the first research question sets out to define the broader context of institutional responses to climate change mitigation in emerging economies, the next two questions address different aspects of NAMA engagement in IBSA. This juxtaposing of a broad

\footnotetext{
${ }^{1}$ The study uses the IBSA initialism for ease of reference to the countries under study. The focus of the study is not the IBSA Dialogue Forum (set up in 2003) per se but the domestic politics surrounding the NAMA engagements of IBSA on both an individual and comparative bases. The collective understanding is subsequently used to compare the experiences of these countries, but not that of the IBSA Dialogue Forum. To avoid any confusion, "IBSA" is used when referring to these three countries' engagements with NAMAs.

${ }_{2}^{2}$ National climate policy is used to refer to domestic climate policy at the national level of governance. It is distinct from climate policy at sub-national level.
} 
perspective with context-specific elements is a consequence of the sequential explanatory research design (Ivankova, Creswell, \& Stick, 2006) adopted in this thesis. Section 4.2 elaborates on this research design in detail. By applying this design, the study identifies historical developments related to the domestic adoption of climate policy, as well as substantiate these developments by a detailed examination of the translation of policy initiatives into action in different country contexts. The research questions guide me in bringing the broader historical developments and three different country contexts together.

By moving from broader to more specific, the thesis travels from the international context of climate policy development to three country contexts. During this journey, the study takes the reader from a broad overview of global climate policy development to the national settings of domestic politics surrounding NAMAs in IBSA. The study focuses on the domestic politics in these three countries to conduct comparative case studies on stakeholder responses to the international climate policy framework of NAMAs. Here, the case study is understood "to include both within-case analysis of single cases and comparisons of a small number of cases" (George \& Bennett, 2005, p. 18). Case studies here serve as a subset of qualitative methods. The within-case, in-depth analysis of NAMA engagements in South Africa is used to identify the challenges faced in the policy process by domestic actors in using the NAMA framework. The findings are then complemented by comparisons across IBSA.

Drawing on the policy process literature, the study uses the policy cycle as a "heuristic device" (Jann \& Wegrich, 2007, p. 57) to study climate policy formulation in the case countries generally and NAMA engagements specifically. Using the policy cycle heuristic helps me analytically categorise the empirical material and delineate the unfolding of NAMA policy processes in IBSA. The influence of NAMAs on IBSA's domestic politics and vice versa is further analysed through the lens of the regulative, normative, and organizational dimensions of institutional analysis (Dang, Visseren-Hamakers, \& Arts, 2016; Dimitrov, 2005; Malets, 2014; Scott, 2014). I do this by means of comparing: a) domestic policy responses to climate change mitigation in emerging economies; b) understandings of the responsibility distribution aspect of addressing climate change in IBSA; and c) the influence of institutional capacity in carrying out consultations and coordination in IBSA.

With the consolidation of NDCs as a common climate policy framework, four important trends can be anticipated. First, ability of NDCs to meet their respective contributions will depend on their effective implementation. Therefore research on drivers and barriers of implementation will be important for climate governance studies. How and why implementation efforts vary will be a fruitful line of enquiry in seeking to understand the challenges in bridging the gap between policy formulation and actual policy implementation (Jordan et al., 2015; Keohane, 2015). This calls for more comparative studies. Second, the nature of these mitigation efforts will be influenced by domestic priorities. Paying attention to domestic factors and comparing them in different country contexts in order to study "governance across governments" will be necessary to get a better picture of how mitigation is evolving in different country contexts (Steinberg, 2012, p. 258). Third, given the scale of the challenge that climate change poses, the national government of the day, i.e. the state, is expected by most stakeholders, to be the central actor in terms of providing oversight, ensuring coordination, and facilitating implementation, all the while involving non-state 
actors to ensure transparency in governance. The state is also crucial because it can choose whether or not to engage with international environmental treaties in first place (Duit, 2014). Institutions governing the environment in developing countries are relatively new and have not developed a core constituency. At a time when the demands on the state in developing countries to address climate change are increasing, this can increase the pressure on the already stretched resources with which these institutions operate. Understanding the state and its institutional makeup in countries that are not yet developed is pertinent, as environmental governance is deeply impacted by other overriding priorities of the government (Steinberg, 2012). Finally, since domestic climate mitigation efforts will vary, their interactions with the international level along the international-domestic frontier will also differ. National climate policy may or may not engage with international climate policy frameworks. As a common international climate policy framework for climate action in developing countries, NAMAs also emphasise implementation, domestic determination, and the central role of the state in coordinating mitigation actions, while providing latitude for varied interpretation. While the implementation of NDCs is awaited, by investigating NAMA engagements in IBSA, this thesis will also reflect on whether or not understanding these engagements can help us better understand NDC engagements.

\subsection{Summary of Papers}

Paper I addresses the first research question by studying the uptake of national climate policy in all UN member states. The study is unique in its coverage and brings to the fore important historical developments regarding the nature of policy-driven approaches undertaken to enhance mitigation, by mapping and categorising national climate policy across the world, during two points in time - end of 2007 and end of 2012. The paper identifies a robust increase in the spread of climate policy, in terms of the number of countries, populations, and emissions covered. A notable increase has been witnessed in the uptake of climate policy in emerging economies (chapter 2), indicating that, as a group, emerging economies have started to institutionalise their mitigation efforts. These efforts follow both binding as well as nonbinding approaches that can create institutional "hooks" for further strengthening interventions to address climate change in these countries.

Paper II, focusing on South Africa, examines one case country but also provides the background for studying NAMA engagements in the other two case countries. It studies challenges in aligning NAMA initiatives with national interests represented by broader legislation and policy. The paper undertakes a detailed examination of NAMA engagements in South Africa until the middle of 2014. It highlights the challenges that various South African actors faced in using the NAMA framework. In doing so it also provides the elements needed to develop an understanding of the various NAMA initiatives undertaken to pursue national interests, and the difficulties faced by different actors, at different stages of the policy cycle in supporting these initiatives. It emphasises that, due to weak institutional support and lack of clarity on international support, new coalitions of ideas and interests have been unable to overcome the resistance of existing ones. The findings presented in the paper are then followed up by two comparative case studies. 
Paper III primarily deals with the second research question concerning how IBSA's engagements with NAMAs in different stages of policy cycle, namely agenda-setting, policy formulation, decision-making, implementation, and evaluation. This question is addressed by studying policy processes surrounding NAMAs in the three case countries. In the process, findings of Paper II are revisited and updated. The policy cycle model comprising five stages, namely, agenda setting, policy formulation, decision making, implementation, and evaluation (Howlett, Ramesh, \& Perl, 2009) - is used to study NAMA policy processes. The paper elaborates on both the individual as well as comparative experiences of IBSA. In answering the how question, the paper identifies a) instances of political engagement by means of resistance to, or acceptance of, NAMAs and b) areas of convergence and divergence in IBSA's NAMA engagements. This provides an understanding of how far along the policy cycle the IBSA nations have travelled and how different their experiences have been in the different stages of the policy cycle. The paper complements the research done in Paper I on the existence of national policies by studying the domestic engagement with the NAMA framework that was expected to support mitigation efforts in developing countries.

Building on the findings of Paper III, Paper IV focuses on how the regulative, normative, and organizational aspects of domestic institutional arrangements facilitated or refrained NAMA engagements in IBSA. By linking NAMA engagements to the broader national settings of each country characterised by the regulative (formal), normative (informal), and organizational (capacity) dimensions of institutions, the paper argues that institutions collectively determine the conception of national appropriateness and thus determine how NAMAs play out. It substantiates its claim by exploring IBSA engagements with NAMAs, which range from prompt policy- and project-level engagements in Brazil, through deliberate and project-specific engagements in South Africa, to cautious, programmatic, and multi-level engagements in India.

\subsection{Structure of the Thesis}

The introduction to the thesis is followed by a background on NAMAs and the relevance of selecting the IBSA countries as cases for the study of NAMA engagements. Delimitations of this approach are also discussed in chapter 2. Chapter 3 introduces the analytical framework of the thesis, which rests on bringing together elements of policy process and institutional theories. Chapter 4 introduces the reader to the mixed-method research design, the sequential explanatory approach, and the research methodology used for data collection and data analysis. The results of the thesis are presented in chapter 5, which explains the nature of climate policy in emerging economies, NAMA engagements in IBSA by delving into: how far along the policy cycle NAMA engagements have progressed in IBSA countries and the broader institutional context in which NAMAs have played out in IBSA. These engagements are discussed in chapter 6 in a comparative manner to find similarities and differences in IBSA's NAMA engagements and the relevance of these findings for broader climate governance. Chaper 7 concludes the thesis and provides some suggestions on areas for future research. 
In 2007, the COP13 to the UNFCCC reached a hard-won agreement in the form of the socalled Bali Action Plan: developing countries would contribute to the global effort through NAMAs, undertaken in the context of sustainable development. Their efforts were to be supported by means of technological, capacity-building, and financial resources (Rajamani, 2009; UNFCCC, 2008). The agreement acknowledged the existing priorities of developing countries and accounted for the responsibility of industrialised countries to support climate action in developing countries. Yet, by encouraging developing countries to take action, based on a facilitative, bottom-up model of international climate politics, it also acknowledged the importance of global action on climate change (Bodansky \& Diringer, 2014; Coetzee \& Winkler, 2014). However, complexities remain. This chapter covers the complexities identified in the NAMA literature from two perspectives: the definitional perspective to highlight differences in agreeing on what qualifies as a NAMA, and the institutional perspective to take account of the challenges identified when engaging with NAMAs. In elaborating on these perspectives, I also identify the definitional and institutional aspects on which I focus as part of my thesis.

\subsection{NAMAs: Definitional Aspects}

Paragraph 1(b)(ii) of the Bali Action Plan (UNFCCC, 2007) provided a very broad reference point for NAMA development, leaving unaddressed essential elements such as what constitutes a NAMA, sources of support, how NAMAs and support are to be measured, reported, and verified ("MRVed"), and how NAMAs might relate to existing policy instruments (Sterk, 2010a; Upadhyaya, Friman, \& Linnér, 2012; van Asselt, Berseus, Gupta, $\&$ Haug, 2010). It was argued that this lack of clarity could prove beneficial, as it provided countries with "tremendous scope for flexibility, customisation and innovation" (CCAP, 2012, p. 1). Initial studies on NAMA concurred with this assertion (Ecofys \& ECN, 2012; IRENA, 2012; Sterk, 2010b; Wang-Helmreich, Sterk, Wehnert, \& Arens, 2011). However, recent literature identifies challenges in translating this "tremendous scope" into reality (Amars, Fridahl, Hagemann, Röser, \& Linnér, 2016; Boyd, Coetzee, \& Boulle, 2014; Fridahl \& Johansson, 2016). Defining more precisely what constitutes a NAMA remains unresolved (Coetzee \& Winkler, 2014), making it worthwhile to delve deeper into some of the various interpretations of NAMAs.

Tyler et al. (2013) identify three approaches to classifying NAMAs. The first interpretation necessarily recognises submissions made to the Copenhagen Accord by developing countries as NAMAs (Sterk, 2010a). UNFCCC also refers to these submissions as NAMAs (UNFCCC, 2011a). However, countries such as India and China never explicitly used NAMAs in their submissions. This definition seems to force the NAMA label and terminology on the submissions made by some countries without their active acceptance of the label per se. As will become evident in chapter 5, Indian stakeholders actively reject such a classification. At the same time, Brazilian submissions to the UNFCCC consisted of a collection of specific NAMAs. Researchers guided by this interpretation of NAMAs have - depending on the 
nature of these submissions - further classified them into more specific categories of NAMAs, namely, National Emission Neutrality Targets, National Intensity Targets, Economy-National Target of Reduction below Business as Usual, Sectoral Emission Targets, Specific Actions, and a combination of Specific Actions and Aggregated Targets (Sterk, 2010a, pp. 5-6). This categorisation indicates the diversity of actions that have come to represent NAMAs, as per the first definition.

In the second interpretation, actions registered with the UNFCCC NAMA Registry, for the purpose of seeking support and/or recognition from the international community, are identified as NAMAs. Unlike the first, the NAMA Registry conception of NAMAs draws legitimacy from developing countries' intentional development of NAMAs and their explicit acknowledgement of the same through the NAMA Registry. Treating only this subset of mitigation actions from developing countries as NAMAs limits the NAMA pool to a smaller subset of mitigation actions. By October 2016, 37 out of 152 NAI countries had registered a total of 140 NAMAs with the NAMA Registry. Going by the composition of these submissions, two observations stand out: First, five countries, namely, Mexico (15), Serbia (13), Uganda, Jordan (nine each), and Pakistan (eight), account for a total of 54 NAMAs (UNEP DTU, 2016). Second, this indicates that in each of the world regions eligible to develop NAMAs, ${ }^{3}$ at least one country has taken the lead in NAMA development. One can argue that although NAMA development is geographically spread, it remains concentrated in a handful of countries. These 140 NAMAs requested total support of USD 8241 million, only USD 176 million or $2.13 \%$ of which has been disbursed by 18 NAMA support avenues (UNEP DTU, 2016). My previous work indicates that very little detail is available as to the nature of the support extended, particularly concerning the technical aspects, which are not specified in the information provided by these avenues on the NAMA Registry (M. K. Shrivastava \& Upadhyaya, 2014).

While all developing countries were encouraged to develop NAMAs, NAMA stakeholders expected that, since NAMAs provided for mitigation while remaining sensitive to domestic priorities, emerging economies stressing their need to develop would find them particularly attractive. Although there is no common definition of emerging economies, in this paper they are understood as those countries included in the Non-Annex I Parties to the UNFCCC that are also part of the G-20. These countries are Argentina, Brazil, China, India, Indonesia, South Korea, Mexico, Saudi Arabia, and South Africa. Most of the emerging economies are already taking domestic action in some form of climate policy (Table 1). Glemarec (2010, p. 9) anticipated that in the "absence of dedicated technical assistance, there is a major risk that only a few emerging economies will be able to develop NAMAs robust enough to lay the foundations for international financial transfers, and we will see a repeat of the CDM experience". "A repeat of the CDM experience" alludes to the fact that almost three-quarters of the CDM market was captured by China, India, and Brazil - all emerging economies (UNEP RIS $\varnothing$ Centre, 2016). Going by the above definition of emerging economies, we are witnessing a totally different picture of NAMA development, one in which, barring Mexico,

\footnotetext{
${ }^{3}$ Latin America, Europe and Central Asia, Africa, the Middle East, and the Asia and Pacific region.
} 
none of the emerging economies has yet submitted any NAMA to the NAMA Registry. NAMA development seems to be driven by countries other than emerging economies (UNEP DTU, 2016). Approaching NAMA development by means of the NAMA Registry presents a picture contrary to expectations, as emerging economies come across as indifferent to NAMAs. This raises a contradiction that is explored in this thesis.

The third definition, encompassing all the mitigation actions of a developing country as constituting a NAMA, is the broadest interpretation of NAMA, irrespective of whether or not it has been communicated to the international community as such. Although the literature indicates that this definition does not find acceptance among the climate practitioners from developing countries (Tyler et al., 2013), in my engagement with climate practitioners, the contrary point, i.e. that NAMAs and domestic mitigation actions are synonymous, also comes to the fore (papers III and IV). This distinction will also be presented in chapter 5. A complication of using this interpretation is that, due to an explicit emphasis on mitigation, other objectives can get undermined. By treating all mitigation actions as NAMAs, this interpretation can make the "national appropriateness" aspect almost redundant - as my previous work indicates - which can also undermine multilateralism (M. K. Shrivastava \& Upadhyaya, 2014).

One approach to studying NAMAs that has been suggested to better capture the spread of NAMAs beyond those officially registered with the UNFCCC is to use both intended as well as ongoing mitigation actions captured in the so-called NAMA Database maintained by Ecofys (Fridahl, Hagemann, Röser, \& Amars, 2015). This approach is also not without its share of problems. In the approach, the NAMA Database is developed along the lines of the wiki model, in which everyone is welcome to submit information regarding NAMAs. While this improves transparency by making the platform available to almost anyone who wants to contribute, the reliability of the information provided cannot be vouched for. Only 19 of the 210 NAMAs from 64 countries currently listed in the database are under implementation, rest are categorised as under development (Ecofys, 2016). Therefore, the information provided through the platform is at best indicative and at worst speculative. While 133 NAMAs in the NAMA Registry are also seeking support for either preparation or implementation, i.e. they are under preparation (NAMA Registry, 2017), the key difference is that the submissions to the NAMA Registry are made through government entities, giving the information greater credibility. In contrast, the information provided in the NAMA Database need not come from government entities and therefore needs to be corroborated by country-specific studies.

Due to lack of agreement on a concrete definition from the UNFCCC (Coetzee \& Winkler, 2014), it has been difficult for NAMA research to coalesce around any one common definition. This is in stark contrast to how the CDM benefited from the presence of a global body in the form of the CDM Executive Board, whose members had the mandate to make decisions on various aspects of implementing CDM and clarifying definitional issues. For the purposes of this thesis, no one NAMA definition comprehensively captures the NAMA developments in IBSA. For example, none of the three countries has shared any information on NAMAs in the NAMA Registry, so this definition would mean that IBSA has had no engagement with NAMAs, which, as noted below, is not correct. Using the Copenhagen Accord interpretation works for the Brazilian case but not for the Indian case, since India did 
submit a pledge under the Accord but did not interpret this pledge as a NAMA. Based on my interactions with the South African stakeholders, I thought that the NAMA Database interpretation is also somewhat unreliable (Paper II). Regarding all mitigation actions as NAMAs spreads the canvas too wide to be acceptable for key stakeholders in developing countries, since this is not how they seem to relate to the concept (Tyler et al., 2013).

Since I give precedence to the domestic contexts in my study, it therefore made sense to use an empirical definition of NAMAs (Paper IV), i.e.:

a) mitigation actions identified as NAMAs by the national government or government departments, or

b) in the absence of such identification by the national government or government departments, those mitigation actions consistently referred to as NAMAs by various stakeholders.

While the former definition is relatively easy to pin down, the latter keeps the door open to various non-state interpretations as well. However, the latter is open to the criticism that NAMAs only become official if sanctioned by the state, i.e. passing through state-designated NAMA approvers or a central agency that tends to be the country's Ministry of the Environment. My interaction with stakeholders in South Africa qualifies this sentiment. Having South Africa's Department of Environmental Affairs on board is a necessary but not sufficient condition for a successful NAMA (chapter 5 and Paper II). This also seems to be the case in India, where NAMAs are expected to be coordinated by India's Ministry of Environment, Forest and Climate Change (henceforth, "Indian Ministry of Climate Change"). It is therefore important to pay attention to the institutional arrangements through which other government bodies are involved in NAMA development, an aspect covered below. While my working definition of NAMA raises the question of comparability based on technical aspects, it still provides instances of how manifestations of climate policy can vary from one country context to another. This makes the task of understanding climate governance much more difficult (Newell \& Phillips, 2011) though, it is hoped, more reliable as well.

For South Africa alone, the international literature identifies more than 10 NAMAs, but researchers engaged with the country's NAMA development contest this, pointing to other "on the ground" activities that present a rich field with multiple institutions and actions beyond NAMAs (Boyd et al., 2014). This finding is in addition to the fact that despite South Africa being one of the main proponents of the NAMA Registry (Republic of South Africa, 2008), it has had a mixed representation of NAMAs across the various NAMA platforms. Similarly, many developing countries, including most of the emerging economies, seem to be taking domestic action on mitigation without necessarily referring to them as NAMAs. This brings me to an important rider to the above definition: not all mitigation actions currently planned or undertaken by a country are accounted for in the analysis (Garibaldi et al., 2013). Many domestic mitigation actions in developing countries do not refer to international terminologies. As will be explored in chapter 5, this distinction is important as it provides the institutional context in which NAMAs have to prove their utility for the emerging economies, in relation to their domestic mitigation efforts. 
As an international climate policy framework that is to be implemented domestically, successful NAMA engagement is influenced by both the ability of the international community to agree on a robust mechanism for NAMA support, as well as by the presence of a domestic climate framework flexible enough to accommodate the use of international climate policy frameworks in describing domestic mitigation actions (Biesenbender \& Tosun, 2014). Literature on the challenges facing NAMA engagement has identified institutional factors at both the international and national governance levels as important factors (Fridahl, Upadhyaya, \& Linnér, 2014; Fukuda \& Tamura, 2012; Garibaldi et al., 2013; Jung et al., 2010; Kim, Corfee-Morlot, \& de T'Serclaes, 2009; La Rovere, Pereira, Dubeux, \& Wills, 2014). In this section, I synthesise the NAMA literature to identify the important institutional aspects that previous research has alluded to. While I do refer to the institutional aspects at the international level, in line with my inquiry I explore the domestic institutional aspects in greater detail.

The literature studying NAMA engagement at the international level primarily focuses on aspects related to support and the measurable, reportable, and verifiable (MRV) aspect of (Levina \& Helme, 2009; Lütken, Aalders, Peters, Pretlove, \& Trexler, 2011; Okubo, Hayashi, \& Michaelowa, 2011; Sterk, 2010a). As discussed above, divergent views of the objectives of NAMAs persist. Support providers are seen to be underscoring mitigation as a key priority of NAMAs, whereas from a developing country perspective, it is often seen as a co-benefit to other objectives. As a result, it has been difficult to agree on common guidelines and modalities to develop NAMAs, resulting in the mushrooming of a number of independent bilateral and multilateral platforms to support NAMAs. This has not been matched by enthusiasm from emerging economies to submit NAMAs to these platforms, possibly because these platforms tend to have different requirements, increasing the transaction costs if a NAMA proposal is not accepted on its first submission. In contrast, there seems to be coherence regarding the timescale needed for NAMA development. Support providers mainly prefer and NAMA developers mostly use short time frames ( $<5$ years) for proposed actions (Fridahl et al., 2015). This can influence the type of effect a NAMA can have. While a transformational change agenda may be better served if its conception and ownership rest with the implementing country (Winkler \& Dubash, 2015), projects with short time frames may not be able to contribute to transformational change unless they have good exit strategies that allow for long project lifetimes once international support comes to an end (Fridahl \& Johansson, 2016).

Finding a balance between domestic ownership and attracting international support is a challenge for both international as well as domestic institutions. In the past, my colleagues and I have shown that even the Green Climate Fund's ability to support NAMAs will depend on clarity concerning its governance functions and finding the middle ground between developed and developing countries' demands (Fridahl et al., 2014). At the national level, the importance of institutions in ensuring successful NAMA engagement has been emphasised (Amars et al., 2016; Garibaldi et al., 2013). Unlike the emphasis on financing aspects at the international level, the focus here is on domestic institutions, institutional coordination, and institutional capacity, factors discussed in detail in section 2.2.3. Views of practitioners from 
IBSA, Colombia, Chile, and Argentina concur that implementing a low-carbon development strategy before taking on NAMAs can ensure that mitigation actions - whether in form of NAMAs or not - are in line with national priorities, as low-carbon development strategies can provide "a coherent framework for NAMAs" (Van Tilburg, Würtenberger, de Coninck, \& Bakker, 2011, p. iii; see also Tyler et al., 2013). Whether or not it actually happens is dependent on a variety of factors, including the development of such strategies in the first place. It is also possible that with the development of climate policy in many developing countries, the need to develop low-carbon development strategy or even low-emissions development strategy has already been catered to. In such a scenario, developing countries that tend to be financially constrained may use national climate policy as a focal point for various mitigation activities, including NAMAs. National climate policy can serve as a means to interpret national appropriateness for domestic actors.

As discussed above, the NAMA literature identifies three aspects of domestic institutional settings to be considered when examining NAMA development; these are:

- formal institutions, specifically the regulative context of climate policy, inclusive of efforts to mainstream, integrate, or align climate policy in national planning;

- informal institutions, specifically the normative context, particularly in relation to the distribution of responsibility for climate change; and,

- organizations and organizational arrangements, specifically the institutional capacity context that influences the ability to consult with stakeholders and facilitate engagement.

While the theoretical underpinnings of these aspects are discussed in detail in chapter 3 , below I summarise how these aspects have been evoked in the NAMA literature.

\subsubsection{Regulatory Context}

The NAMA literature indicates that NAMAs should be developed on the basis of mature national legislation or policy (Jung et al., 2010). Domestic actors can interpret what qualifies as nationally appropriate based on the respective institutional conditions, guiding principles, and long-term goals identified by domestic policy frameworks. These can be provided either by means of a top-down approach - driven by a country's overall priorities - in relation to mitigation or development, or by means of specific programme- or project-based approaches wherein each NAMA comes to be defined individually (Tyler et al., 2013). Studies indicate that support providers also highly prioritise both government ownership and consistency with national development strategies, even more than the means of measuring emission reductions or high sustainable development quotients for NAMAs (Fridahl et al., 2015). Based on a set of developing country studies, Coetzee and Winkler (2014, p. 4) argue that mitigation studies need to be "aligned either with national developmental priorities or poverty alleviation at some level". The national climate policy context is therefore important because it can provide a common reference point for NAMA developers, who can use it to align NAMA initiatives with domestic priorities. In South Africa's case however, Masters (2013, p. 274) argues that although many policy documents make "reference to climate change, this has not translated into a coherent approach to climate governance." To study this dimension of institutions, I therefore not only focus on the existence of the climate policy but also the efforts that were 
undertaken by IBSA to mainstream climate change mitigation efforts in general and the use of NAMAs in particular to pursue alignment amongst multiple objectives.

Fukuda and Tamura $(2012$, p. 2) identify mainstreaming as an essential element of NAMA formulation, comprising three components: inclusion of climate change mitigation in national plans, identification of priority sectors and actions, and spelling out of mitigation actions' operational details. By attracting international support, NAMAs are also expected to mainstream investment opportunities for clean energy into existing policy frameworks (Kim et al., 2009), sometimes provided by a low-carbon development strategy (X. Van Tilburg et al., 2011) or national climate policy. The mainstreaming exercise could also be approached in the reverse direction such that development prerogatives are mainstreamed into NAMAs (M. K. Shrivastava, Pahuja, Tewari, Pandey, \& Agarwal, 2014). While the involvement of important ministries and departments is key to the successful mainstreaming of climate change agendas, who leads the mainstreaming efforts could also be important. Even in a small subset of five South-East Asian countries, different ministries have been tasked with pursuing the mainstreaming agenda (Fukuda \& Tamura, 2012). Mainstreaming efforts also have an influence on institutional capacity. Tyler et al. (2014) anticipate that the closer mitigation actions are to mainstream governance activities (e.g. a carbon tax in South Africa), the less dependent they will be on institutional capacity to get implemented. However, the NAMA literature does not problematise the concept of mainstreaming per se. Alongside mainstreaming, several concepts have been used when discussing two or more multiple objectives such as win-win, synergies, integration. However, in the NAMA literature, two concepts stand out: alignment and linking. Both are used interchangeably in the literature to emphasise the importance of establishing synergy and connections among two or more policy objectives, often by developing avenues for cooperation. For example, in a national context, it is often used to refer to the conjunction of climate policy objectives and development (Van Tilburg, Würtenberger, et al., 2011; Tyler et al., 2014). Tyler (2011) explores how South Africa's energy policy and its mitigation efforts can be aligned. Similarly, links are explored between climate change mitigation and poverty (Wlokas et al., 2012); and other national development goals (Amars et al., 2016; Fridahl \& Johansson, 2016). These are also used from the support perspective to discuss how NAMAs should be designed so as to they can be linked to the available support (Fridahl et al., 2015, 2014; Kim et al., 2009; van Asselt et al., 2010).

\subsubsection{Normative Context in Relation to Responsibility Distribution}

Another important factor affecting how countries engage with NAMAs is how actors understand what constitutes a fair distribution of responsibility in international climate policy. This factor speaks to the normative context by bringing to the fore the views of participants on various norms in relation to responsibility distribution. I elaborate on the norm contestation resulting from these differences in section 3.3.2.

NAMA engagement in emerging economies provides an interesting empirical case in which the interpretation of and engagement with an international climate policy framework are to be carried out at national but also possibly at sub-national levels. As discussed above, efforts are underway to clarify what a NAMA entails, but there has been no agreement on its precise 
definition (Coetzee \& Winkler, 2014). However, in my previous work with Shrivastava (Shrivastava \& Upadhyaya, 2014), I show that NAMAs embody norms such as sovereignty, historical responsibility, multilateralism, and the obligation of developed countries to support mitigation in developing countries. NAMAs are also perceived as an instrument to pursue neo-colonialism (Amars et al., 2016), indicating that the normative legitimacy of the concept is questioned. The donor conception of NAMAs with a focus on carbon-centric conceptions of transformational change seems to dominate supporters' expectations of NAMAs (Winkler \& Dubash, 2015). By requiring that NAMA objectives be aligned with donors' criteria, bilateral sources of funding can undermine the sovereignty of developing countries (M. K. Shrivastava \& Upadhyaya, 2014), making it important to pay attention to the normative aspect of institutions in relation to NAMA development.

\subsubsection{Institutional Capacity}

According to Garibaldi et al., (2013), a favourable policy context for undertaking mitigation actions needs to be complemented by a strong institutional capacity to pursue the goals and objectives defined by climate policy. The ability to establish new institutional capacity is highlighted in Brazil for successfully implementing mitigation actions - particularly in the forestry sector (Garibaldi et al., 2013), but also regarding the MRV of transport NAMAs at the sub-national level (La Rovere et al., 2014). In Tanzania, the inability of the existing institutional framework to realise NAMA potential is attributed to lack of capacity in the lead department (Amars et al., 2016). When analysing four proposed South African NAMAs against a number of criteria, including existing relevant institutional capacity, Tyler et al. (2014) observe that, while weak state institutions are a concern, capacity issues do not hamper proposals that are distinctive in their approaches to climate mitigation. ${ }^{4}$ They are, however, not sure whether the international community can help overcome such constraints for other NAMAs. Amongst NAMA-specific criteria needed to support implementation, they also identify the availability of capacity to MRV GHG emissions as important.

Although La Rovere et al. (2014) argue that the availability of international finance is seen as a means to improve existing institutional settings, just making finance or technology available does not necessarily ensure the realisation of planned NAMAs. Comparisons across developing countries also identify institutional capacity (both technical and financial) as a crucial factor determining the success of mitigation actions. Garibaldi et al., (2013) identify variations in institutional capacity at the sectoral level in Brazil, Chile, Colombia, Peru, and South Africa as determining what actions are implemented. While Brazil created a new financial institution to meet the requirements to reduce deforestation, Colombia undertook a market-oriented approach to planning and regulation. Whereas ministries of energy are identified as stronger in Colombia, Chile, and Peru, ministries in charge of forestry are seen as having lower capacity. In South Africa, a capacity gap at the municipal level is identified, whereas central government is identified as having a strong design capacity, indicating that capacity is unevenly distributed. This is an important factor in my analysis (Paper IV).

\footnotetext{
${ }^{4}$ Two such actions identified were the South African Renewable Initiative (SARi) and the National Sustainable Settlement Facility (NSSF); both were seen as the "most advanced in their development as NAMAs" (Tyler, Boyd, Coetzee, \& Winkler, 2014) but have now been shelved (papers II and III).
} 
I assess the institutional capacity for NAMA development by studying the initiatives undertaken by national governments to conduct stakeholder consultations and enhance institutional coordination. According to Tyler et al. (2014) the ability to engage with a range of state and non-state actors by means of stakeholder consultation, striking a balance between different interests and capabilities is also an important facet of institutional capacity. Who constitute the stakeholders of a NAMA depends on the nature of the NAMA. NAMAs supported only by domestic means would cater to national stakeholders that may expect the NAMAs to meet domestic priorities. NAMAs supported by international finance or technology would also need to cater to global stakeholders who may expect the NAMAs to achieve the transformation of an economy (Linnér \& Pahuja, 2012). Transparent, participatory, and locally driven stakeholder consultations during the NAMA development phase are seen as important in order to garner across-the-board support (Röser, Van Tilburg, Davis, \& Höhne, 2011; Wang-Helmreich et al., 2011). Röser et al. (2011) considers regularly and openly communicating roles and responsibilities, establishing leadership and political ownership and involving stakeholders during NAMA development phase, as important learnings to avoid confusion. In addition, they consider coordinated inter-governmental processes to be particularly beneficial for NAMAs that involve multiple sectoral agencies. At the same time, these processes are often time-consuming. The relationship between stakeholder consultation and national climate policy development is best understood as mutually constitutive and iterative in nature.

The presence of a favourable policy environment therefore needs to be complemented by the capacity of the government department responsible for climate policy coordination and consultation in general (Garibaldi et al., 2013) to ensure successful implementation. Worthington (2014) and Chandrashekaran et al. (2014) for South Africa and Dubash and Joseph (Dubash \& Joseph, 2015) for India, identify uneven institutional coordination as a factor responsible for the ad hoc manner in which climate policy implementation has been approached in India and South Africa. Institutional coordination is crucial for undertaking mitigation actions in sectors such as buildings, transport, and demand-side management, which tend to have dispersed stakeholder groups (Cheng, 2010). Levina and Helme (2009, p. 24) suggest setting up "national NAMA coordination committees" or institutional structuresbeen suggested as a way to coordinate NAMA development, submission, and implementation (also see Fukuda \& Tamura, 2012 and; Röser et al., 2011). Most of the relevant literature emphasises inter-ministerial coordination at the national level - referred to here as horizontal integration - but also takes note of the small proportion of mitigation at the sub-national level (Xander Van Tilburg, Cameron, Würtenberger, \& Bakker, 2011, p. 12). The South African government indicated the development of "a vertically-integrated nationally appropriate set of mitigation actions (V-NAMA)" linking all levels of government, i.e. national, provincial, and local (Republic of South Africa, 2014, p. 154). The VerticallyIntegrated Nationally Appropriate Mitigation Action (V-NAMA) concept has been developed as part of a project by the German Federal Enterprise for International Cooperation (GIZ; in German, Deutsche Gesellschaft für Internationale Zusammenarbeit) to involve sub-national actors in Indonesia and South Africa in implementing a pilot multi-level governmental approach $(\mathrm{GIZ}, 2013,2014)$ to NAMA development. Taking a cue from the V-NAMA 
concept, I refer to the efforts to involve actors across different governance levels in NAMA engagement as vertical integration. Translating climate policy into action is dependent on both the ability and willingness of the relevant line departments to coordinate with other government departments (Tyler et al., 2013). I will show how institutional coordination or the lack thereof can determine the efficacy of efforts undertaken to implement NAMAs.

Based on the NAMA literature, I identify three institutional aspects as crucial to understanding NAMA engagement in different countries: domestic regulatory context, normative context regarding responsibility distribution, and institutional capacity. The theoretical underpinnings of these institutional aspects and the method used in studying them are further elaborated in chapters 3 and 4.

\subsection{Climate Policy and Mitigation in Emerging Economies}

The political, economic, cultural, and institutional circumstances that drive NAMA interpretation and formulation vary immensely amongst emerging economies. The mainstream understanding of domestic climate change politics used to be largely driven by studies of industrialised countries (Compston \& Bailey, 2008; Harrison \& Sundstrom, 2010; Selin \& VanDeever, 2009; Sugiyama \& Takeuchi, 2008; Wurzel \& Connelly, 2010) largely comprising single-country case studies (Purdon, 2015; Steinberg \& Vandeveer, 2012). Several recent initiatives are starting to share developing country perspectives on mitigation efforts in a systematic manner (Bailey \& Compston, 2012; Garibaldi et al., 2013; Held et al., 2013a; Tyler et al., 2013; WWF, 2010). Nevertheless, mitigation actions in emerging economies, though elaborated on in several initiatives (Bailey \& Compston, 2012), tend to remain unevenly explored.

It was expected that emerging economies would approach NAMA development aggressively, leaving little room for other developing countries (Glemarec, 2010). NAMAs also featured prominently in the pledges made by emerging economies after COP15, including the ones made by Brazil (Government of Brazil, 2010; UNFCCC, 2011a). South Africa and South Korea also submitted proposals on establishing a NAMA Registry, indicating the importance they attributed to NAMAs (Republic of South Africa, 2008; UNFCCC, 2009a, 2009b). Substantial diplomatic capital was channelled through technical workshops on NAMAs, organized by the UNFCCC Secretariat, to flesh out the conceptual and technical details of NAMAs (UNFCCC, 2012, 2014). However, these efforts have not paid dividends along the expected lines. This is in sharp contrast to the development of climate policy and the setting up of coordinating bodies to address climate change in most emerging economies (Table 1). 
Table 1: National-Level Climate Policy Initiatives in Emerging Economies.

\begin{tabular}{|c|c|c|}
\hline $\begin{array}{l}\text { Emerging } \\
\text { economy }\end{array}$ & Policy type & Details \\
\hline Argentina & Strategic & 2002: Climate Strategy and Coordinating Body \\
\hline \multirow[t]{2}{*}{ Brazil } & Strategic & 2008: National Plan on Climate Change \\
\hline & Legislative & $\begin{array}{l}\text { 2007: Inter-Ministerial Committee on Climate Change } \\
\text { (Portuguese: Comite Interministerial sobre Mudança do Clima) } \\
\text { based on Presidential Decree no. 6. 263/2007; } \\
\text { 2009: Law } 12187 / 2009 \text {, National Policy on Climate Change, } \\
\text { regulated by Decree } 7390 / 2010\end{array}$ \\
\hline \multirow[t]{2}{*}{ China } & Legislative & $\begin{array}{l}\text { 2011: 12th Five-Year Plan for the Development of National } \\
\text { Economy and Society (2011-2015) }\end{array}$ \\
\hline & Strategic & $\begin{array}{l}\text { 2007: China's National Climate Change Programme; } \\
\text { 2014: National Plan for Tackling Climate Change, 2014-2020 }\end{array}$ \\
\hline India & Strategic & $\begin{array}{l}\text { 2008: National Action Plan on Climate Change and Advisory } \\
\text { Council on Climate Change }\end{array}$ \\
\hline Indonesia & Strategic & $\begin{array}{l}\text { 2007: National Action Plan Addressing Climate Change; } \\
\text { 2011: Presidential Decree 61/2011, National Action Plan to } \\
\text { Reduce GHG Emissions; } \\
\text { 2015: Presidential Decree } 16 / 2015 \text {, Structure of the Environment } \\
\text { and Forestry Ministry }\end{array}$ \\
\hline $\begin{array}{l}\text { Korea, } \\
\text { South }\end{array}$ & Legislative & $\begin{array}{l}\text { 2010: Framework Act on Low Carbon, Green Growth, Act No. } \\
\text { 9931; } \\
\text { 2012: Act on the Allocation and Trading of GHG Emissions } \\
\text { Rights }\end{array}$ \\
\hline \multirow[t]{2}{*}{ Mexico } & Legislative & 2012: General Law on Climate Change \\
\hline & Strategic & $\begin{array}{l}\text { 2007: National Strategy on Climate Change; } \\
\text { 2013: National Climate Change Strategy }\end{array}$ \\
\hline $\begin{array}{l}\text { Saudi } \\
\text { Arabia }\end{array}$ & None & None \\
\hline $\begin{array}{l}\text { South } \\
\text { Africa }\end{array}$ & Strategic & $\begin{array}{l}\text { 2004: National Climate Change Response Strategy; but no } \\
\text { coordinating body; } \\
\text { 2011: National Climate Change Response White Paper and } \\
\text { Inter-Ministerial Committee on Climate Change }\end{array}$ \\
\hline
\end{tabular}

Source: Based on GLOBE International (2016a) and Paper I.

While emerging economies are implementing domestic measures as means to address mitigation, they were also expected to benefit from NAMA formulation by taking the lead in developing them. However, they seem to be maintaining distance from this policy framework. Only two emerging economies - Mexico (15) and Indonesia (2) - have submitted NAMAs to the NAMA Registry. What explains this paradox? It seems that, despite acknowledging the 
host country's prerogative to formulate and implement mitigation actions in a way deemed to address domestic priorities, NAMAs have failed to find enough buy-in. This assumption is tested in this thesis by studying the reception of the international climate policy framework of NAMAs in IBSA and by identifying the factors influencing this reception.

\subsection{Climate Policy in India, Brazil, and South Africa}

\subsubsection{Socio-Economic Aspects and Domestic Priorities}

The IBSA nations face various social and economic challenges that influence their domestic priorities. While these priorities vary in nature (Table 2), they constrain these countries from addressing environmental demands in general and climate change mitigation demands specifically with the urgency needed. Although each country has its own set of challenges, the common challenge these three countries face is how to address climate change while remaining committed to resolving their overriding socio-economic challenges. For example, India has a much higher population as well as a relatively high percentage of the population that falls within the multidimensional poverty category compared with the other IBSA nations. It also has a large portion of its population still dependent on agriculture while having a relatively low gross domestic product (GDP) per capita. At the same time, it has a very low unemployment rate, a lower percentage of people living in urban areas, and a better income Gini coefficient - a parameter used to measure inequality within a given country. In contrast, South Africa has a much smaller population but a relatively high GDP per capita, a higher percentage of female representation in national parliament, a greater number of people dependent on the service sector for employment, and a lower percentage of people vulnerable to sea level rise. On the negative side, it has a very high unemployment rate as well as high inequality, as reflected by its high Gini coefficient. In comparison, Brazil is ahead of both India and South Africa in most of the parameters but has a much higher concentration of its population living in urban areas, making it imperative for Brazil to focus on urban amenities. It also happens to be facing a damning crisis of governance at this time. 
Table 2: Socio-Economic Parameters, by IBSA countries

\begin{tabular}{|l|c|c|c|c|}
\hline Socio-Economic Parameters & $\begin{array}{c}\text { Year/ } \\
\text { sector }\end{array}$ & India & Brazil & $\begin{array}{c}\text { South } \\
\text { Africa }\end{array}$ \\
\hline $\begin{array}{l}\text { Access to electricity (\% of total } \\
\text { population) }\end{array}$ & 2012 & 78.7 & 99.5 & 85.4 \\
\hline $\begin{array}{l}\text { Gross Domestic Product (GDP) per } \\
\text { capita-Purchasing Power parity } \\
\text { (PPP), in constant USD }^{\mathrm{b}}\end{array}$ & 2015 & 5,730 & 14,455 & 12,390 \\
\hline $\begin{array}{l}\text { GDP-PPP (constant 2011 USD } \\
\text { billions) }\end{array}$ & 2015 & 7,512 & 3,004 & 680 \\
\hline $\begin{array}{l}\text { Population (millions) } \\
\text { d }\end{array}$ & 2015 & $1,311.05$ & 207.84 & 54.95 \\
\hline Urban population (in \%) $^{\mathrm{e}}$ & 2015 & 33 & 86 & 65 \\
\hline $\begin{array}{l}\text { Population living in areas where } \\
\text { elevation is }<5 \text { meters (in \%) }\end{array}$ & 2010 & 2.7 & 2.6 & 0.2 \\
\hline $\begin{array}{l}\text { Multidimensional Poverty Index (\% } \\
\text { of total population) }^{\mathrm{g}}\end{array}$ & Various & 53.7 & 5.3 & 11.1 \\
\hline $\begin{array}{l}\text { Seats held by women in national } \\
\text { parliaments (in \%) }^{\mathrm{h}}\end{array}$ & 2016 & 12 & 10 & 42 \\
\hline Human Development Index ranking $^{\mathrm{i}}$ & 2014 & 130 & 75 & 116 \\
\hline Income Gini Coefficient $^{\mathrm{j}}$ & 2013 & 33.9 & 54.7 & 63.1 \\
\hline Total employment in 2012 (in \%) $^{\mathrm{k}}$ & Agriculture & 47 & 14.4 & 4.7 \\
\cline { 2 - 5 } & Industry & 24.7 & 21.7 & 25.7 \\
\cline { 2 - 5 } & Services & 28.3 & 63.9 & 69.5 \\
\hline Unemployment rate $^{\mathrm{l}}$ & 2016 & 3.5 & 11.5 & 25.9 \\
\hline
\end{tabular}

Sources:

a: World Bank (2016a).

b: World Bank (2016b).

c: World Bank (2016c).

d: World Bank (2016d).

e: World Bank (2016e).

f: World Bank (2013).

g: Oxford Poverty and Human Development Initiative (2016).

h: World Bank (2016f).

i: UNDP (2017).

j: UNDP (2013).

k: ILO (2014). Data available online at:

http://www.ilo.org/legacy/english/get/2014/GET_sector_share.xlsx.

1: $\operatorname{ILO}(2017$, p. 39).

In terms of GHG emission profiles (Table 3), the IBSA nations are again quite different from each other. While all three are amongst the top 20 GHG emitters in terms of annual as well as cumulative total emissions, their historic GHG emissions, annual GHG emissions at this time, as well as per capita emissions vary. The sectoral distribution of their GHG emissions also varies. In 2012, they collectively accounted for close to $11 \%$ of current global GHG 
emissions. This figure is reduced drastically if historical emissions are taken into account. Brazil's emissions are highly dependent on whether or not land use, land use change, and forestry (LULUCF) emissions are introduced in the calculations. India has the highest total emissions but its per capita emissions are lowest. The reverse is true for South Africa.

Table 3: GHG Emissions Including LULUCF, by IBSA countries

\begin{tabular}{|c|c|c|c|c|c|}
\hline \multicolumn{2}{|l|}{ Country } & \multirow{2}{*}{$\begin{array}{l}\text { India } \\
43301.80\end{array}$} & \multirow{2}{*}{$\begin{array}{l}\text { Brazil } \\
37125.42\end{array}$} & \multirow{2}{*}{$\begin{array}{l}\begin{array}{l}\text { South } \\
\text { Africa }\end{array} \\
9662.21\end{array}$} & \multirow{3}{*}{$\begin{array}{l}\text { World } \\
949965.78\end{array}$} \\
\hline \multirow{2}{*}{$\begin{array}{l}\text { Total GHG } \\
\text { emissions (1990- } \\
\text { 2013) }\end{array}$} & $\begin{array}{l}\text { in million tonnes of } \mathrm{CO}_{2} \\
\text { equivalent }\left(\mathrm{MtCO}_{2} \mathrm{e}\right)\end{array}$ & & & & \\
\hline & $\%$ of world total & $4.55 \%$ & $3.90 \%$ & $1.01 \%$ & \\
\hline \multirow{2}{*}{$\begin{array}{l}\text { Annual emissions } \\
\text { (2013) (all gases) }\end{array}$} & in $\mathrm{MtCO}_{2} \mathrm{e}$ & $3,031.34$ & $1,317.22$ & 512.25 & \multirow[t]{2}{*}{$48,257.30$} \\
\hline & $\%$ of world total & $6.28 \%$ & $2.73 \%$ & $1.06 \%$ & \\
\hline $\begin{array}{l}\text { Per capita } \\
\text { emissions (2013) }\end{array}$ & in $\mathrm{tCO}_{2} \mathrm{e}$ & 2.37 & 6.45 & 9.63 & 6.72 \\
\hline \multirow{5}{*}{$\begin{array}{l}\text { Emissions from } \\
\text { select key sectors } \\
(\text { in } \mathrm{MtCO} 2 \mathrm{e}) \text {, } \\
(2013)\end{array}$} & Energy & $2,027.86$ & 481.27 & 439.12 & $35,520.28$ \\
\hline & Industrial Processes & 192.64 & 54.79 & 21.43 & $3,054.30$ \\
\hline & Agriculture & 628.27 & 436.78 & 30.52 & $5,179.42$ \\
\hline & LULUCF & 122.29 & 299.34 & 2.01 & $2,996.05$ \\
\hline & Waste & 60.28 & 45.03 & 19.17 & $1,507.33$ \\
\hline
\end{tabular}

Source: WRI (2016).

While the GHG figures for the IBSA countries differ distinctly from each other, all three countries - especially South Africa and India - face the common challenge of developing in a world that is increasingly coming to terms with its constrained reality. However, one aspect in which the IBSA countries differ drastically is their current energy mixes. This difference reflects the diversity of their natural resource endowments. While the Brazilian economy is based on the abundant supply of hydropower, the South African economy is dependent on readily available coal. Any efforts to take on mitigation in South Africa need to deal with the "mineral-energy complex" - the material basis of the South African political economy that continuously reinforces the country's dependence on the extraction and consumption of fossil fuels (Fine \& Rustomjee, 1996). India has both hydro and coal in its energy mix, but has a much bigger economy.

The socio-economic and emission profiles of the IBSA countries help us appreciate the different stages of development of these countries and the different challenges that they face. As part of my thesis, I carry out cross-case analysis to highlight the differences or similarities observed in the approaches taken by the case countries in their NAMA engagement. By taking a case study approach, this study - based on national policy documents, UNFCCC negotiation text, and a rich array of interviews from the case countries - seeks to explain the variance in responses to the NAMA framework in the different country contexts. 


\subsubsection{Climate Policy in IBSA}

Over the last 25 years, India's climate policy has been characterised by consistency in terms of its positions in international negotiations, its domestic policy, and in staffing (Dubash, 2013; Fisher, 2012; Michaelowa \& Michaelowa, 2012). When the Ministry of External Affairs was tasked with engaging in UN climate negotiations in the 1990s, it crafted its positions based on existing foreign policy discourses on the need to develop and ensure energy security (Fisher, 2012). Indian engagement with climate policy has since then largely been confined to the international level, in which it strongly defends its position and invokes the UNFCCC provision that climate change is a common concern for humanity, but that countries have differentiated responsibilities to act based on their historical contributions to climate change (Friman, 2016).

In recent years, however, at least two factors have come to challenge this discourse: 1) India's economy has been growing at a healthy rate, making it a major emitter in absolute terms; and 2) its high vulnerability to climate change is making it qualify its assertion that climate change should be predominantly addressed by the global North. Impacts of climate change are becoming a notable material factor challenging the state interest in development. All the Indian states have developed State Action Plans on Climate Change. However, these plans are adaptation centric (Dubash \& Jogesh, 2014). Domestically, although a number of policies are relevant to mitigation objectives, the country's climate policy, the National Action Plan on Climate Change (henceforth, "Action Plan") provides the strategy for tackling climate change while pursuing the state's development agenda. The Action Plan was developed by the Prime Minister's Council on Climate Change (created in 2007) under the leadership of the then Prime Minister, Manmohan Singh. The Action Plan identifies measures that ensure India's "development objectives while also yielding co-benefits for addressing climate change effectively" (Government of India, 2008, p. 4) by means of eight national missions covering both mitigation and adaptation. Although its public has a small consumption footprint, its traditional position is being questioned as it has been unable to reconcile India's equity arguments in the international arena with its own efforts to establish equity within. Efforts to realise the Action Plan have been criticised on the grounds that they neither provide concrete solutions for a low-carbon pathway nor enhance inclusiveness (Raghunandan, 2012; Rajan \& Byravan, 2011). There has been a growing emphasis on using co-benefit or multiple benefit framing as a better means to develop while also addressing climate change (Dubash, 2013; Singh, 2009). The traditional strand of India's climate policy that emphasises its developing country identity meshes uncomfortably with its ambitions to be a global player, resulting in various coalitions of norms and interests competing for institutional control (Atteridge, 2013). Institutionally, a framework for domestic action was established in the Action Plan allowing the responsible ministries for each national mission to formulate plans that could include NAMAs. However, the institutionalisation of climate policy in India continues to suffer from both coordination and capacity issues, the former due to a lack of consistent overarching structure, the latter due to the demands that the specialised nature of climate change puts on developing cross-sectoral links and on a very small number of dedicated staff working in "closed structures of climate governance" (Dubash \& Joseph, 2015, pp. 26-27). 
Brazil's track record on climate policy has been encouraging. As early as 1999, the country had created an Inter-Ministerial Commission on Climate Change, which was followed up by the establishment of the Brazilian Forum on Climate Change in 2000 - a forum that served as an interface between the government and the broader society (Held, Roger, \& Nag, 2013b). The time period between 2005 and 2010 has been identified as having been particularly favourable for climate politics in the country (Viola \& Franchini, 2014). During this time many developments that were favourable to address climate change took place. Brazil managed to break the historical trend of high emissions from illegal Amazonian deforestation by confronting illegal deforestation and reducing it from an average of $21,000 \mathrm{~km}^{2}$ annually during the timeperiod 2000-2004 to almost a third by 2009 (Hochstetler \& Viola, 2012). The Inter-Ministerial Commission was replaced by the Inter-Ministerial Committee on Climate Change in 2007. The Committee was created under the Leadership of the President and was tasked to formulate the National Policy on Climate Change - subsequently released in December 2008 (Held et al., 2013b). The 2010 presidential campaign of the Minister of Environment, Marina Silva, as the Green Party candidate, further advanced the sustainable development norm in the country (Nunes \& Peña, 2015). The period witnessed increased media attention to climate change, a spate of public events covering the topic, the mobilisation of non-governmental organizations (NGOs) and support from business coalitions (Hochstetler \& Viola, 2012; Viola \& Franchini, 2014), resulting in increased public awareness on the topic. Climate change is now considered to be a very serious issue by $86 \%$ of the Brazilian public, (Stokes, Wike, \& Carle, 2015). All these factors created groundswell in favour of legalizing the National Policy on Climate Change. In January 2010, President Lula signed the National Policy on Climate Change into National Law (henceforth, "National Law"). This was followed by sub-national policy initiatives.

As of now, in addition to the National Law, six Brazilian cities have approved climate change policies, with at least five of them indicating intentions to reduce GHG emissions. Five Brazilian states already had climate change policy in place before the National Law was approved. As of 2017, 14 Brazilian states have climate policy in place, six of which have indicated their intention to address GHG emissions (Barbi \& Ferreira, 2016). Even at the time of its crisis of governance, Brazil has been able to set an absolute emission reduction target as part of its Intended Nationally Determined Contributions (INDCs), one of the very few emerging economies to do so.

During COP15, President Zuma announced South Africa's pledges to cut emissions by 34\% by 2020 and by $42 \%$ by 2025 from a 1990 "business as usual" trajectory, albeit contingent on international support (Zuma, 2009). The targets were announced on the back of a statesponsored research initiative, the Long Term Mitigation Scenario exercise, which provided different scenarios for reducing GHG emissions. The exercise was one of the first such initiatives amongst the developing countries (Tyler \& Gunfaus, 2015). By engaging with a large number of stakeholders, the Long Term Mitigation Scenario process provided a foundation for the South African Department of Environmental Affairs' efforts to address climate change. This subsequently helped formalise the country's climate change policy The National Climate Change Response White Paper (henceforth, "White Paper") (Republic of South Africa, 2011a) - indicating that although the challenges of poverty, unemployment, 
and inequality ${ }^{5}$ remain, the norms of sustainability were also given due recognition. South African response to climate change needs to be seen within its developmental framework (Republic of South Africa, 2011a). The country's ruling party, the African National Congress, stressed the importance of "sustainable development based on high growth rates, restructuring of the economy and socio-economic inclusion" as an important aspect of the aspiring South African developmental state a decade ago (ANC, 2007, paras. 188-193). The developmental state agenda provides the broader context (National Planning Commission, 2011) within which the climate policy is operationalised. The White Paper presents eight priority areas referred to as its flagship programmes. Seven of these flagship programmes relate to mitigation. The development of initiatives to address climate change, however, has not come together to present a coherent governance strategy, primarily because of competing interests and priorities amongst domestic actors that hamper the efforts to coordinate action on climate change (Chandrashekeran et al., 2014; Masters, 2013). At the sub-national level, climate policy development is uneven. Some provinces, such as the province of Western Cape and Gauteng, have climate policies in place. Similarly, the municipality of eThekwini has a climate strategy in place.

By focusing on the domestic factors that determine NAMA engagement while also taking into account domestic interpretations of international factors, IBSA's NAMA engagement is approached from a domestic politics perspective (Harrison \& Sundstrom, 2010; Putnam, 1988; Risse, Ropp, \& Sikkink, 1999; Vogel, 1997). The variance in IBSA's NAMA engagement internationally, the influence of IBSA's domestic institutional responses on NAMA engagements, and how these engagements in turn influence IBSA's institutional arrangements form the core of this inquiry.

An important delimitation arises because of the selection of IBSA as the case countries. The findings from studying NAMA engagements in IBSA are not fully applicable to developing countries in general. As shown in Paper I, developing countries overall apply different approaches to climate mitigation at the national level.

\footnotetext{
${ }^{5}$ Most of the South African stakeholders I interviewed pointed to a combination of these three issues as the key challenges for the country.
} 
In this chapter, I outline the analytical concepts that I use in studying NAMA engagements by drawing on elements of policy process and institutional theories. The analytical concepts are borrowed from different theoretical frameworks of policy processes and institutions in order to develop a customised analytical framework that helps me focus on my research object from different perspectives. Each constituent paper of this thesis covers a different aspect of climate policy experimentations currently underway in different jurisdictions, to provide a balanced picture of climate governance in IBSA. This chapter links the various theoretical elements utilised in the articles to present an analytical framework that takes into account different institutional contexts influencing national climate policy processes.

\subsection{Policy Process Theories}

To account for the broader overview of NAMA engagements in IBSA, the domestic setting needs to be paid closer attention. To do so I make use of the policy process literature. Policy process is a dynamic field of research, that is in constant flux from the improvement of existing theories as well as the development of new theories that enhance our understanding of policy dynamics (P. A. Sabatier \& Weible, 2014). Studies of the policy process focus on "how decisions are made and how policies are shaped in action" (Hill, 2014, p. 5; Howlett et al., 2009). Depending on their inbuilt preferences, each policy process theory accounts for policy change differently (Schlager, 1999). While this flux makes the field exciting and dynamic, it also makes it difficult to achieve theoretical convergence (Cairney \& Heikkila, 2014). In general, policy process theories emphasise six different aspects of policy process i.e. institutions, contexts, ideas, actors, networks, and events - to varying degrees (Cairney \& Heikkila, 2014). As the NAMA literature also identifies institutions as an important factor, I focus on the institutional strand of the policy process literature. My initial studies indicated that NAMA engagements develop differently at different stages of the policy process (Paper III). To further account for these differences, I found it suitable to use the policy cycle model (Howlett et al., 2009; Hill, 2014). This model is used as a heuristic device rather than as a coherent theoretical construct in this thesis, as it helps me study the differences in reception to NAMAs during agenda-setting, policy formulation, decision-making, implementation, and evaluation and discuss how far along the policy process NAMA engagements have advanced in IBSA. In line with, Jann and Wegrich (2007), I chose to characterise it as a heuristic device as the policy cycle model has certain limitations and problematic aspects that are addressed below.

The policy process is complex and involves a range of actors who interact over a long course of time. Policy processes can be studied from various theoretical departure points. Prominent amongst these are the institutional analysis and development framework (Kiser \& Ostrom, 1982; Ostrom, 2011), the advocacy coalition framework (P. A. Sabatier \& Jenkins-Smith, 1993), punctuated equilibrium theory (Baumgartner \& Jones, 1993; Baumgartner, Jones, \& Mortensen, 2014), and the multiple streams approach (Kingdon, 2011). Each of these theories or frameworks focuses on different aspects of the policy process (Cairney \& Heikkila, 2014; 
Schlager, 1999). In addition, there are numerous other emerging theories on policy process (Schlager \& Weible, 2013). Here I provide a brief overview of the key aspects of some of these theories and frameworks.

The institutional analysis and development framework emphasises the importance of institutions in enabling and shaping human interactions. It centres on the "action arena", in which a set of variables representing actors (i.e. individuals or firms), interacts with another set of variables, referred to as the "action situation". The latter is specifically in focus here. Institutional analysis and development also accounts for external variables, such as material conditions, norms, and community attributes, and their interaction with the action situation in predicting outcomes (Ostrom, 2011). Punctuated equilibrium theory seeks to explain policy stability as well as policy change. Based on policymaking in the United States, it explains policy making as characterised by long periods of stability punctuated by brief periods of policy change (Baumgartner et al., 2014). Punctuated equilibrium theory argues that the same institutional setting and rules can provide for incremental as well as sudden change. The concept of institutional friction when translating input into policy output is highlighted, to describe the effort needed to overcome resistance from existing institutional arrangements (Cairney \& Heikkila, 2014). Another policy process theory that enhances our understanding of policy change and stability is the advocacy coalition framework, which gives primacy to the policy subsystem as the primary unit of analysis in studying policy processes. Policy subsystems are referred to as comprising "policy topic, territorial scope, and the actors" directly or indirectly involved in influencing the policy subsystems (Jenkins-Smith, Nohrstedt, Weible, \& Sabatier, 2014, p. 189). The individuals involved in a policy subsystem interact regularly to influence the subsystem by forming long-term coalitions (Howlett, McConnell, \& Perl, 2016; Jenkins-Smith et al., 2014). However, one of the most popular policy frameworks used by policy process scholars is the multiple streams approach. This approach employs the stream metaphor in arguing that policy entrepreneurs determine the policy process by purposefully coupling the three streams of problems, policies, and politics which flow largely independently - when favourable circumstances emerge (Kingdon, 2011; Zahariadis, 2014). Focusing events can provide favourable circumstances for bringing these streams together by creating windows of opportunity for policy entrepreneurs to pursue policy alternatives. These events can be both predictable, such as elections and unpredictable, such as unusual weather phenomenon. Although the assumptions of the multiple streams approach have been empirically validated in a range of applications, it is seen as primarily occupied with influencing the policy process during the agenda setting (Cairney \& Heikkila, 2014; Kingdon, 2011).

There is considerable diversity in how these and other theories and frameworks, such as the social construction framework, policy feedback theory, narrative policy framework, and diffusion of innovations framework, treat features of the policy process. ${ }^{6}$ Each theory comes with its own strengths and weaknesses. For example, while the multiple streams approach is widely applied to various policy problems, its applicability is limited primarily to explaining

\footnotetext{
${ }^{6}$ For a comprehensive comparison of different types of theories, see Cairney and Heikkila (2014).
} 
agenda-setting dynamics. At the same time, it suffers from a "lack of institutional language" (Zahariadis, 2014, p. 44), reflecting its lack of attention to institutions (however, see Zohlnhöfer, Herweg, \& Huß, 2015 on how political Institutions can be accounted for in the multiple streams approach). The multiple streams approach is driven largely by qualitative case studies. In contrast, while original work on punctuated equilibrium theory combined qualitative and quantitative methods, over time the theory has increasingly been used with quantitative datasets, leading to increased generalizability (Cairney \& Heikkila, 2014). Punctuated equilibrium theory pays close attention to institutional venues and therefore could be useful for studies of climate politics at COP meetings, for example. The advocacy coalition framework is attentive to policy subsystems and policy venues; although it seems ideal for the methods employed here (chapter 4), it still needs to be tested comparatively across different institutional settings (Gupta, 2012). A major portion of the advocacy coalition framework literature deals with environmental policy, focusing on non-state actors in venues where coalitions are formed in order to convert beliefs into action (Jenkins-Smith et al., 2014). However, it also does not pay sufficient attention to the role of institutions (Cairney \& Heikkila, 2014).

In contrast, though the institutional analysis and development framework pays very close attention to institutions, it has largely been used to study common-pool resource management at the micro, community level. There are multiple examples that emphasise its salience for studying local-level governance (on its usage, see Ostrom, Cox, \& Schlager, 2014, pp. 286289). The social construction framework and policy feedback theory both use case studydriven analysis, but policy feedback theory is more attentive to institutional configuration. However, it considers institutions primarily through the lens of formal institutions, predicating the ideas, beliefs, and role and possibility of individual choice on the performance of formal institutions themselves. It has little space for institutions other than those that get institutionalised in the form of policies (Cairney \& Heikkila, 2014). Further, policy feedback studies tend to focus on policies that stick, ignoring those which do not get adopted (Jordan \& Matt, 2014). However, in studying the question of "what makes climate change policies stick?" in the South African context, Chandrashekeran et. al $(2014$, p. 1) argue for an indictive approach to assessing how policies get institutionalised rather than interpreting these based on theories generated in the North Atlantic world. The social construction framework, on the other hand, takes a constructivist-driven approach to evaluating how frames are utilised during agenda setting, giving greater say to the actors and to the values and emotions that they hold dear. The narrative policy framework uses mixed methods, primarily at the micro and meso levels, but it has yet to result in macro-level studies (McBeth, Jones, \& Shanahan, 2014, p. 246). The diffusion of innovations framework indirectly focuses on institutions and is largely quantitatively driven. For the purposes of my analysis, no one theory seemed to consistently satisfy all the relevant parameters. At the same time, applying all of these theories would lead to very different outcomes. In fact, comparing different policy process theories in explaining a common phenomenon to find the one with the best fit is one of two emerging trends in comparative public policy work, comparing the same theory across different institutional settings being the other (Gupta, 2012). Table 4 compares these eight prominent theories of policy process based on: how these theories take into account 
institutions, the broader context, and ideas; the levels of analysis applied; and the analytical methods used (P. A. Sabatier, 1999; P. A. Sabatier \& Weible, 2014).

\section{Table 4: Comparison of Policy Process Theories}

\begin{tabular}{|c|c|c|c|c|c|}
\hline & Institutions & Context & Ideas & $\begin{array}{l}\text { Level } \\
\text { analysis }\end{array}$ & $\begin{array}{l}\text { Key method and } \\
\text { field of analysis }\end{array}$ \\
\hline $\begin{array}{l}\text { Multiple } \\
\text { streams } \\
\text { approach }\end{array}$ & $\begin{array}{l}\text { Not emphasised, } \\
\text { refers to informal } \\
\text { rules and formal } \\
\text { venues }\end{array}$ & $\begin{array}{lr}\text { National mood } & \text { as } \\
\text { interpreted } & \text { by } \\
\text { policymakers; } & \text { policy } \\
\text { conditions } & \end{array}$ & $\begin{array}{l}\text { Policy solutions } \\
\text { play out over } \\
\text { time }\end{array}$ & $\begin{array}{l}\text { Implicitly at the } \\
\text { system level } \\
\text { during agenda- } \\
\text { setting }\end{array}$ & $\begin{array}{lr}\text { Mostly } & \text { case } \\
\text { studies; } & \text { applied in } \\
\text { various r policy } \\
\text { domains }\end{array}$ \\
\hline $\begin{array}{l}\text { Punctuated } \\
\text { equilibrium } \\
\text { theory }\end{array}$ & $\begin{array}{l}\text { Institutional } \\
\text { venues }\end{array}$ & $\begin{array}{l}\text { Internal context of the } \\
\text { subsystem; the wider } \\
\text { policy environment }\end{array}$ & $\begin{array}{l}\text { New ideas } \\
\text { provide } \\
\text { breakthroughs } \\
\text { or changes }\end{array}$ & $\begin{array}{l}\text { System level } \\
\text { with a focus on } \\
\text { major changes }\end{array}$ & $\begin{array}{l}\text { Mostly } \\
\text { quantitative; focus } \\
\text { on budgets and } \\
\text { agendas }\end{array}$ \\
\hline $\begin{array}{l}\text { Advocacy } \\
\text { coalition } \\
\text { framework }\end{array}$ & $\begin{array}{l}\text { Policy venues in } \\
\text { broader contexts, } \\
\text { but less directly }\end{array}$ & $\begin{array}{l}\text { Institutions influencing } \\
\text { the subsystem }\end{array}$ & $\begin{array}{l}\text { Belief systems } \\
\text { are shared by } \\
\text { actors }\end{array}$ & $\begin{array}{l}\text { Policy } \\
\text { subsystems and } \\
\text { coalitions }\end{array}$ & $\begin{array}{l}\text { Mixed-method } \\
\text { approach; used } \\
\text { extensively in } \\
\text { environmental } \\
\text { policy }\end{array}$ \\
\hline $\begin{array}{l}\text { Institutional } \\
\text { analysis and } \\
\text { development }\end{array}$ & $\begin{array}{l}\text { Close attention to } \\
\text { rules and norms } \\
\text { in shaping } \\
\text { behaviour }\end{array}$ & $\begin{array}{l}\text { Physical and material } \\
\text { contexts, community } \\
\text { characteristics, and } \\
\text { existing local institutions }\end{array}$ & $\begin{array}{l}\text { Norms or shared } \\
\text { preferences are } \\
\text { important but } \\
\text { not explicit }\end{array}$ & $\begin{array}{l}\text { Primarily } r \\
\text { micro, at } \\
\text { level }\end{array}$ & $\begin{array}{l}\text { Mixed-method } \\
\text { approach; } \\
\text { Common-pool } \\
\text { resources }\end{array}$ \\
\hline $\begin{array}{l}\text { Social } \\
\text { construction } \\
\text { framework }\end{array}$ & $\begin{array}{l}\text { Implicitly } \\
\text { examines policy } \\
\text { design }\end{array}$ & $\begin{array}{l}\text { Primarily past policy } \\
\text { design; also social and } \\
\text { cultural characteristics }\end{array}$ & $\begin{array}{lr}\text { Framings } & \text { used } \\
\text { by } & \text { target } \\
\text { population } & \end{array}$ & $\begin{array}{l}\text { Implicitly at the } \\
\text { system level }\end{array}$ & $\begin{array}{l}\text { Mostly case } \\
\text { studies; different } \\
\text { policy issues }\end{array}$ \\
\hline $\begin{array}{l}\text { Policy } \\
\text { feedback } \\
\text { theory }\end{array}$ & $\begin{array}{l}\text { Institutionalised } \\
\text { policies that } \\
\text { influence } \\
\text { institutional } \\
\text { interaction }\end{array}$ & $\begin{array}{l}\text { Implicitly by accounting } \\
\text { the past policy decisions } \\
\text { and the broader context }\end{array}$ & $\begin{array}{l}\text { Ideas appear as } \\
\text { interpretations } \\
\text { of existing } \\
\text { policies and } \\
\text { rules }\end{array}$ & $\begin{array}{l}\text { Implicitly at the } \\
\text { system level }\end{array}$ & $\begin{array}{lr}\text { Mostly } & \text { case } \\
\text { studies; } & \text { social } \\
\text { policy } & \end{array}$ \\
\hline $\begin{array}{l}\text { Narrative } \\
\text { policy } \\
\text { framework }\end{array}$ & $\begin{array}{l}\text { As part of the } \\
\text { broader context }\end{array}$ & $\begin{array}{l}\text { Key factors (e.g. legal, } \\
\text { constitutional, normative, } \\
\text { and scientific findings) } \\
\text { used by actors to } \\
\text { construct narratives }\end{array}$ & $\begin{array}{l}\text { Utilises } \\
\text { Narratives } \\
\text { based } \\
\text { existing belief } \\
\text { systems }\end{array}$ & $\begin{array}{l}\text { No macro } \\
\text { studies yet; focus } \\
\text { on meso- or } \\
\text { micro-level } \\
\text { studies }\end{array}$ & $\begin{array}{l}\text { Mixed-method } \\
\text { approach; } \\
\text { relatively new }\end{array}$ \\
\hline $\begin{array}{l}\text { Diffusion of } \\
\text { innovations }\end{array}$ & $\begin{array}{l}\text { Indirectly by } \\
\text { means } \\
\text { communication }\end{array}$ & $\begin{array}{lr}\text { Key } & \text { socio-economic } \\
\text { aspects, } & \text { religion, } \\
\text { ideology, education, etc. }\end{array}$ & $\begin{array}{l}\text { Emulation of } \\
\text { relevant policy } \\
\text { solutions }\end{array}$ & $\begin{array}{l}\text { Policymaking } \\
\text { venues available } \\
\text { for a collection } \\
\text { of states }\end{array}$ & $\begin{array}{l}\text { Mostly } \\
\text { quantitative; } \\
\text { multiple policy } \\
\text { issues }\end{array}$ \\
\hline
\end{tabular}

Source: Based on Cairney and Heikkila (2014) and Schlager (1999).

Table 4 brings into focus the complexities involved in studying policy processes as well as the contradictions in how the different approaches treat the various aspects that are useful in studying policy processes. Institutions is a dimension that all the theories address, albeit to varying degrees. Norms are not treated uniformly by these theories. In fact, norms seem not to be a major focus, only the institutional analysis and development framework giving them prominence, while the narrative policy framework treats norms as a contextual factor. Institutions are an important dimension of most of the theories, but the level of institutional setting under study tends to vary, and can be deployed by studies that are open to synthesizing multiple theories. There is diversity in terms of how contextual factors and ideational factors are treated as well. Actors also play an important role in almost all these theories. As shown in Table 4, the institutional analysis and development framework refers to norms under both 
institutions and ideas. This makes it difficult to focus on norms using any of these theories. As part of this thesis, I treat norms as part of the institutional analysis (Paper IV) and cover norms and their relationship with ideas in more detail in section 3.3.2. Institutions are treated by almost all the theories, although they are emphasised differently.

Institutions are also treated in a variety of ways by these theories. Policy venues are emphasised in punctuated equilibrium theory and the advocacy coalition framework, whereas institutionalised policies are important in policy feedback theory. There is considerable overlap in certain theories between institutions and contexts, particularly in those theories that attribute more importance to ideational factors such as narratives, framings, and belief systems, as reflected in the narrative policy framework, social construction framework, and advocacy coalition framework. Policy equilibrium theory seems to be an exception, as it attributes breakthroughs to ideas and focuses on institutional venues where multiple ideas compete. It is also interesting to note that one of the widely used policy process theories, the multiple streams approach, does not emphasise institutions significantly (Zahariadis, 2014).

While this diversity definitely reflects the vibrancy of the policy process research field, it also drives home the point that policy processes are inherently complex and need analytical devices that can make them more decipherable. In my analysis, applying these different theories would result in very different outcomes. It is here that the policy cycle as a heuristic device proves useful in making sense of these complex processes.

\subsection{Policy Cycle Model used for studying Policy Processes}

Policy process tends to be complex. In order to manage the complexity involved in studying public policy processes, it was first approached "as a series of steps in a decision-making process" by Harold Lasswell (Howlett \& Giest, 2015, p. 17), who suggested a seven-stage approach comprising intelligence, promotion, prescription, invocation, application, termination, and appraisal (Lasswell, 1956, 1971). This stage-wise approach was subsequently modified and came to be referred to as "the policy cycle model" (Jann \& Wegrich, 2007). More recently, the policy cycle model has been further modified and reduced to the five stages of agenda setting, policy formulation, decision making, policy implementation, and policy evaluation (Howlett \& Giest, 2015; Howlett et al., 2009). I use this interpretation of the policy cycle in examining NAMA processes in IBSA (Paper III).

The strength of the policy cycle model is that it provides an approach to untangle the policy process and permits examination of "the intertwined role of all actors, ideas, and institutions" (Howlett et al., 2009, p. 13). For this study, I keep institutions at the centre of my analysis. While I do remain attentive to ideas and actors in IBSA's domestic context, I do not explore them in the comparative studies. ${ }^{7}$ Studying the intertwining of actors, ideas, and institutions is

\footnotetext{
${ }^{7}$ In Paper II, in which I take a case study approach to examining climate policy and climate politics in South Africa, I do study the interaction between interests - represented by various domestic actors - and South African ideas that influenced both national and international climate discourses. In the paper, I argue that existing ideas and interests resisted the ideas and interests represented by NAMAs but do not explicitly study institutions. Since then, institutions have started to weigh in favour of NAMAs in South Africa (see Paper IV).
} 
beyond the scope of this thesis. Instead, I delve more deeply into the institutional dynamics. The model allows the analysis of specific stages of the policy cycle and of the relationship between one stage and other stages of the policy cycle (Howlett et al., 2009). It can also account for perspectives outside the governmental configuration. Its main strength is in "categorizing policy actions as they vary from stage to stage" (deLeon, 1999, p. 26). At the same time, it has some disadvantages. Referred to as a stage "heuristic device", the policy cycle model is also criticised for presenting a simplified representation of a complex process (Jann \& Wegrich, 2007, p. 57) as "a disjointed, episodic process rather than a more ongoing, continuous one" (deLeon, 1999, p. 23). It presents the efforts to address policy problems in a linear and systematic fashion with "a single iterative loop", whereas the reality is often idiosyncratic and irregular, comprising of "a series of smaller loops" in which the implementation of today may influence future policy formulations (Howlett et al., 2009, p. 13). It is also not considered a causal theory as it fails to account for the factors that move policy from one stage to another (Weible, 2014). Furthermore, the model provides neither clarity on the level of governance at which it can be applied nor any notion of causation (Howlett et al., 2009).

As discussed above, the inadequacy of the policy cycle heuristic led researchers to develop causal theories that could better represent the relationship between factors responsible for translating policies into action. Eight such theories were explored above (Table 4) to emphasise the fact that having a theoretically driven approach does not necessarily make the task of studying complex policy processes any simpler. In order to make sense of this complexity, I use policy cycle as a heuristic device to study the policy processes surrounding NAMA engagements in IBSA (Howlett et al., 2009; Jann \& Wegrich, 2007) it still provides "a basis for viewing and categorizing actors and actions in ways that help unravel and elucidate given policies, both in retrospect and - more cautiously - in the future" (deLeon, 1999, p. 26). This approach is applied in Paper III as it gives me the flexibility to study and compare these policy processes in IBSA, either as a whole or to delve deeper into the process by focusing on specific stages. Here I summarize how policy cycle as a heuristic device has been applied in paper III.

The agenda-setting stage is characterised as a process by which problems and policy options are not only brought to the attention of the government and political actors but can also be kept away from government attention (Kingdon, 2011). This stage typically involves almost all those actors that identify and frame the problem or demand action to address it. Number of issues that the government can accommodate in its agenda is dependent on the availability of time and resources at its disposal (Birkland, 2007). I study IBSA actors' perception of climate change as a policy problem, their perception about whether and why NAMA made it to the agenda as a suitable policy proposal for addressing climate change and the influence of two events, COP15 in Copenhagen and COP21 in Paris, on the ability of NAMAs to make their way onto the agenda of governments in IBSA.

Policy-formulation involves efforts to develop policy options using which the government can pursue its agenda. It comprises efforts to refine the policy objectives defined by the government (Hill, 2014) in terms of detailed out policy proposals, by providing more specific information on the policy instruments to be employed, institutional capacity and resources 
required and the target groups the policy seeks to reach out to. The government may decide how open or close it wants to keep the policy formulation process. The policy ideas available for consideration and the institutional arrangement within which these ideas are considered at a given point in time are crucial at this stage (Sidney, 2007). Climate policy instruments that were under consideration as NAMAs or were available under the national climate policy in IBSA between 2009 and 2016, and how the presence of one policy proposal affected the prospects of other policy proposals are studied under this stage in paper III.

Under decision-making, a select group of state actors, typically represented by politicians, judges, and bureaucrats are involved. These actors decide either in favour of undertaking a new course of action or maintaining the status-quo. The decisional context sets the structural limits - in terms of stability and transformation potential - within which the decisions are to be undertaken. Therefore it becomes important for these actors to time their decision when the opportunity to shift the status quo arises (Dente, 2014). Depending on the interests' of the actors involved, a decision may be categorised as being positive (shifting the status quo), negative (maintaining the status quo), or in instances where choices fail to reach decisionmaking stage, as non-decision (Howlett et al., 2009). I study attention of interviewees' perspective on the role and influence of key actors on the decisions that impacted NAMA engagements in IBSA.

As noted by Sabatier and Mazmanian (1980), policy processes do not end with taking decisions; policy evolves also through implementation. Policy implementation encompasses actual governmental efforts to realise policies into practice. It includes officials' specification of public policy through action, often by interpretation of how the policy is to be executed, and allocated resources are to be spent (Fischer, Miller, \& Sidney, 2007). Implementation of climate policy in developing countries gets undermined by factors such as the funding opportunities that create perverse "incentives for domestic inter-ministerial competition [...] to capture funding channels", and "uneven domestic capacity and divergent interests among different institutions in the same country" (Held et al., 2013a, p. 21). I study interviewees' views on the drivers and barriers to NAMA implementation, particularly on inter-ministerial coordination and policy alignment.

Evaluation is undertaken for measuring direct and indirect effects of the policy implementation and evaluating success or failure against the overall policy goals defined by the government. It can provide information on transparency, help establish accountability and lead to enhanced learning over time. Depending on the clarity of aforesaid objectives and the nature of feedback desired, evaluation exercises can be simple or complex in nature. Evaluation can also be undertaken to identify the reasons holding a policy back from implementation or to assess the cost-effectiveness of financial plans during the policy formulation stage itself (Fischer et al., 2007; Smismans, 2015). Lessons learned from evaluation exercises are used in revisiting the agenda for terminating, maintaining, or modifying existing policies or for formulating new policies (Bennett \& Howlett, 1992; Hogwood \& Peters, 1982; Schmitt, 2015). Since very few NAMAs in IBSA have actually been implemented yet, therefore evaluation is here referred to in relation with interviewees' perspective on high or low capacity to conduct the same; and the organizational culture of openness or closeness. 
Using the policy cycle as a heuristic device, by itself, helps me become familiar with the policy terrain in the case countries by providing a somewhat structured approach. As a heuristic, it makes possible to have a broad overview of NAMA engagement, though it has its limitations. When using the policy cycle I remain attentive to the criticism it has faced, and while remaining attentive to the sequence of the stages, I do not take them as given (Hill, 2014, p. 159). The analytical stage model is used to distinguish different stages of the policy cycle, while at the same time being aware that these stages not only interact with each other in various ways but also tend to overlap (P. A. Sabatier \& Weible, 2014). The policy cycle continues to be used in supporting national planning for undertaking climate friendly development (CDKN, 2017), as well as to understanding climate and energy policy development (Chapman, McLellan, \& Tezuka, 2016; Vogel \& Henstra, 2015; Wellstead \& Stedman, 2015).

\subsection{Institutional Perspectives}

In travelling from the international arena to domestic settings, international climate policy frameworks interact with the political realities of different countries. It is therefore pertinent to be aware of how the regulative response to these international climate policy frameworks is shaped at the national level. As indicated in chapter 1, the advent of NAMA also indicated a tilt towards the involvement of developing countries in climate mitigation using state-driven approaches to address climate change. This is also substantiated by the INDCs submitted to the UNFCCC. This entails accounting for the role that the state in developing countries plays in determining the nature of these engagements. To study these aspects, i.e. engagements with international climate policy frameworks in the context of developing countries or emerging economies, each of which has its own constraints, climate policy evolution, and state capacities, I focus on domestic institutions.

Institutions have been "the dominant tradition of political analysis" (Heywood, 2013, p. 94). They are stable and "enduring collection[s] of rules [...] relatively invariant in the face of turnover of individuals and relatively resilient to the idiosyncratic preferences and expectations of individuals and changing external circumstances" (March \& Olsen, 2009, p. 159). If functioning well, they can be a source of strength and stability but, by being path dependent, can also, in instances of institutional decay, be hard to rectify or dislodge (North, 1990). Institutions can be both formal (e.g. policy, the law, the judiciary, and elections) and informal (e.g. gender roles, norms, and customs) in nature. These can of course, be used to reinforce or challenge each other. Institutions give prominence to formal and explicit rules of the game (North, 1990). They are "socially accepted constraints or rules that shape human interactions" (Milner, 1997, p. 18). "Institutions comprise regulative, normative, and culturalcognitive elements that, together with associated activities and resources, provide stability and meaning to social life" (Scott, 2014, p. 56). They can be characterised as a continuum varying from being enforced to being taken for granted in nature. Much like how institutionalists studying norms from their institutional lens categorise norms as informal institutions, norms scholars' (constructivists) studying formal institutions from the normative lens, categorise them as regulative norms (Finnemore \& Sikkink, 1998). Finnemore and Sikkink (1998, p. 
891) distinguish between norm and institution in that the "norm definition isolates single standards of behaviour, whereas institutions emphasise the way in which behavioural rules are structured together and interretale." As I would argue in section 3.3.2, the notion of "single standards of behaviour" could be a problem as it seems to approach norms as a binary construct. It signals that a norm can be coherently identified across different contexts. As is visible in UNFCCC negotiations, interpretations of norms such as historical responsibility and sustainable development varies. I return to this distinction in 3.2.2.

For my analysis, I take into account the regulative and normative elements of institutions (Scott, 2014) and complement them with organizations, together with their structures and procedures, so as to cast light on the institutional capacity aspect. In the developing country context, institutional or state capacity is seen as a limiting factor. Furthermore, studying implementation alone is incomplete without factoring in the "behaviour of implementing organizations" (Friedman, 2006, p. 482). Organizations, together with their structures and procedures, constitute important determining factors influencing institutional capacity (Scott, 2014; Williamson, 1975) and are responsible for facilitating implementation, and other forms of engagement throughout the policy cycle. The theoretical implications of studying these institutional aspects are discussed below.

As discussed in section 2.2, these three aspects, i.e. regulative, normative, and institutional capacity, are identified as important in the NAMA literature as well. Formal institutions can facilitate or refrain the pursuance of ideas or material interests (Harrison \& Sundstrom, 2010), informal institutions such as norms can influence actor behaviour by guiding people's actions and behaviour in groups (Finnemore, 1996), and organizations can determine the effectiveness of implementing regulatory measures and normative expectations by making use of organizational structures and procedures. This approach facilitates consideration of formal and informal interpretations of institutions and of how regulative directives and normative expectations are translated into implementation.

\subsubsection{Formal Institutional Context: Climate Policy in IBSA}

By formulating policy, states not only set rules but also determine the means to monitor the actions being regulated and establish penalties for not meeting the defined expectations. By enacting policy, the state simultaneously plays multiple roles of rule maker, referee, and enforcer through its different arms. Legislation and strategies are used to influence behaviour by means of coercion. Regulating by means of climate policy is a function of domestic politics and can both empower and restrain actors and actions. While climate policy development is generally ascendant (Paper I), it faces the challenge of simultaneously being rigid in providing predictability to investors as well as being flexible enough to take into account unforeseen consequences of climate change (Jordan \& Huitema, 2014b). Based on the comparative-institutional literature, Lachapelle and Paterson (2013) observe, that domestic regimes with favourable incentives representing a broader coalition of interests and capabilities in terms of the nature of the state, can be expected to enact and implement strong mitigation policies. At the same time, the climate policy developed by any government reflects its preferences, beliefs, power distribution among various actors, and the government capability to control the state of play, indicating that these institutional factors are linked to 
each other (Bang et al., 2015). By developing national climate policy, government signals that these factors have collectively crossed the threshold of not taking any action.

In the emerging economy context, climate policy has to be formulated and implemented amidst various pre-existing challenges that influence state priorities. This calls for means to simultaneously address multiple policy problems. The literature refers to concepts such as mainstreaming, alignment and linking to refer to the efforts undertaken to achieve the same. These are often used alongside each other in the climate literature to indicate the relationship between climate policy objectives and other policy objectives or in exploring how different levels of government interact with each other to influence policy objectives (Brouwer, Rayner, \& Huitema, 2013; Dubash \& Jogesh, 2014; van Asselt, Rayner, \& Persson, 2015).

Mainstreaming is mostly used in adaptation context as a means of "integrating climate adaptation measures into existing policies and programs" (Wellstead \& Stedman, 2015, p. 48). Mainstreaming may refer to the process of bringing usually marginal environmental and climate issues to the centre of policy-making efforts. With the increased uptake of climate policy in developing countries, this development seems to have taken place to a certain extent (Paper I). The more pertinent challenge in the developing country context may be to find a balance between these different objectives.

The NAMA literature uses the term mainstreaming but does not problematise it per se, and differs as to whether mitigation should be mainstreamed in development processes or vice versa (cf Fukuda \& Tamura, 2012; with M. K. Shrivastava et al., 2014). NAMAs, as an offshoot of the sustainable development - policies and measures approach (Linnér \& Pahuja, 2012), was "aimed at stimulating action on climate change in developing countries" (Republic of South Africa, 2006). The sustainable development - policies and measures approach contested the trade-off between climate and development, arguing that both could reinforce each other via domestically driven action, remaining open to varied approaches, and maintaining focus on development imperatives (Linnér, Mickwitz, \& Román, 2012). The approach did so by advocating a co-benefit approach linking sustainable development and climate change (Republic of South Africa, 2006). Bali Action Plan Para 1(b)(ii) articulates an extension of this approach as it encourages pursuing a co-benefit or multiple-benefit approach.

Mainstreaming a given policy objective, indicates increased attention in the policy-making process. But as the climate policy literature indicates, the term mainstreaming is used to indicates a process of incorporating policy objective $\mathrm{x}$ into policy objective $\mathrm{y}$. In doing so, it not only seems to subsume the former into latter. This could lead to predicating one objective on the promotion of another. To avoid this, I use the term alignment in studying how emerging economies are trying to achieve multiple objectives simultaneously (Coetzee \& Winkler, 2014; Halsnæs et al., 2014; Tyler, 2011). In this interpretation, by providing attention, mainstreaming serve as a precursor to alignment, the process of making policies compatible with each other without subsuming one into another. The act of alignment would require that both objectives need to give and take in order to find a balance. 


\subsubsection{Informal Institutional Context: Norms Related to Responsibility Distribution}

Norms by definition concern behaviour and "shared expectations about appropriate behaviour held by a community of actors" (Finnemore, 1996, p. 12). Unlike ideas, which can be individualistic and need not necessarily result in any behavioural implications, norms represent collective understandings that are concerned with promoting appropriate behaviour (Finnemore, 1996; Risse et al., 1999). These collective understandings shape interests (Klotz, 1995) and influence actors' behaviour by becoming part of their identity (Checkel, 1998; Finnemore, 1996). By defining standards for appropriate conduct, norms are called upon to justify actions and to persuade others to act. Norms are the principles that guide action and people's behaviour in groups. Norms are different from ideas. Ideas can be individualistic and may not have behavioural implications

The literature illustrates how scholars expect institutionalised transnational norms to influence national interest (Busby, 2007; Finnemore, 1996; Finnemore \& Sikkink, 1998; Risse et al., 1999) - by framing domestic actors' conceptions of the possible and necessary or by providing a moral court of appeal (Busby, 2007; Reus-Smit, 2005, p. 198). However, research on norms has been criticised on two major counts. First, in its efforts to emphasise norms that regulate behaviour and define state identities and interests (Finnemore, 1996; Katzenstein, 1996) it neglects prior questions related to why certain norms and ideas get picked over others (Acharya, 2004; Bernstein, 2000), often claiming the benchmark for what should be considered good. While arguing that norms matter, it also fails to consider what norms matter, how they matter, and how they fare compared with other factors. The norm literature often gives a "misguided sense of the range and depth of the impact" (Legro, 1997, pp. 31-32) of transnational norms as it tends to focus on successful cases only. This criticism branches into two streams.

The first stream studies cases in which the "dog doesn't bark" (Checkel, 1998, p. 339), i.e. when "norms did not emerge or were not consequential" (Legro, 1997, p. 34) enough. As indicated above, the "single standards of behaviour" definition of norms (Finnemore \& Sikkink, 1998, p. 891) creates a binary construct for norms. Either a norm exists or not, leaving little space for nuances. Such an approach remains on an active lookout for instances of norm displacement - instances when a morally or functionally inadequate local norm, already challenged domestically, is replaced by a foreign norm (Acharya, 2004). Thus, giving ascendency to a transnational norm at the cost of regional and local norms. However, as Checkel (1998) and Legro (1997) argue above, such an approach pays scant attention to instances where norm displacement did not occur. Notable amongst norms used in climate change discourse that are often used in rhetoric, but have proved elusive when it comes to operationalisation are sustainable development (Bernstein, 2000) and historical responsibility (Friman, 2013). These norms have been accepted as a guiding principle (sustainable development) (UN, 1992, para. 3.4) and as a key concept in the distribution of responsibilities to act on climate change (historical responsibility) (UNFCCC, 2010, para. 1), but remain difficult to operationalize and are subject to varied interpretations. Furthermore, both these concepts are far from eliciting homogenous interpretations. In particular, sustainable development is advanced as a guiding principle by a variety of economic, social, and political interests (e.g. Mobjörk \& Linnér, 2006), by liberal capitalist and socialist proponents, by 
conventional neoliberal economists and GDP-growth critics alike. In these instances, the dog does bark but is not loud enough or is not seen to bite, i.e. transnational norms do emerge but do not guide domestic actions.

The second stream takes issue with the agency behind the transnational norms by arguing that their proponents tend to be on the lookout for cases of norm displacement - and not norm diffusion. A dichotomous taxonomy of norms is presented in which transnational norms are categorised as good and regional or local norms are juxtaposed as bad (Acharya, 2004). In doing so, the proponents overlook cases in which new transnational norms are modified to be aligned with pre-existing domestic norms and practices. Throwing light on the dynamics of two transnational norms - the European idea of common security proposed in the 1982 report of the Independent Commission on Disarmament and Security Issues and the idea of flexible engagement, underpinned by the norm of Humanitarian Intervention - in the context of the Association of Southeast Asian Nations (ASEAN), Acharya (2004, p. 270) identifies norm localization as a valid and pragmatic response to transnational norms by the norm-takers in a manner that is not produced at the "expense of pre-existing normative frameworks".

The second criticism of the norm literature, also linked to the second stream discussed above, is in their treatment of the norm-takers or the recipient states. In some cases of constructivist research, the norm-makers are presented as "active teachers with well-defined lesson plans for their pupils" (Finnemore, 1996, p. 12). In this perspective, the pupils or the norm-takers tend to be treated as passive recipients of good transnational norms, thereby downplaying the agency of local actors (Acharya, 2004). In doing so, it reduces "agency to the question of whether a static norm had already been internalised or not" (Hofferberth \& Weber, 2015, p. 85). This perspective does not seem to take the domestic circumstances of the "pupils" seriously enough. By presenting a binary outcome of norm diffusion, it also downplays the role that domestic factors - including the material ones - could play in determining change, making "states appear equally capable of normative shifts and identity reconstruction $[\ldots$ and downplaying] the important context of wider struggles between North and South" (Landolt, 2004, p. 581). These material factors stem from the political economy of the domestic structures, processes, and priorities that the state may inherit. The tendency to see local actors as passive recipients of transnational norms and to give material factors insufficient attention affects norm research in at least two ways: first, by influencing the norm selection in favour of transnational norms and, second, by making one norm more decisive than others in determining the future course of action. It thus showcases transnational norms as the benchmark against which local norms have to compete for survival, setting the stage for resistance from local norms and norm takers. As a result, the possibility of norm localization - "a complex process and outcome by which norm-takers build congruence between transnational norms and local beliefs and practices" (Acharya, 2004, p. 241) is ignored. Localization may involve reinterpretation, re-representation and possibly reconstitution of a foreign norm in the image of established domestic normative order. Resistance on the other hand occurs if the local actors have doubt about the utility of the foreign norm in terms of legitimacy and efficacy. Acharya's conception of resistance, localization and norm displacement (2004) are better suited to my thesis than say, the notion of a norm life cycle approach proposed by Finnemore and Sikkink (1998) because their conception of a norm life 
cycle does not explicitly acknowledge resistance or contestation with transnational norms. ${ }^{8}$ Studies focused on domestic processes explain how material interests can tamper with norms to create hollow institutions such that while norms explain the creation of an institution, the shape it ultimately takes is determined by material interests (Dimitrov, 2005). Similarly, domestic processes influence the efficacy of transnational standards' implementation (Malets, 2014) as well as the resistance to and localization of transnational norms (Cortell \& Davis, 2005; Zimmermann, 2016). This calls for studying domestic explanations of political change (Bueno de Mesquita \& Smith, 2012; Harrison \& Sundstrom, 2010; Putnam, 1988; Stålgren, 2006).

NAMAs provide an interesting case in which the engagement and implementation of the norms embodied in an international climate policy framework are to be implemented within national boundaries. The thesis relates to the relevant local norms invoked by actors in IBSA in relation to their engagement with NAMAs. I study how stakeholders draw upon norms when discussing the global distribution of responsibility to act on climate change mitigation, and how these conceptions determine the ways in which, IBSA position themselves in relation to NAMA engagements (Paper IV). By doing so, the local actors will be presented as active recipients that are acutely aware of both - their own domestic priorities and the constraints manifested by climate change at a global scale. These instances of resistance and localization can present opportunities to test the possibility of mutually constituted norms as a means of building trust and cooperation in the interest of common resource management, and the role of the reciprocity and complementarity of norms in determining the future course of action.

\subsubsection{Organizational Context: Institutional Capacity in IBSA}

Organizations pave the way to factor in another institutional aspect identified in the NAMA literature, namely, institutional capacity. Before exploring institutional capacity, it is useful to clarify the relationship between organizations and institutions. Three views of this relationship are identified (Scott, 2014, pp. 182-183). The first view refers to institutions as the rules of the game and organizations as the players of the game (North, 1990, pp. 4-5). Players act within the rules but can also influence the rules. Since both are seen as distinctive elements of the game, organizations are not part of institutions. The second view draws on Williamson (1975) to recognise organizations, their structures, and procedures as institutions. Here organizations are seen as the systems designed to "exercise governance [...] and minimise transaction costs" (Scott, 2014, p. 182). Organizational structure is identified as an important factor determining the effectiveness of policy measures (Prado, 2013). The third view draws on the cultural-cognitive aspects of institutions to emphasise that the elements of these components are readily available in their contextual settings. In this conception, the distinction between organization and their broader institutional setting are underplayed. The organizational patterns are embedded in the culture to such an extent that it is not possible to make distinctions between them. Cultural aspects become crucial to the act of understanding institutions. For my analysis, I take the second definition of organization wherein

\footnotetext{
${ }^{8}$ Finnemore and Sikkink do acknowledge norm contestation but their approach presents norm dynamics postcontestation.
} 
organizations, organizational structures, and procedures are themselves seen as institutions. Doing so acknowledges their role in determining the fate of policy approaches aimed at addressing climate change.

Developing countries face challenges in implementing regulations on account of their limited state capacity (Braithwaite, 2006; Dubash \& Morgan, 2013; Laffont, 2005; Mcallister, 2010). Capacity is referred to as the ability to implement policy (Estache \& Wren-Lewis, 2009). It is identified as one of the key institutional problems that undermine regulation in developing countries. "Uneven domestic capacity and divergent interests among different institutions" (Held et al., 2013a, p. 21) in many developing countries are also seen to be hampering climate policy making and its implementation. It is not a binary construct, however. While finding that developing countries do not have enough state capacity, Evans (1995), in his study of the information technology sector in South Korea, Brazil, and India, classifies states as predatory, developmental, or "in between"; as such they can destroy, nourish, or construct state capacity over due course of time. Capacity is also conceptualised in terms of the style of the regulating entity, which ranges from restrained to energetic (Mcallister, 2010). Availability of resources is understood to be an important factor determining regulatory capacity. Lack of access to resources can be a result of a shortage of revenue or a casualty of domestic politics, handicapping an agency by limiting its ability to attract talent in an already limited professional pool (Estache \& Wren-Lewis, 2010).

The literature suggests two approaches to dealing with the challenge of limited state capacity (Braithwaite, 2006; Estache \& Wren-Lewis, 2010). The first approach calls for more centralisation of the functioning of the regulatory structure so that the overlaps in various regulatory tasks can be dealt with more efficiently by developing multi-sectoral agencies. The second approach is to engage with non-state actors, either by contracting out part of the regulation or by using networks to enrol various non-state actors, as a means to overcome the capacity deficit. Since the state is often not capacitated enough in developing countries, it has to make up for its limitations by actively engaging non-state actors in various roles to be effective (Braithwaite, 2006; Laffont, 2005). This adds another layer of complexity to the literature. To factor in this aspect, I also take into account the perspective of non-state actors on NAMA engagements, which helps to triangulate the claims made by state actors. State capacity is defined "thinly" in terms of relatively objective concerns such as personnel, institutional design, financial independence, and training, whereas "thick" issues refer to the ability of the state to engage with various stakeholders in its efforts to address multiple objectives simultaneously (Dubash \& Morgan, 2013; Prado, 2013). To factor into my analysis the institutional capacity aspect of efforts to engage with the NAMA framework, I focus on IBSA actors' perceptions of the organization of work to allow for both horizontal and vertical integration, and of the efforts of respective ministries of environment either to increase their own capacities or to engage with various other state and non-state actors to compensate for their lack of capacity. I study the willingness of the environment ministries to conduct coordination and stakeholder consultations as both avenues and means to involve various other state and non-state actors. The extent and nature of actors engaged in stakeholder consultation can be expected to indicate the nature of the NAMAs emerging in IBSA. By institutional coordination, I refer to the "horizontal concentration or diffusion of authority 
within a national government and the vertical concentration or diffusion of authority among levels of government" (Harrison \& Sundstrom, 2010, pp. 16-17). In this conception, the concentration or diffusion of power in IBSA varies along both the horizontal and vertical axes, and the degree of consolidation or fragmentation determines the nature of engagement with NAMAs in different contexts (Bang et al., 2015).

This conception is different from the one used in the usage of the term climate policy integration (Adelle \& Russel, 2013; van Asselt et al., 2015). Climate policy integration, used predominately in the European Union context (van Asselt et al., 2015), refers to "the incorporation of the aims of climate change mitigation and adaptation into all stages of policy-making in other policy sectors (non-environmental as well as environmental) [...] and a commitment to minimise contradiction[s] between climate policies and other policies" (Mickwitz et al., 2009, p. 19). climate policy integration is seen as prioritizing climate objectives over other policy objectives without paying much attention to the pursuit of multiple and sometimes competing objectives (Adelle \& Russel, 2013). The concept of climate policy integration finds little resonance in the developing country or emerging economy contexts (however, see Dubash \& Jogesh, 2014 on mainstreaming across different levels of governance), possibly because it seems to give normative prominence to environmental objectives over others. Therefore I do not use the term integration in studying policy integration, rather I use it to study horizontal and vertical integration when it comes to operationalising the climate policy. 
This chapter will elaborate on the mixed-method sequential explanatory research design adopted in this study, outline the empirical material used, and summarise the methods used to analyse the empirical material for papers I-IV.

\subsection{Mixed-Method Approach}

Traditionally, social science research has been marked by a quantitative-qualitative divide, which has been described in terms of war, religion, and alternative cultures with their own sets of "values, beliefs and norms" (King, Keohane, \& Verba, 1994, p. 1; Mahoney \& Goertz, 2006, p. 227; Tarrow, 2010, p. 102). Multiple efforts have been undertaken to overcome this divide, all arguing that a mixed-method approach provides additional understanding (Ivankova et al., 2006; Lieberman, 2005; Ragin, 1987; Schrodt, 2006). Mixed methods refer to a process of "collecting, analysing, and mixing or integrating both quantitative and qualitative data at some stage of the research process within a single study" (Ivankova et al., 2006, p. 3). ${ }^{9}$ Depending on the stage at which the methods are mixed, such studies can be further categorised as mixed data-collection studies or mixed data-analysis studies (Small, 2011). Such studies are already being utilised to study environmental policy and climate policy dynamics. For instance the papers in this thesis come together to follow the approach taken by Jörgens, Lenschow, and Liefferink (2014) who combined the results of a quantitative study with in-depth case studies, in analysing the extent of environmental policy convergence, i.e. increase in similarity among policies across space and time. Another example is the study taken by Never and Betz (2014) to study the climate policy performance in emerging economies by applying a fuzzy set qualitative comparative analysis using a set-theoretic technique drawn on Boolean algebra.

This thesis follows a mixed-method approach to understanding domestic engagements with the international climate policy framework of NAMAs for enhancing mitigation in emerging economies. While differing in their data-collection and data-analysis approaches, the four papers have a common area of inquiry: engagements for pursuing mitigation at the national level in emerging economies. Paper I undertakes a survey of climate policy across all UN member states in two time periods, i.e. 2007 and 2012, to account for the policy approaches undertaken at the national level to mitigate climate change; based on the data collected, it identifies the historical development of the diffusion of these approaches in different parts of the world. In doing so, Paper I establishes the broader context in which the rest of the papers qualitatively study NAMA engagements in IBSA. Paper II undertakes a case study approach in examining how NAMAs have been pursued in an attempt to align multiple policy objectives in South Africa. Papers III and IV respectively undertake small-N case studies of how have NAMAs fared along the policy cycle and how domestic institutions have influenced

\footnotetext{
${ }^{9}$ The mixed-method approach is sometimes referred to as multi-method approach. Some studies also use multiple methods without explicitly claiming to use a mixed-method approach. To be consistent, I use mixedmethod approach in this study to refer to all such efforts.
} 
NAMA engagements in IBSA. Taken together, the two approaches complement each other and provide a better understanding of the historical development of and variations in current climate policy processes.

Mixed methods are increasingly being used across various policy fields, including climate policy (Never \& Betz, 2014; Preston, Mustelin, \& Maloney, 2015; Scrieciu, Belton, Chalabi, Mechler, \& Puig, 2014; Stevenson, 2015). There is much to be gained by mixing methods to confirm, complement, or contradict findings (Small, 2011). Using mixed-method approaches can also pave the way for stronger inferences about policy processes at different levels of governance. In this study, I use both quantitative and qualitative approaches to inform our understanding of climate policy regulation across countries, more specifically, of how three emerging economies engage with the common NAMA framework in their constituencies. In doing so, I enhance our understanding of both the global historical developments visible in policy approaches to climate governance and of context-specific knowledge of climate policy engagements in three important democracies of the global South. In this chapter, I delve into the utility of taking a mixed-method approach as well as elaborate on the sequential explanatory design (Ivankova et al., 2006), case selection, and analytical methods used in this study.

Three trends are evident in the application of mixed data collection techniques (Small, 2011). First, the motivation for combining different data types can be either to confirm or to complement the findings derived from using any one data collection technique by itself. Second, the sequencing, or lack thereof, of two or more data collection approaches is undertaken to meet methodological requirements. Third, mixed data collection approaches tend to employ nested data and are referred to as nesting.

Mixed data types can be deployed to confirm, complement, and even contradict the findings derived from using any one data type. For example, the "environmental state" as a topic of enquiry has been researched using different methods, such as sociological research (Meadowcroft, 2012) or historical cluster analysis (Duit, 2016). While Meadowcraft (2012) takes on comparative macrosocial analysis to situate the emergence of environmental regulation in the broader evolution of the state by shedding light on historical emergence of the environmental state, Duit (2016) analyses the patterns of environmental governance regimes by scoring the regulative initiatives undertaken by 28 countries across 25 environmental problems. The former takes on a qualitative approach to studying environmental state, whereas the latter takes a quantitative approach to illuminate different aspects of the same topic under observation. Bringing the two approaches together could fuse the broader historical context of environmental state's evolution with more context specific mechanisms visible in such an evolution, thus potentially making the argument even more persuasive. Mixed data types can also end up with either conflicting results or explain conflicting observations. Such studies are powerful as they can avoid the limitation of being dependent on any one research approach. For example, while climate adaptation research has grown in recent years, it has not translated into adaptation implementation. To understand this divergence, quantitative content analysis of the adaptation literature has been complemented with qualitative analysis of the heuristic used in adaptation literature, revealing that this 
heuristic does not capture the complexity associated with adaptation implementation (Preston et al., 2015).

\subsection{Sequential Explanatory Research Design}

Sequential explanatory research design refers to those studies in which one type of data collection exercise creates a platform for other, more specific data-collection efforts. These studies involve one type of data-collection exercise at a given time. Such a research design is more fruitful for studies covering longer time scales. One such design is mixed-methods sequential explanatory design (Ivankova et al., 2006). This research design tends to be divided into phases wherein establishing or analysing quantitative datasets is followed by elaborate, in-depth data collection and analysis (Fridahl \& Johansson, 2016). The contrary approach, referred to as concurrent design, is better suited for studies in which multiple data types from the same period are needed. Concurrent design studies need bigger teams with varied skill sets to be effective. These studies could also be nested within each other, which is referred to as Nesting. Nesting implies basing two or more data-collection exercises on the same set of entities. The universe of cases for a nested study is the same. A study comprising a large survey of individuals, followed by focused interviews of individuals selected from the same set falls in this category. Nesting is particularly useful when situating small-N studies within large-N studies. Nested analysis has also been presented as a unified approach to carrying out mixed-methods research (Lieberman, 2005). In contrast, non-nested research designs are useful when different data types from multiple sources are needed.

I collected and analysed data for a large-N study for Paper I, and followed it up with document analysis and interview-driven studies from three emerging economies. The data collection for these studies provides complementary data and follow two distinct phases, meeting the requirements for mixed-method and sequential exploratory design studies, respectively. Therefore, I define my research as following a mixed-method sequential explanatory research design.

Although all four papers are based on the same universe of cases, namely, nation states, I refrain from using nested analysis as a strategy for conducting my analysis. My reservations about using the oft-tested nested analysis approach are twofold. First, by prescribing that "a prerequisite for carrying out a nested analysis is availability of a quantitative dataset, with a sufficient number of observations for statistical analysis, and a baseline theory" (Lieberman, 2005 , p. 438), Lieberman seems to give structural primacy to quantitative large-N analysis in defining the fate, direction, and purpose of qualitative small-N analysis. While I do agree that one study may favour a quantitative over a qualitative approach, and vice versa for the second study, I share concerns about using "a quantitative template for qualitative research" (Brady \& Collier, 2010, p. 1), as it can ignore the possibility of equifinality - "several explanatory paths, combinations, or sequences leading to same outcome" (George \& Bennett, 2005, p. 20), and increase the chances of conceptual stretching (Sartori, 1991) by means of forcing generalizations, thus setting up structural imbalances favouring one approach determining the purpose and utility of another. Second, and more importantly for my study, the availability of a quantitative dataset is defined as a prerequisite and emphasis is put on using statistical analysis to assess the relative strength of the variables under consideration. While dependence 
on readily available datasets is one weakness of large- $\mathrm{N}$ analysis, I overcome this limitation by contributing to the development of a novel database that covers climate policy development in all UN member states - and being the only study to do so (Paper I). The dataset maps the evolution of climate policies across the world in 2007 and 2012 and has been used to map historical developments in the spread of climate regulation at the global level without sacrificing simplicity. However, as per Lieberman's expectation, I do not conduct any statistical analysis of the dataset.

Another important consideration is whether to give priority to quantitative or qualitative data collection and analysis. While I emphasise quantitative data collection and analysis in Paper I, the other three papers are based on qualitative data collection and analysis methods. Paper I contributes to a general understanding of climate policy development, whereas papers II-IV delve deeper into the selected case countries and provide contextual depth to the study. My findings provide both broad and in-depth knowledge of climate governance, particularly in emerging economies. Table 5 summarises the key features and focuses of all four papers.

Table 5: Roles of Different Methods in the Four Papers

\begin{tabular}{|c|c|c|c|c|c|}
\hline & $\begin{array}{l}\text { Study } \\
\text { design }\end{array}$ & Cases & Documents & Role of documents & $\begin{array}{l}\text { Role of } \\
\text { interviews }\end{array}$ \\
\hline $\begin{array}{l}\text { Paper } \\
\text { I }\end{array}$ & $\begin{array}{l}\text { Large-N } \\
\text { study } \\
(193)^{10}\end{array}$ & $\mathrm{~N} / \mathrm{A}$ & $\begin{array}{l}\text { National climate } \\
\text { regulations }\end{array}$ & $\begin{array}{l}\text { Informing the } \\
\text { categorisation of } \\
\text { countries' climate } \\
\text { approaches }\end{array}$ & None \\
\hline $\begin{array}{l}\text { Paper } \\
\text { II }\end{array}$ & $\begin{array}{l}\text { Case } \\
\text { study (1) }\end{array}$ & $\begin{array}{l}\text { South } \\
\text { Africa }\end{array}$ & 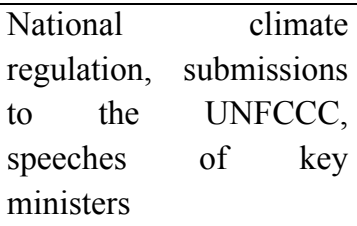 & $\begin{array}{ll}\text { Objective } & \text { of } \\
\text { analysis } & \end{array}$ & $\begin{array}{l}\text { Informing } \\
\text { the } \\
\text { document } \\
\text { analysis }\end{array}$ \\
\hline $\begin{array}{l}\text { Paper } \\
\text { III }\end{array}$ & $\begin{array}{l}\text { Small-N } \\
\text { study (3) }\end{array}$ & IBSA & $\begin{array}{l}\text { National climate } \\
\text { regulations, submissions } \\
\text { to the UNFCCC, INDCs, } \\
\text { and other government } \\
\text { documents }\end{array}$ & $\begin{array}{l}\text { Informing the } \\
\text { interview analysis }\end{array}$ & $\begin{array}{l}\text { Objective } \\
\text { of analysis }\end{array}$ \\
\hline $\begin{array}{l}\text { Paper } \\
\text { IV }\end{array}$ & $\begin{array}{l}\text { Small-N } \\
\text { study (3) }\end{array}$ & IBSA & $\begin{array}{l}\text { National climate } \\
\text { regulations, submissions } \\
\text { to the UNFCCC, INDCs, } \\
\text { and other government } \\
\text { documents }\end{array}$ & $\begin{array}{l}\text { Informing the } \\
\text { interview analysis }\end{array}$ & $\begin{array}{l}\text { Objective } \\
\text { of analysis }\end{array}$ \\
\hline
\end{tabular}

Sequential explanatory research design provided me with the flexibility to prioritise amongst qualitative and quantitative data collection and analysis. The mixed-method approach

\footnotetext{
${ }^{10}$ Indicates the number of countries covered by the paper.
} 
followed in this thesis uses the quantitative data from Paper I "as a frame for qualitative analysis" (Tarrow, 2010, p. 106) of NAMA engagements in three emerging economies. By studying emerging economies' efforts to enhance mitigation in their domestic constituencies, the research sheds light on how the international climate policy frameworks are used in different ways in IBSA countries. By doing so, the breadth of Paper I is complemented by the depth of contextual analysis provided by the three remaining papers. Taken together, the papers inform us that the emerging economies are undertaking national initiatives to address climate change in a variety of ways.

\subsubsection{Case Study}

Three of the four papers follow different case study methodological traditions. Case study methods "include both within-case analysis of single cases and comparisons of a small number of cases" (George \& Bennett, 2005, p. 18). The thesis includes a within-case analysis (Paper II) and three cross-case comparisons, one using a large-N study sample (Paper I) and two using a small-N study sample (papers III and IV) from emerging economies (Ebbinghaus, 2005). This approach permits an in-depth analysis of a small number of cases (Lijphart, 1971) and subsequently to use the information gained to identify outcomes that can be linked to overarching themes across the cases under study. In a small-N study sample, it is typical to have only two to five cases under observation, in order to be empirically intimate with the cases. A small-N selection of cases reflects a closed universe distribution, i.e. relevant cases in relevant periods (Pennings, Keman, \& Kleinnijenhuis, 1999). Small-N approaches are particularly useful in new research areas - including climate policy in emerging economies and developing countries - where the availability of data with which to gauge policy performance is limited (Purdon, 2015). These studies do not aspire to be representative of all the cases in a given sample but are helpful in providing analytical generalisation for a small number of cases. Developing a better understanding of the reasons behind different national responses to a common policy framework (i.e. NAMAs in this research) is possible, provided the study focuses on a manageable number of cases. Following such an approach, this research strives to identify the institutional factors that trigger specific responses in the case countries.

Comparisons are used to make sense of the cases by understanding and explaining the similarities and differences in the phenomenon under study in different contexts. There are four main reasons to apply comparisons: to develop contextual descriptions, make classifications, test hypotheses in order to build theories, and predict outcomes beyond the cases studied (Landman, 2008). Contextual descriptions are the basic building blocks for undertaking comparisons. The function of contextually descriptive studies is to gather more knowledge and help identify probable avenues and factors that could be keys to explaining the phenomenon under study. Contextually descriptive studies, also referred to as case studies, can help achieve high conceptual validity, derive new hypotheses (which can be further tested using comparative studies), explore causal mechanisms (usually unobservable processes through which agents in specific contexts attempt to bring about desired changes), and produce narrow and contextual generalisations - besides accounting for complex interactions and path-dependency arguments (Brady \& Collier, 2010; George \& Bennett, 2005, pp. 1922). Contextual descriptions (case studies, as in Paper II) and classifications are keys to 
deriving testable hypotheses and to theory building (by possibly leading to typological theory). This leads to the last objective of comparisons: making predictions. Not all comparative studies pursue the aim of prediction, as it is not feasible to conduct repeatable empirical verifications when it comes to studying nation states.

All four papers of the thesis relate to comparative approaches. Paper I uses a comparative method primarily to make classifications. Based on these classifications - along the lines of developed versus developing countries and countries with versus without climate policy - I identify central contextual factors affecting climate policy developments. Using a large- $\mathrm{N}$ study sample, Paper I provides the broader context for the thesis, i.e. there was a surge in the uptake of national-level climate policy, particularly in developing countries during the 20072012 period, that has since started to taper off (GLOBE International, 2016b). Paper I is followed by a case study (Paper II) and two small-N case studies (papers III and IV) developing the contextual description of the cases under study. This helps us understand what prompts countries to engage or not engage with internationally designed policy frameworks, such as NAMAs. New evidence generated during the course of study was constantly used to refine the study. In Paper II, for example, I concluded that "the mitigation debate in South Africa has moved to ideas beyond NAMAs" (Upadhyaya, 2016, p. 477). However, I eventually revisited this finding in light of new evidence. Up until 2015, despite various South African initiatives, NAMAs seemed to be getting stuck at the decision-making stage. This changed in 2016 when at least one such initiative managed to reach the appraisal stage in one of the NAMA support platforms. Such developments are of importance for better understanding the dependent variable under scrutiny in my research, i.e. NAMA engagement in IBSA.

\subsection{Empirical Material}

In this section, I provide an overview of the empirical material used in this study, which consists primarily of interviews and documents. National climate policy documents formed the backbone of the material for Paper I. For Paper II, South African climate policy, submissions to the UNFCCC on NAMAs, speeches of the president and key ministers, and important national policy documents provided the contextual background. Interviews served as the primary material for papers II-IV. Papers III and IV are predominately based on interviews but are informed by document analysis of IBSA's national climate policies, submissions to the UNFCCC on NAMAs, and INDCs.

\subsubsection{Interviews}

I developed a semi-structured interview guide (Appendix I) based on my readings of the secondary literature on NAMAs. The interviews it guided served as the primary mode of data collection on NAMA engagements in IBSA. While the interview guide had a common set of questions, using a semi-structured interview format provided latitude for probing, clarifications, and accommodating spontaneous issues that arose during the interviews (Irvine, Drew, \& Sainsbury, 2013). The format also provided avenues to ask prompting questions, giving greater scope to acquire in-depth and contextual knowledge (Silverman, 2006). The interview guide consisted of three sets of questions, beginning with broad questions before 
going to more specific ones (Doody \& Noonan, 2013; Sandberg \& Alvesson, 2011). The first set of questions pertained to the general climate and development policy space of the given context and to climate policy processes. This approach also helped establish rapport with the interviewee. This was followed up by an intervention to clarify whether or not the interviewees considered themselves experts on NAMAs. ${ }^{11}$ Depending on interviewee responses, the conversation continued to a second set of NAMA-specific questions (for NAMA experts) or a third set of general questions on climate governance (for non-NAMA experts). These three set of questions in the interview guide provided me with latitude to either keep the negotiations broadly on climate change mitigation or to go more specifically on NAMA engagements. The interview guide provided avenues to discuss climate policy development as well as NAMA engagements in relation to both the policy processes and institutional responses without specifying the stages of policy process or type of institutional response, so as to avoid influencing the response of the interviewee. The initial questions were intentionally kept broad so as to develop rapport with the interviewee. More specific questions were raised once the interviewee indicated familiarity with the topic.

The interviewees were selected based on their expertise, familiarity with climate negotiations, and recommendations by fellow interviewees (i.e. snowball sampling). The interviewees in the study represent a wide spectrum of actors, including government representatives, international agencies, academia, NGOs, industry, as well as independent actors (Table 6). Although the study focuses on NAMA processes in IBSA, it was useful to interact with nonNAMA experts as well, as this helped me familiarise myself with the broader contexts and get outsider perspectives on the UNFCCC climate negotiations and national climate policy processes.

\section{Table 6: Interviewee Distribution ${ }^{12}$}

\begin{tabular}{|l|l|l|l|}
\hline Category & India & Brazil & South Africa \\
\hline Government/international agency representatives & $2 / 2$ & 2 & $4 / 1$ \\
\hline NGO/independent & 3 & 1 & $3 / 3$ \\
\hline Research and academia & 4 & 3 & 5 \\
\hline Private/consultant & 3 & 1 & 4 \\
\hline Other & 1 & - & - \\
\hline
\end{tabular}

This approach was particularly helpful in South Africa, where non-NAMA experts shared their opinions on topics such as constitutional imperatives, international relations, carbon capture and storage, and a defining feature of the South African economy, i.e. the mineral-

\footnotetext{
${ }^{11}$ NAMA experts were defined as respondents who were familiar with the NAMA concept and who engaged with it at either a conceptual or implementation level.

${ }^{12}$ The interviewees are categorised based on the roles they identified for themselves. In some instances, the interviewees have multiple roles, for example, as both researchers and government negotiators, in which case they clarified in which capacity they were responding to the interview questions. Some of the respondents were formerly part of their government dispensation, their responses were crucial to get a historical perspective on NAMA development.
} 
energy complex. ${ }^{13}$ Such interactions encouraged self-exploration (Doody \& Noonan, 2013) and helped develop an in-depth understanding of the South African context that was particularly helpful in undertaking a South African case study (Paper II).

The interviews benefited from the review of government documents and secondary literature, which helped raise context-specific questions. In-person interviews were conducted in South Africa and India. A total of 19 in-person interviews were conducted in South Africa from 13 May to 20 June 2014. During this time, I was hosted by the Energy Research Centre (ERC) at the University of Cape Town. Fifteen in-person interviews were conducted from 16 April to 14 May 2015 in India, where I was hosted by the Climate Initiative, Centre for Policy Research, and Iora Ecological Solutions Pvt. Ltd. Due to time and financial constraints, the seven Brazilian interviews were conducted via Skype (Hanna, 2012) and telephone between 15 October 2015 and 9 March 2016. Two of the interview calls also used the video function. These were followed up by two more South African interviews in May 2016 and one more Indian interview in November 2016, to take into account the most recent NAMA developments in both countries. The follow-up interviews did not follow the interview guide as they focused on very specific aspects of NAMA development; these are not included in the categorisation in Table 6. Leaving apart these three interviews, 12 South African, 11 Indian, and six Brazilian interviewees identified themselves as NAMA experts. The interviews formed the basis of papers II-IV. All except the last three interviews were recorded (Harvey, 2011), transcribed verbatim, and summarised. The last three interviews were not summarised. More information about the interviewees is provided in Appendix .

As the study was spread across time and geography, certain modifications were necessary, leading to certain limitations. After the first round of interviews in South Africa, the interview guide was revisited to make minor modifications, so as to improve the clarity of the questions and address the overlap between some of them. In India, despite repeated requests for an interview at the Indian Ministry of Climate Change, I could not get approval for an interview at the time. ${ }^{14}$ One reason for my inability to secure an interview at the Ministry was that the period of my field visit to India coincided with the Ministry's efforts to prepare the country's Intended Nationally Determined Contribution (INDC). This indicated to me that NAMAs had not gained much traction in India, that the Ministry attributed much more importance to preparation and stakeholder consultation for INDCs than for NAMAs, and, finally, that the capacity of the department to deal with a range of issues was limited. This limitation of the study was partially addressed by interviews with former decision makers from the Ministry who had represented India in the Bali and Copenhagen negotiations. Towards the end of 2016, India submitted NAMAs to the NAMA Facility for support. These NAMAs were developed based on NAMA feasibility studies supported by GIZ-India. At least three of my initial 15 interviewees in India were directly involved in the NAMA feasibility studies in various capacities. I conducted a follow-up interview to account for this development. In

\footnotetext{
${ }^{13}$ Particularly interviews with SA5, SA9, SA17, and SA19.

${ }^{14}$ I managed to spend time with the key climate negotiator from the Ministry during Bonn intersessional meetings in 2016. I sensed a general lack of interest in NAMAs as a policy framework at that time, confirming the impression formed in my conversation with other stakeholders from India.
} 
addition, to assess the level of awareness surrounding this development, I sent follow-up emails to all the Indian interviewees enquiring whether they were aware of this development and, if so, what in their opinion could explain this development. I received five responses, all of which expressed ignorance of this development. This was an important observation, to which I return in section 5.2. In Brazil, I interviewed fewer people than in the other two countries. Since I wanted to ensure a broad overview of NAMA engagement in Brazil, I prioritised reaching out to stakeholders who were highly influential in shaping the NAMA engagements in Brazil. Three of the seven Brazilian interviews were conducted after COP21. This resulted in increased reference to INDCs over NAMAs compared with previous interviews, but did not affect the historical discussion of NAMA engagements in Brazil.

\subsubsection{Documents}

National climate policies are key documents for my study. Paper I exclusively examines the existence of national climate policy documents, which are divided into two sub-categories of climate legislation and climate strategies. Documents that were publicly available by December 2012 have been accounted for in the categorisation; sectoral approaches or acts focusing only on adaptation are not accounted for.

Table 7 provides an overview of the documents that form part of the empirical material for my thesis. Climate legislation in Brazil and climate strategies in India, and South Africa are the key documents for papers II-IV. These documents came into being at different points in time. This is in contrast to the letters submitted by IBSA to the UNFCCC in response to the Copenhagen Agreements.

In addition, IBSA made some submissions specifically regarding NAMAs. These submissions, along with those submissions referred to or hinted at in the interviews, were also part of the empirical material. The details of these submissions are as follows:

- South Africa: sustainable development - policies and measures (Republic of South Africa, 2006); register of NAMAs by developing countries (Republic of South Africa, 2008)

- India: climate change negotiations - India's submissions to the UNFCCC on climate change (Government of India, 2009, pp. 14-19); increasing ambition level under the Durban Platform for Enhanced Actions (Government of India, 2012, para. 3)

- Brazil: Elements of the New Agreement under the Convention Applicable to all Parties (Government of Brazil, 2014b); Accelerating the Implementation of Enhanced Action (Government of Brazil, 2014a). 


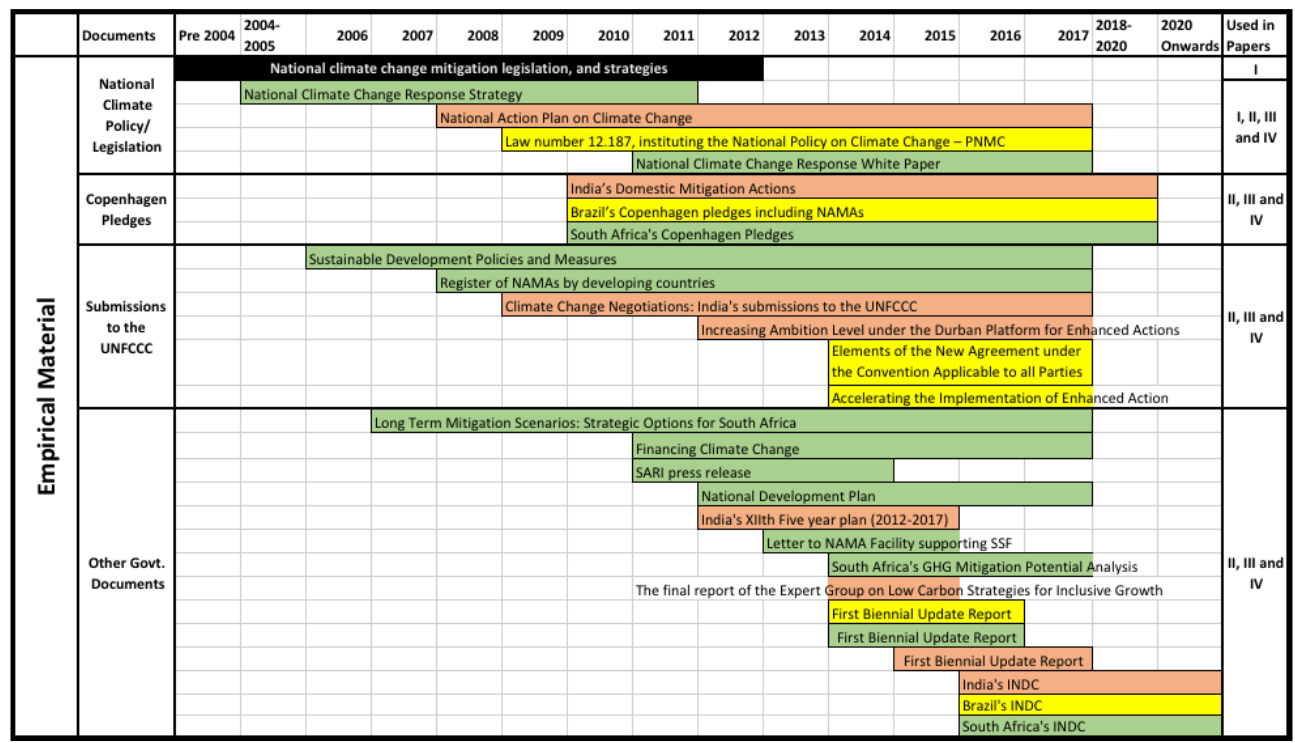

In addition to these documents forming the core empirical material for the study, other government documents were used as supporting material in order to understand the broader context of IBSA as well as to inform the analysis. The INDCs submitted by IBSA to the UNFCCC are also included in these documents as they help indicate the direction of IBSA's efforts to enhance mitigation. During my field visit in India, I also had the opportunity to participate in the stakeholder consultations on NAMA engagements organized by GIZ and the Ministry of Climate Change. I attended these consultations as an observer. The notes taken during these consultations were used to triangulate developments related to NAMA engagements in India.

\subsection{Linking Theory and Empirical Material}

Each paper in the thesis takes a different but related approach to understanding IBSA's engagement with international climate policy frameworks. In doing so, they illuminate different parts of the broader picture of how these engagements play out when travelling from international to national and, at times, sub-national levels. While a separate analytical method was developed for each paper, each succeeding paper was informed by the previous papers. In this way, they built on each other to present a contextually aware picture of NAMA engagements in IBSA. This section presents the methods employed to study the object of analysis, i.e. climate policy and NAMA engagements in IBSA.

\footnotetext{
${ }^{15}$ Green cells refer to South African documents, orange to Indian documents, yellow to Brazilian documents and black to documents of all countries.
} 


\subsubsection{Paper I: Developments in Mitigation Legislation and Strategy}

As indicated above, Paper I is based on a survey of national climate policies divided into the climate legislation and climate strategy categories. The former refers to those documents passed by national parliaments or equivalent institutions and having a legal character; the latter refers to strategies, plans, or frameworks developed by national governments without the approval of the national parliament. In the latter case, availability of a coordinating body is also necessary. The presence of such a body is interpreted as an indication of intent to implement climate strategy. Policies in both categories require the presence of limited or reduced GHG emissions, either in the title or in the statement of objectives. To account for countries that did not meet the above requirements, a third category, "none of the above", was created. Countries for which data were unavailable were placed in the incomplete analysis category. Thus, irrespective of whether or not there was any national-level regulation on climate change, all the UN member states were accounted for.

Once the policy categories were defined, official government websites were analysed to assess the availability of climate policy. Information communicated through national communications to the UNFCCC or made available through UN agency websites was used to cross-check government sources. Exceptions were made for the government documents that were available on non-government websites. The data thus collected were placed into two time categories, December 2007 and December 2012. In addition, the findings were related to the annual GHG emissions in 2010, cumulative GHG emissions, 1970-2010, and population data to account for historical developments in the update of climate policy in a total of 193 countries.

\subsubsection{Paper II: Aligning Climate Policy with National Interest in South Africa}

Paper II explores the South African state's conception of its national interest and the strains this puts on national climate policy. Based on analysis of South Africa's national policy documents, submissions to the UNFCCC, and key speeches of the president and ministers, the priorities of the state in pursuing its national interests are identified. The secondary research literature also helped me become aware of the domestic context. With this awareness, I conducted 19 semi-structured, in-person interviews with various stakeholders representing government, industry, research organizations, and NGOs. Three stakeholders identified themselves as independent. The interviewees were a mix of NAMA experts (12 interviewees) and non-NAMA experts (seven interviewees). All the interviews were recorded and then transcribed verbatim. Seven interviews were selected randomly for an inductive analysis using NVivo software, to tease out key recurring themes. This analysis was useful in identifying key themes in the South African climate policy process (Table 8). 
Table 8: Key Themes in the South African Climate Policy Process

\begin{tabular}{|l|l|}
\hline Key Themes & Details \\
\hline Key challenges & Poverty, unemployment, and inequality \\
\hline $\begin{array}{l}\text { NAMAs under } \\
\text { development }\end{array}$ & $\begin{array}{l}\text { Sustainable Settlement Facility (SSF) } \\
\text { South African Renewable Initiative (SARi) } \\
\text { Vertically-integrated NAMAs (V-NAMAs) }\end{array}$ \\
\hline $\begin{array}{l}\text { Prominent ideas in } \\
\text { policy formulation }\end{array}$ & $\begin{array}{l}\text { Sustainable development - policies and measures } \\
\text { Long Term Mitigation Scenario } \\
\text { Mitigation Action Plans and Scenarios } \\
\text { Desired Emission Reduction Outcomes }\end{array}$ \\
\hline $\begin{array}{l}\text { Organizational } \\
\text { structures }\end{array}$ & $\begin{array}{l}\text { Inter-Ministerial Committee on Climate Change } \\
\text { Inter-Governmental Committee on Climate Change } \\
\text { National Committee on Climate Change }\end{array}$ \\
\hline $\begin{array}{l}\text { Key } \\
\text { departments }\end{array}$ & $\begin{array}{l}\text { Involved in SSF: Department of Environmental Affairs } \\
\text { Involved in SARi: Department of Public Enterprise, Department of } \\
\text { Trade and Industry, and Department of Energy } \\
\text { Involved in V-NAMA: Department of Environmental Affairs, } \\
\text { Department of Energy, and Department of Public Works } \\
\text { Other relevant departments: National Treasury and Department of } \\
\text { Human Settlement }\end{array}$ \\
\hline Prominent interests & Mineral-energy complex and the developmental state agenda \\
\hline
\end{tabular}

Summary sheets were prepared for all the interviews to better organize the responses in relation to the questions asked. Responses were then coded based on the key themes identified, and new themes identified in other interviews were used to refine this categorisation. Secondary research and key speeches from various ministers that were brought to my notice by the interviewees during the course of our conversations were referred to (but not coded) in order to improve contextual descriptions of the NAMA engagements. The experience of using NVivo for coding proved helpful in analysing interviews from India and Brazil that were subsequently used for papers III and IV. The analysis in Paper II raised the importance of policy processes in determining the fate of various NAMA initiatives. Two more interviews were conducted in 2016 to update the findings of this paper.

\subsubsection{Paper III: Comparing NAMAs in IBSA’s Policy Cycles}

While conducting interviews, the interviewees were asked to reflect on the broader climate policy process. Those interviewees who identified themselves as NAMA experts were also asked to elaborate on NAMA process (Appendix I, Section II). Using a staged approach as a heuristic device, the interviewees' views on NAMA policy processes in IBSA were analysed. This interpretation was used to identify and code the roles of different policy cycle stages in IBSA's NAMA engagements. Except for the three interviews from India and South Africa that were conducted in 2016, the summary sheets were prepared for all the interviews. These summary sheets and the complete interviews from the three aforesaid interviews were coded as per the framework developed for paper III. We identified the instances in which the 
interviewees referred to different functions of the NAMA cycle in explaining NAMA processes. For example, consultation with the general public was classified under the agendasetting stage. Instances in which government departments took positive or negative decisions regarding which policy should be approached as NAMA were allocated to the decisionmaking stage. On the other hand, if interviewees raised concerns about implementation or pondered as to why it was difficult to translate policies into action, then allocation was made to the evaluation stage, as the interviewees were evaluating the reasons for the lack of implementation, rather than the implementation itself. We drew upon this data to argue our case, backing it up with relevant documents from the three governments and secondary literature on climate policy in IBSA.

\subsubsection{Paper IV: Institutional Explanations of Variations in NAMA Engagements}

For Paper IV, the analysis of summary sheets was undertaken in three steps. The first step involved qualitatively coding the summary sheets for the policy, normative, and organizational aspects of institutions as defined in section 3.3, identifying views related to our theoretical understanding of these three concepts. The next iteration used the content analysis method, "key word in context" (Guest, MacQueen, \& Namey, 2012) to substantiate the coding with expected keywords. In this method, the text surrounding the identified key concepts was retrieved and analysed to scrutinise their contexts. The list of indicator words was extended by introducing country-specific codes to reflect the country context. Finally, we analysed in the third step, we analysed the text surrounding the indicator words.

This study contributes to the literature on NAMAs by carrying out in-depth comparisons of NAMA engagements in three emerging economies by focusing on their domestic contexts. In doing so, it pays attention to the domestic policy processes and institutional dynamics surrounding NAMA engagements. Studying these three cases exposes similarities and differences in NAMA policy processes along the institutional dimensions. 


\section{$5 \quad$ RESULTS}

This chapter synthesises the results of papers I-IV. In doing so, it travels from the broader international context of climate policy development to the specific context of NAMA engagement in IBSA. The former provides the broader context in which the latter can be explored. The chapter begins in section 5.1 by summarizing the historical development of climate policy in emerging economies over the 2007-2012 period. By making observations related to climate policy development in emerging economies based on Paper I, this section provides answers to research question 1. Apart from taking note of overall historical developments in developing countries and emerging economies, climate policy development in IBSA is particularly highlighted.

Sections 5.2, 5.3, and 5.4 present the results of NAMA engagements in IBSA. In these individual case discussions, engagements along the policy cycle and the institutional factors that influenced these engagements are elaborated upon. The section draws on papers II-IV to provide answers to research question 2 and to the "how" part of research question 3. The second part of research question 3, i.e. why institutional factors have influenced IBSA's NAMA engagements, is addressed in section 6, which comparatively highlights the observed similarities and commonalities related to NAMA engagements in IBSA.

\subsection{Domestic Policy Responses to Climate Change in Emerging Economies}

Paper I provides an overview of national-level climate policy development from 2007 to 2012 in all UN member states. More specifically, the paper focuses on the national policies for mitigating climate change. Overall, the percentage of countries that have climate policies increased from $23 \%$ in 2007 to $39 \%$ in 2012 . While the corresponding percentage for countries with climate legislation only increased from $18 \%$ to $21 \%$ over the same period, there was a substantial increase in the proportion of countries with climate strategies, which increased from a meagre 5\% in 2007 to $18 \%$ in 2012 .

The data bring to the fore some important regional developments from 2007 to 2012; for example:

- Asia (34 countries): the absolute number of countries having climate policies increased from 3 to 20 ; percentage of the population covered increased from $43 \%$ to $97 \%$; and the cumulative GHG emissions covered (1970-2010) increased from $64 \%$ to $88 \%$

- Latin America (33 countries): the absolute number of countries having climate policies increased from 5 to 11 ; percentage of the population covered more than doubled from $34 \%$ to $76 \%$; and the cumulative GHG emissions covered increased from $25 \%$ to $76 \%$

- Middle East and Africa (66 countries): the absolute number of countries having climate policies increased from a very low base of 1 to 7 ; the percentage of the population covered increased from less than $1 \%$ to $17 \%$; and the cumulative GHG emissions covered increased from $5 \%$ to $16 \%$ 
Along the developed-developing country divide, in 2007 a total of 35 developed countries had climate policies, whereas only nine developing countries did. Of these nine developing countries, four were emerging economies (i.e. Argentina, China, Indonesia, and Mexico). By the end of 2012, the number of developed countries having climate policies increased marginally to 37 , whereas the corresponding number of developing countries jumped to 38 . Of the nine emerging economies identified as per my definition, eight now had some sort of climate policy in place. Of these, Brazil, China, Mexico, and South Korea choose to take a climate legislative approach. An equal number of emerging economies - i.e. Argentina, India, Indonesia, and South Africa - instead choose to develop climate strategy. It is safe to argue that both climate legislation and climate strategies continue to be seen as equally justifiable modes of addressing climate mitigation in emerging economies. More importantly, barring Saudi Arabia, all the emerging economies indicated their willingness to take domestic action to enhance mitigation.

By the end of 2007, there were no dedicated formal institutions in IBSA to address climate change. South Africa had its National Climate Change Response Strategy but no coordinating body in place. The Strategy was seen as "a discussion document, not a strategy"16 to address climate change. Brazil established its Interministerial Committee on Climate Change and its Executive Group on Climate Change in 2007 and also had an overarching organizational structure, the Interministerial Commission on Climate Change, as early as 1999 . However, its National Plan on Climate Change was only passed in 2009. In 2007, India did not have a dedicated climate policy in place. Within a few years all this changed. Now all three countries have established climate policies as well as organizational structures to oversee their implementation. The year 2007 is therefore an important one, as the formal institutions to deal with climate change had not yet concretised in IBSA. In light of this fact, the next two sections chart NAMA engagements in these three countries to understand their development.

It has been close to a decade since the Bali COP13 (in 2007), where negotiators, particularly those from the USA, China, and India, had an intense debate over the placement of a comma in the negotiating text (Biniaz, 2016; Bloomberg, 2009; Bodansky, 2007). The negotiating text under contention was the Bali Action Plan paragraph 1(b)(ii), i.e. the paragraph on NAMAs. The issue under contention was the MRV of both mitigation actions in developing countries and support to be provided by developed countries. This issue had been interpreted in different ways, depending on the applied perspective (Rajamani, 2009), resulting in both flexibility and frustration. This vagueness was interpreted differently by IBSA stakeholders as well, resulting in varied approaches to NAMA engagements.

\subsection{NAMA Engagements in India}

Although India was actively involved in NAMA negotiations, its domestic engagements with NAMAs have been limited - particularly until the beginning of 2015 - and still remain low profile. To begin with, India did not refer to NAMAs in its Copenhagen Pledge. The

\footnotetext{
${ }^{16} \mathrm{SA} 8$.
} 
mitigation space in India was already occupied by the Action Plan, which identified eight national missions. Three of these missions relate to mitigation, whereas the rest are primarily focused on adaptation, indicating adaptation to be the priority of the Indian government. In spite of limited avenues for NAMA development, the Indian Ministry of Climate Change, supported by GIZ, recently submitted two NAMAs to the NAMA Facility, in the forestry and waste sectors. The NAMA submitted in the forestry sector is entitled "Reducing forest degradation and deforestation in Assam through sustainable fuel management" whereas the waste NAMA is a waste to energy NAMA entitled "Core processing of refuse derived fuel from municipal solid waste for co-processing in cement industry" (Paper IV). ${ }^{17}$ They are referred to below as the Forestry NAMA and the Waste NAMA, respectively.

\subsubsection{NAMA Engagements along the Policy Cycle}

Setting aside the GIZ-supported initiatives, NAMAs did not gain traction at the agendasetting stage in India. To begin with, the Indian government considered only those voluntary mitigation projects as NAMAs that were "required to be supported and enabled by technology transfer, capacity building and financial transfers by developed countries" (Government of India, 2009, p. 18). Therefore, to be of any utility in India, any NAMA had to fit within this template. Submitting a NAMA proposal to the UNFCCC or to any other institution providing support to NAMAs, under the assumption of securing international support, seems to be a fair trade-off for national actions to be labelled NAMAs. However, lack of clarity on the support available for NAMAs and concern about potentially onerous MRV requirements made developed country commitments suspect in the eyes of Indian stakeholders. This lack of clarity and the deep-rooted suspicion about the motives of support providers were often cited as reasons to question the overall utility of NAMAs in the Indian context (Paper III). At the policy formulation stage, NAMAs also had to compete with the national missions identified in the Action Plan. While stakeholders stressed that there is no need to treat NAMAs as any different from the national missions, there is also a nuanced perspective that distinguishes NAMAs submitted for international support from the NAMAs that may be domestically supported by way of policy. The latter were, however, not labelled NAMAs because of the inability (or possibly unwillingness) of domestic actors to create links between NAMAs and existing domestic institutional arrangements provided by the national missions, further undermining NAMAs' relevance in the Indian context. Any remaining utility for NAMAs was perceived to have suffered collateral damage due to the emergence of INDCs at the policy formulation stage. Even before being considered for a decision: "NAMAs got killed because by the time NAMA rules were finalised, the discussion [of INDCs] had already started". ${ }^{18}$ As mentioned above, NAMAs, particularly up to the beginning of 2015, were unable to become embedded enough at the domestic level. The same reasoning, combined with significant concerns about the demands that would be exerted by providers of international support, haunted the fate of NAMAs at the decision-making stage. In particular, it was at the agenda-setting and decision-making stages that NAMAs faced stiff resistance. There was no reference to any NAMA during the implementation stage.

\footnotetext{
${ }^{17}$ IN 16.

${ }^{18}$ IN7.
} 
In this context, a NAMA feasibility study was commissioned in September, 2013 by GIZIndia. The Indian Ministry of Climate Change endorsed the study and decided what sectors would be its focus. The study remained rather low in profile and only began wider stakeholder consultation at the beginning of 2015. In March 2015, during my field visit, I had an opportunity to observe, the stakeholder consultations organized in Delhi, to discuss both the Forestry and Waste NAMA options. Explaining the choice of sectors, an interviewee reasoned that:

there is plenty of scope in these two, both in terms of the work to be done [...] and their implications on GHG emissions. [...] waste management had a number of CDM projects, in the forestry sector there were [...] very small numbers compared to the waste management sector, in that sense there was a difference, we could know what the difficulties in formulating a NAMA [were] in one sector where India is a major CDM player and one sector where there are very few CDM projects. ${ }^{19}$

While this interviewee approached NAMAs from the reference point of India's CDM experience, it is important to qualify that another interviewee observed, “don't think you can talk of NAMAs and CDM in the same breath. Resources for NAMAs are the public resources, whereas the carbon credit purchases were market resources. So, these two are completely different". ${ }^{20}$ This indicates friction in how international climate policy frameworks are approached within the country.

The stakeholder consultation exercises for both sectors presented traits of agenda-setting exercises in which broader stakeholders were engaged. Those directly involved in the study sounded cautiously optimistic about its potential, but were also aware of the slow pace at which things were moving on the ground. Reports based on the feasibility studies were submitted to the Ministry by June, 2015. While these reports are not yet in the public domain, they provided the Indian Ministry of Climate Change and other relevant line departments with potential NAMA options to choose from. However, it was only in July 2016 that a decision on the NAMA options from both sectors to be submitted to the NAMA Facility was made by the bilateral project steering committee under the chairmanship of then Additional Secretary R. R. Rashmi. Rashmi was recently shifted back to the Indian Ministry of Climate Change and was also one of the pivotal officials in launching the NAMA Feasibility study in the first place. ${ }^{21}$ Within a few months, NAMAs in each sector were developed and submitted to the NAMA Facility.

However, most of the stakeholders remain unaware of the process and specificities surrounding these two studies. The interviewees who responded to my email queries indicated their lack of knowledge by stating that they were "not tracking these NAMA processes at all", "not fully conversant with these developments", "completely unaware", and "surprised that

\footnotetext{
${ }^{19}$ IN3; the same reasoning was also cited publicly during the stakeholder consultations in March 2015 (source: personal notes).

${ }^{20} \mathrm{IN} 10$

${ }^{21}$ Interviews with IN5 and IN16.
} 
India has submitted a proposal to the NAMA-Facility". 22 This confirmed my observation that NAMAs were off the radar for most respondents and were not being attended to. Neither could any of them offer any explanations for this development. At the same time, some of the interviewees continued to be part of the NAMA development, but for some reason did not choose to respond to my query. I interpret this development in Indian climate policy cycle as NAMAs "coming in from the cold".

From a policy cycle perspective, while the initial efforts to develop NAMAs were blocked at the agenda-setting stage, the Forestry and Waste NAMAs have reached the decision-making stage. Although considerable time has been spent developing them, the importance of ensuring ownership amongst implementing agencies was paramount for the actors involved. As described below, this is best understood as an aspect of institutional capacity.

\subsubsection{Institutional Factors}

By establishing the Action Plan, India sought to address the normative pressure being exerted at the international level as well as the domestic development need, i.e. "maintaining a high growth rate" (Government of India, 2008, p. 2; See also Atteridge, Shrivastava, Pahuja, \& Upadhyay, 2012). Set up in 2008, the Action Plan laid the domestic framework for addressing climate change. It also included a range of initiatives aimed at climate change mitigation. Prominent amongst these was the Perform, Achieve and Trade scheme that spread a wide net to address climate change by covering eight industrial sectors. This was undertaken despite the common perception that climate change mitigation was not India's responsibility, and definitely not a political one. The objective of the Action Plan was also interpreted "to insulate ... the development processes from any pressures due to climate change". ${ }^{23}$ Climate change mitigation becomes relevant only because of its linkage to other pressing issues, such as energy access and energy security. Although the Action Plan managed to make climate change a mainstream concern, the rush with which it was drafted did not endear it to various government departments, hampering its overall implementation. By structuring the work along the existing institutional arrangements, it tried to address the challenge of climate change - a cross-cutting policy problem - along sectoral lines. In doing so, it failed to overcome the existing institutional silos in the government's organizational configuration. In the absence of an institutional mechanism, leadership eager to link NAMAs to national missions, and clarity on additional resources from international sources, NAMAs failed to appeal to the existing priorities of the government. At the same time, continuous emphasis on the mitigation aspects of NAMA in the international sphere did more harm than good to the prospects of taking up NAMAs in India. The arrival of the INDC mechanism further relegated them to the sidelines, whence very few actors were keen to take their ownership.

Normative aspects of responsibility distribution are particularly emphasised in India by the use of equity framing (Dubash, 2013; Jayaraman, Kanitkar, \& D'souza, 2011b; Narasimha, 2011). The centrality of equity framing can be gauged from the fact that it has been used to bolster India's reasoning along the line of per capita emissions, equitable access to sustainable

\footnotetext{
${ }^{22}$ Quotations from actual email responses.

${ }^{23}$ IN 13.
} 
development (Jayaraman, Kanitkar, \& D'souza, 2011a), and climate justice, also used in its INDC (Government of India, 2015). Indian stakeholders strongly believe that without meeting its support obligations, the global North has no moral right to ask developing countries to bear the burden of mitigation. Instead of other countries telling India what to do, the Indian culture of sustainability and its frugal consumption patterns are invoked to affirm that India is "best placed to tell the world how to live in a climate-friendly manner". ${ }^{24}$ This is also reflected in the fact that Indian consumers are consistently ranked as number one in sustainable consumption (National Geographic \& GlobeScan, 2014). At the same time, those arguing for "radical ecological democracy" see India's insistence to develop as being predatory to the poor in India (A. Shrivastava \& Kothari, 2012). In climate negotiations though, India's insistence on the right to keep developing has often been interpreted as the exercise of its right to pollute. The challenge India faced was to communicate its objectives better. This was because, despite its natural fit as well as usage in the Action Plan, co-benefit formulation was not being used in government's outreach to the international community. It was only through the efforts of non-state actors that co-benefits entered the government's lexicon. These nonstate actors accept that while development is a priority, it "will also give co-benefits on mitigation and adaptation". ${ }^{25}$ For GIZ also, treating "mitigation more [as] a co-benefit rather than interpreting it vice versa, is actually our first sort of criteria in this whole selection process", ${ }^{26}$ indicating that in GIZ, the Indian Ministry of Climate Change found a potential partner who appeared to be sensitive to India's normative imperatives.

Given its vastness and diversity, India's capacity to enforce policies remains inadequate. By adding climate change to the nomenclature of the Ministry of the Environment, the current dispensation signalled the priority given to addressing climate change. In addition, all the Indian states have State Action Plans on Climate Change in place. When it comes to mitigation, however, they have only a small role to play as mitigation is driven top-down by the Ministry of Climate Change. However, the Ministry of Climate Change is only a coordinating department and the State Action Plans are predominately about adaptation. The ability to allow for the horizontal and vertical integration of climate change with existing structures is therefore dependent on the priorities of other national-level governmental actors. National-level bodies such as the Prime Minister's Council on Climate Change and the Executive Committee on Climate Change provided a higher level of coordination, but at the implementation level, climate change seems to have been "added on to the regular duties to people and their line positions. [...] there is no additional capacity, people just see it as an additional aspect of their jobs. Sort of annoying I think". ${ }^{27}$ Up until COP15 in Copenhagen in 2009, India had an integrative force in the form of its Special Envoy on Climate Change, Shyam Saran, but since his departure the multiple layers of coordination have only added to the confusion regarding roles and responsibilities. In addition, it is reported that a NAMA

\footnotetext{
${ }^{24} \mathrm{IN} 11$.

${ }^{25} \mathrm{IN} 02$

${ }^{26}$ IN 16.

${ }^{27} \mathrm{IN} 13$.
} 
(sub-)committee was formed, but I could not find any information to confirm its conception or functioning.

Between 2013 and 2016, GIZ conducted groundwork for developing NAMAs in the forestry and waste sectors by hiring roping in consultants, carrying out stakeholder consultations, and identifying potential partners for implementing NAMAs (Paper IV). For the Waste NAMA, the buy-in of the Indian Ministry of Urban Development was secured, which alongside the Indian Ministry of Climate Change provided endorsement letters supporting the initiative. In addition to the four cities that volunteered for the NAMA, the Ministry of Urban Development also suggested including the city of Varanasi, the constituency of the Indian Prime Minister, in the NAMA, bringing in considerable political heft. For the Forestry NAMA, the Indian Ministry of Climate Change, citing existing resource flows to the state of Madhya Pradesh, decided to pick the second preferred state of Assam for NAMA implementation (Paper IV). Apart from accepting these decisions, GIZ also waited more than a year for the Indian government to make the final call on the fate of these potential NAMAs. A GIZ representative explained the rationale for waiting by emphasizing the importance of the Indian government taking ownership of the process:

The feasibility studies were already at a stage where you could say, well, they are basically done. We could take a decision now and move forward to the development of that particular NAMA action. But we did not do that because for us that working together with the partner, that ownership, that's the crucial part. And in retrospect I am very happy we also followed this process because if we had decided unilaterally which NAMA option we think is the best, and which NAMA option would suit India ideally, then we can be sure that we would not have received the endorsement to all the requests and the invitation and the endorsement to suggest and work together on the NAMA facility outline. ${ }^{28}$

By allocating separate resources to develop NAMA-specific institutional structures, GIZ invested in shoring up the institutional capacity as well as strengthening the coordination function to ensure NAMA development by involving a range of non-state actors - both Indian and German - in the process. At the same time, it left crucial decision making to the Indian Ministry of Climate Change and the NAMA bilateral project steering committee. This approach finally seemed to have developed links between the Waste NAMA and the corresponding National Mission on Sustainable Habitat, which identifies material recycling and urban waste management as one of its three initiatives, and between the Forestry NAMA and the National Mission for a Green India. ${ }^{29}$

In India, most of the actors perceive mitigation as the obligation of developed countries. It is acknowledged that development should provide mitigation as a co-benefit, but without assurance of international support, engagements with international climate policy frameworks were seen to be redundant and a norm of resisting international climate policy frameworks has gained credence. The national missions identified in the Action Plan were seen as the primary

\footnotetext{
${ }^{28}$ IN16

${ }^{29}$ Based on the interview with IN16.
} 
site for mitigation actions. Only after increased clarity on international support was made evident, did institutional arrangements to engage with NAMAs become active. The NAMA initiatives undertaken by the Ministry of the Environment in collaboration with GIZ-India are addressing the low institutional capacity by drawing on the capability of non-state actors and developing linkages primarily along the vertical axis, but also in Waste NAMA (along the horizontal axis).

\subsection{NAMA Engagements in Brazil}

In its response to the so-called Copenhagen Accord (see section 2.1), agreed to on the sidelines of COP15, the Brazilian government submitted its Copenhagen Pledge including 11 intended NAMAs that by 2020 were expected to reduce Brazil's projected emissions by 36.1$38.9 \%$. The aggregate reduction figure was adopted in the country's National Law (Law No. 12,187/2009) (Government of Brazil, 2009). In doing so, Brazil's Copenhagen Pledge and its constituent NAMAs formed the basis of the National Law. The 11 intended NAMAs were also identified by the interviewees as five national plans for mitigating climate change along sectoral lines. These are: combating deforestation in the Amazon; combating deforestation in the Cerrado; various interventions in the energy sector; promotion of sustainable charcoal for the iron and steel sector; and finally, the low-carbon agriculture plan. This last element, referred to as the $\mathrm{ABC}$ plan, comprises four NAMAs from the Copenhagen Pledge that promote sustainable agricultural practices along with other specific technologies. Understanding NAMA engagement in Brazil is therefore contingent on the study of these five national plans (papers III and IV).

\subsubsection{NAMA Engagements Along the Policy Cycle}

Labelling the Brazilian plans as NAMAs caused little resistance at the initial stages of the policy cycle, namely, during agenda setting, policy formulation, and decision making. The promptness with which the specific actions were labelled NAMAs in 2009 indicates that the stakeholders perceived the NAMA framing and domestic mitigation efforts to be aligned. Another important aspect is the fact that the domestic actions were labelled NAMAs by the end of 2009, when there was hardly any clarity on sources of international support. This development in Brazil is explained by the observation that its government "does not see NAMAs as action to get support. NAMA is our commitment to do something" ${ }^{30}$ NAMAs are not contingent on support, nor are they closed to the notion of receiving international support. As a developing country, the willingness of Brazil to acknowledge its domestic efforts as unsupported NAMAs is an important development. This is also reflected in its recently submitted INDC in which it stresses that "implementation of Brazil's INDC is not contingent upon international support, yet it welcomes support from developed countries with a view to generate global benefits" (Government of Brazil, 2015, p. 3), as well as in the nuanced shift in

\footnotetext{
${ }^{30}$ BR6.
} 
its informal institutions, which is discussed below. Unfortunately, consolidation of this position is also attributed to the perception that "the international support will never come". ${ }^{31}$

At the implementation stage, the differences in the status of NAMAs across the five plans starts to become visible. The Amazon NAMA has achieved widely acknowledged success in reducing deforestation. Stakeholders do not make much reference to the other four NAMAs, particularly regarding their performance. The success of the Amazon NAMA is attributed to three factors, namely, use of satellite data to identify deforestation in real time, ensuring effective and transparent monitoring; backing monitoring by strong law enforcement undertaken by the federal police; and, finally, denying bank credit to private properties that allow illegal deforestation. The effectiveness of these interventions broke a previously prevalent myth that controlling deforestation in Amazon was unfeasible. On a broader level, this also reflected the enhanced institutional capacity of the Brazilian Ministry of the Environment (Portuguese: Ministério do Meio Ambiente). The success in the Amazon NAMA has dramatically reduced Brazil's emissions but "without advancing in low-carbon development". ${ }^{32}$ This is also reflected in the fact that other NAMAs, primarily the Cerrado NAMA and the Energy NAMA, have not been successfully implemented yet. Overall, the current crisis of governance does not provide the political willingness and configuration to allow

for wise decisions [...] So, in many areas we actually are going backwards. Like the shares of renewable energy are going down. Deforestation stopped to drop. Over last five years, basically stable [...] not going anywhere. The creation of protected areas has simply stopped. ${ }^{33}$

By limiting the priority of the government to survival on a weekly basis, the ongoing crisis of governance may have already started to affect NAMA implementation on the ground (Tollefson, 2016). How the impeachment of Brazilian President Dilma Rousseff in mid 2016 will further affect the climate agenda remains to be seen. The short-term crisis has considerably limited the manoeuvring room available for the Brazilian government to address the long-term policy objectives of climate change.

Furthermore, with the arrival of the INDCs, NAMAs no longer seem to occupy centre stage in Brazilian climate policy. Most of the respondents are of the view that INDCs have replaced NAMAs. The conversation has shifted to INDCs to such an extent that one respondent argued that "I don't think we still need to use the language of NAMAs because INDCs have already, let's say, embraced what were the principles of NAMAs". ${ }^{34}$ This indicates continuity of policy but with the new label of INDC.

For Brazil, NAMAs proved useful at the agenda-setting stage and were catapulted to policy status by packaging existing and planned activities as NAMAs. NAMAs, as an international climate policy framework, provided the means for domestic efforts to gain legitimacy in the

\footnotetext{
${ }^{31}$ BR2.

32 BR4.

${ }^{33}$ BR6.

${ }^{34}$ BR3.
} 
eyes of the international community. As the new terminology of INDCs emerged, Brazil seems to have repackaged its mitigation efforts in the new mould, indicating its socialisation in the international community. At the same time, initiating INDCs without any international support is seen to communicate that Brazil is in " $100 \%$ control of the situation ... [as] part of the international diplomacy of Brazil [...] to make very clear that because of the perception of sovereignty that Brazil can do whatever it wants [...] because it does not depend on anyone". ${ }^{35}$ Given the current crisis of governance facing Brazil, these efforts to pursue mitigation actions by the previous Rousseff government represent an attempt to strike a delicate balance between achieving international recognition and using that recognition to shore up its domestic legitimacy.

\subsubsection{Institutional Factors}

The embrace of the NAMA policy framework in Brazil was preceded by the first phase (2004-2008) of the Action Plan for the Prevention and Control of Deforestation in the Legal Amazon. This subsequently became the NAMA for combating deforestation in Amazon, and article 6 of the Brazilian National Law includes it as one of its instruments (Government of Brazil, 2009). The Minister of Environment between 2003 and 2008, Marina Silva, prioritised efforts to bring down the deforestation rate. To do so, she invested in the institutional capacity of the Ministry of the Environment, which in turn seems to have led to improved implementation of the Amazon NAMA, as it comes directly under the Ministry of the Environment's ambit (Viola \& Franchini, 2014). Silva's tenure also coincided with an overall increase in environmental activism in Brazil. By leveraging support from NGOs and climate scientists and fusing it with the improved institutional capacity of Ministry of the Environment, Silva managed to bring climate change into the Ministry of the Environment's fold. In 2007, the Ministry of the Environment's Secretariat for Environmental Quality was transformed into a Secretariat for both Environmental Quality and Climate Change (Carvalho, 2012), giving the Ministry of the Environment considerable say in all things related to climate change, both domestically and internationally. By 2008, the Ministry of the Environment was also starting to take a greater role in the international climate negotiations, a development that challenged the hold of the Ministry of External Relations (Portuguese: Ministério das Relações Exteriores) on climate change in the UNFCCC negotiations. After Marina Silva, the new Minister of Environment, Carlos Minc, was able to continue this consolidation and overcame resistance from the Ministry of External Relations to announce Brazil's voluntary international commitments in November 2009 in its Copenhagen Pledge. This consolidation of NAMA development at a central level had some negative consequences as well. Since NAMA development is driven in a top-down manner, it leaves little space for innovation and experimentation outside the ambit of the national government. At the provincial level, for example, at least one initiative in the province of Mato Grasso on ecosystem services and environmental goods and services was claimed to be a NAMA by an interviewee. However, sub-national initiatives are not officially recognised as NAMAs by the Ministry of the Environment, which at best sees them as means to support national NAMA implementation.

\footnotetext{
${ }^{35} \mathrm{BR} 3$.
} 
Around the same time, informal institutions were starting to call for enhanced climate action. With her entry as the Green Party's Presidential candidate in August 2009, Silva introduced sustainable development as a development alternative for Brazilian voters. The Brazilian city of Rio de Janeiro was also elected host city for the 2016 Olympics in October 2009, a month referred to as "the best month for Brazil since about June 1494" (Rothkopf, 2009). ${ }^{36}$ The country was high in confidence. In conjunction with the steep decline in the Amazon's deforestation rate, the country felt confident about taking greater responsibility in the international arena. This is reflected in a tilt towards Brazil's willingness to consider making an international commitment on climate change. These factors culminated in Brazil announcing its actions as NAMAs:

an important step forward, because before that, the developing countries did not have any kind of target reduction, because they were very much in the Kyoto paradigm [...]. Some years after Kyoto in 1997 this proved to be completely absurd, because today, most of the emissions are coming from developing countries. We have to deal with this problem, we cannot be like the Ostrich [...] so we have to commit. But what happened before 2009? Brazil had the same position, let's say, that India has today: "Oh, we are a developing country, we are a poor country, we cannot reduce our emissions". Then we started this movement in Brazil, some big demonstrations just before the Copenhagen conference. Two or three months before, we did this big demonstration in Rio with thousands of people, and then there was the candidacy for president of Senator Marina Silva and there were lots of pressures. So, government for the first time, during the Copenhagen conference, curbed to civil society pressure. ${ }^{37}$

Around the Copenhagen conference, it was felt that "the differentiation of the world in just two group just doesn't make sense anymore. $" 38$ This position also seems to have influenced the President's approach towards international support. In meetings with President Lula, it is reported that the President wanted to know the cost associated with meeting the targets and how much of that could Brazil achieve by itself. Two reasons are cited for why Brazil decided to not link its actions to international support. First,

[President Lula] said that it's very unlikely that this support will happen. [...] The second reason, which I think it's strong in this government is [...] it's so difficult $[\ldots]$ do the first part and then what is the second part, then you will say like, you spend most of your time afterward, if you want to receive any support to actually demonstrate that this support is actually for implementing something that is plus something that you are actually proposing. It's a nightmare. ${ }^{39}$

In other words, this interviewee recognised an acknowledgement at the presidential level that the world has changed since the adoption of the UNFCCC and that satisfying all the requirements for international support is tedious, because it is very difficult to distinguish actions taken with international support from actions already taken without international

\footnotetext{
${ }^{36}$ When Portugal and Spain settled an agreement on how to divide, from their perspective the newly discovered land of South America.

${ }^{37}$ BR1.

${ }^{38}$ BR6.

${ }^{39}$ BR6.
} 
support. As a consequence, Brazil emphasised that its INDC implementation was not contingent upon international support, although it was not averse to receiving such support. This was not perceived as a big shift, though, as the principles and provisions of the UNFCCC and the obligations of developed countries to meet their financial commitment continue to remain important for Brazil. This stance, along with the enhanced institutional capacity of the Ministry of the Environment, set the backdrop against which the National Law could be drafted to internalise the actions communicated to the UNFCCC.

Because NAMAs constitute its National Law, there is a strong alignment between Brazil's internationally pledged NAMAs and its national climate policy, to the extent that it is difficult to see any difference between them. As one interviewee noted, "the Brazilian NAMA was the climate change law". ${ }^{40}$ As the NAMAs were based on leveraging existing institutional arrangements, they perpetuated the trend that was evident before NAMAs were announced the Amazon NAMA continued showcasing better results than the other NAMAs - until the overall crisis of governance started to affect the policy making. At the same time, there was a strong perception amongst the interviewees that INDCs have not only continued and improved on NAMAs but that they have replaced them. While the government representatives did not echo this perception, they did see NAMAs as having provided a good learning process.

The increased institutional capacity of the Ministry of the Environment in Brazil was instrumental in controlling the deforestation in Amazon forest. This also increased the Ministry's say in international climate negotiations, particularly in 2009 and 2010 (Viola \& Franchini, 2014). During the same time, the Brazilian public was highly concerned about climate change. This lead to a slow shift in norms related to responsibility distribution, such that it became increasingly acceptable to argue that Brazil and other emerging economies should take on mitigation actions, without necessarily linking them to the availability of international support (Government of Brazil, 2014b). Increased institutional capacity and favourable norms coincided with the creation of National Law, providing an opportunity to align NAMAs with Brazil's formal institutions. However, the role of NAMAs in Brazil - and to an extent of INDCs as well - seems to be limited to the repackaging of existing initiatives for consumption by an international audience and in turn using these international climate policy frameworks to shore up its domestic credentials.

\subsection{NAMA Engagements in South Africa}

Efforts to develop NAMAs in South Africa have been undertaken by both state and non-state actors. I study three such NAMA initiatives: the Sustainable Settlement Facility (SSF), intended to facilitate the South African government's constitutional mandate to provide housing to all; the South African Renewable Initiative (SARi), designed to support the introduction of renewable energy into the country's energy mix; and the V-NAMA, being developed to promote energy efficiency in public-sector buildings (papers II-IV). The SSF

\footnotetext{
${ }^{40} \mathrm{BR} 4$
} 
and the V-NAMA have been submitted to the NAMA Facility but have met different fates. Another NAMA that was submitted to the NAMA Facility and has now been withdrawn - the Private-Sector Energy Efficiency Project, coordinated by the National Business Initiative and Carbon Trust - is not part of the analysis as it was neither recognised as a NAMA in official documents nor referred to as a NAMA by the interviewees in 2014.

\subsubsection{NAMA Engagements Along the Policy Cycle}

SSF and the SARi took somewhat similar trajectories: high receptivity to the concept of NAMAs at the agenda-setting and policy formulation stages, followed by challenges or a lack of cooperation amongst governmental actors that hampered their development at the decisionmaking and implementation stages. SSF, pursued by non-state actors, was in line with the South African constitutional obligation to provide accommodation to all. It is also mentioned in South Africa's climate policy under the energy-efficiency flagship programme and was therefore perceived to be nationally appropriate. Although supported by the Department of Environmental Affairs, it failed to bring the implementing line department (i.e. the Department of Human Settlements) on board and could not secure funding from the NAMA Facility to support its implementation. In parallel, the COP17 at Durban provided an important focal point for the country's various climate initiatives, which were being developed to showcase instances of tangible success in South Africa's climate policy (Morris \& Martin, 2015; Tyler \& Gunfaus, 2015). Taking advantage of this opportunity, SARi was launched during COP17 in the presence of South African ministers from the Department of Energy and the Department of Trade and Industry, and their European partners (Republic of South Africa, 2011b). Beyond signing, however, SARi did not lead to actual results on the ground. Its status is questioned on the grounds that:

it didn't really get formulated into even a policy document, as far as I understand. And I mean, we in South Africa have a great difficulty moving from well-drafted policy to implementation of policy and SARi didn't even make it to policy. ${ }^{41}$

This was despite the fact that it had secured international support and was committed to at an international forum. SARi has, however, fed into another policy initiative, namely, the Renewable Energy Independent Power Producers Procurement Programme, which has been successful in bringing renewable energy into the country's energy system (Boyd et al., 2014, p. 7). This indicates that the evaluation of SARi has provided lessons for new and successful interventions.

Unlike SSF and SARi, the V-NAMA initiative continues to make steady progress through the policy cycle (papers III and IV). South African V-NAMA is developed as part of GIZ's pilot programme in Indonesia and South Africa. V-NAMA involves three South African government departments at the national level: the Department of Environmental Affairs, the Department of Energy, and the Department of Public Works. In addition, it also includes subnational departments. It was first submitted to the NAMA Facility in July 2014 and reached the appraisal stage in 2016 in its third attempt. It is expected to begin implementation in 2017.

\footnotetext{
${ }^{41}$ SA17.
} 
So far, V-NAMA has involved various government departments at the agenda-setting, policy formulation, and decision-making stages (Paper III). Furthermore, in order to leverage commonalities with the Private Sector Energy Efficiency NAMA, the V-NAMA team also

communicated with the National Business Initiative on which of the concepts were stronger and if there was perhaps a better way to go about it than competing against one another. ${ }^{42}$

As a result, the National Business Initiative team got involved with the V-NAMA team to strengthen the proposal. Both the National Business Initiative (a voluntary coalition of South African and multinational companies) and the Carbon Trust (a British organization providing advice on low-carbon strategies) are expected to be part of the proposal, possibly as implementing agencies. The government also intends to submit the private building initiative to the Green Climate Fund. The Department of Energy officially leads the V-NAMA, but the Department of Environmental Affairs provides coordination. Against this backdrop, it is hoped that NAMAs could help ensure alignment and coordination amongst departments. The three NAMAs have been studied to understand their utility in aligning climate policy with other policy objectives and in facilitating coordination across departments.

\subsubsection{Institutional Factors}

South Africa generally has high human capacity at the conceptual level, which helps it to develop strong policies. By 2011, the country had its national climate policy in place. However, implementation remains weak on the ground. With respect to NAMAs, at the formal institutional level, stakeholders perceive NAMAs and flagship programmes as interchangeable: "when I talk about flagship [programmes], implicitly I am talking about NAMAs". ${ }^{43}$ While there was considerable interest in labelling flagship programmes as NAMAs within the Department of Environmental Affairs, other stakeholders not only perceived NAMAs as marginal to the debate but also the Department of Environmental Affairs itself as a marginal department. With respect to the norm underpinning framings of responsibility distribution, NAMAs are seen as a means to secure support as well as international recognition for contributions to addressing climate change, which is mainly perceived as the responsibility of the global North. Labelling domestic actions NAMAs is seen to be contingent on the availability of international support (Paper II and IV). In its Copenhagen pledge, South Africa also emphasised the conditionality aspect by stressing that "the extent to which this action will be implemented depends on the provision of financial resources, the transfer of technology and capacity building support by developed countries" (Republic of South Africa, 2010). The fact that no South African NAMAs are unilateral in nature, i.e. without provision for international support, underlines their importance in the South African context. At the same time, norms such as historical responsibility, or common but differentiated responsibility were not invoked by interviewees to buttress the argument for international support.

\footnotetext{
${ }^{42}$ SA21.

${ }^{43}$ SA 10.
} 
Based on the experiences with SSF and SARi, the non-availability of support only partially presents the NAMA story (Paper II). SARi had secured international support before it was fully conceptualised and SSF could have received international support provided a relevant line department was on board. While both SSF and SARi could be approached as new coalitions of ideas and interests, they were not labelled NAMAs because they faced resistance from existing coalitions of ideas and interests. SSF was not supported by the NAMA Facility due to lack of ownership by the relevant line department, whereas SARi was initiated by two ministries that were not mandated to lead renewable energy policy. In both instances, institutional overreach is evident, indicating lack of coordination and absence of "overarching governance bodies that can 'reach in' and coordinate action" (Chandrashekeran et al., 2014, p. 27; Worthington, 2014), despite recognition of such coordinating bodies within the White Paper. V-NAMA, on the other hand, seems more pragmatic in responding to donor requirements. It seems to have internalised the lessons learned from the failures of both SSF and SARi. Although the formal and informal institutional contexts of the three NAMAs are largely the same, what distinguishes V-NAMA is how the institutional capacity aspect slowly shifted in favour of using NAMA terminology. Juxtaposing the views of certain respondents is especially telling in this regard. In 2014, towards the end of my field visit, a respondent commenting on the hindrances to presenting South African actions as NAMAs said:

You require two or three government departments to package a piece of work into programmes or projects that will be whether invested on as a NAMA. Is that, is there capacity at Environmental Affairs to have people who can put together bankable projects as well as secure fiscal support from two or three departments? [...] So, it's difficult, for example, the Department of Environmental Affairs may like a solar water heater thing but the Department does not have the competency and the mandate to do the actual work, all right. [...] So, if you are to implement it, that means that the Department of Environmental Affairs in partnership with the implementing ministries must have budget lines that talk to the same project so that they can contribute their various components and the Department of Environmental Affairs can play its role in interfacing with the international support, because the Department is a focal point for UNFCCC. ${ }^{44}$

During the same week, in another interview with a respondent from the Department of Environmental Affairs, I had already been told that managing flagship programmes was a challenge:

There's definitely capacity issues. It's a vast, it's just an enormous amount of work to be able to put in place. The institutional mechanisms and link those with the hubs and nodes together to get something flowing from one into other, it's an enormous amount of work and capacity is definitely a challenge. ${ }^{45}$

In 2016, when I again asked the same official about the capacity aspect, the response was quite different:

\footnotetext{
44 SA 18.

${ }^{45}$ SA 16.
} 
Yes, increasingly we subsequently got some support from GIZ, to bring on board three people [...] and specifically in the coordination function and dealing directly with the lead sectors who are implementing the programmes and to deal with components of each of the flagship programmes and also ... to make sure we are able to assist programme developers where they need help. ${ }^{46}$

This indicates that the Department's capacity had increased over the two elapsed years. The V-NAMA initiative benefitted from this increased institutional capacity. It gave the Department of Environmental Affairs space to allocate personnel for the coordination function. To facilitate coordination, first, an inter-departmental steering committee was set up to track flagship programmes' implementation and, second, the level of support and assistance that the Department of Environmental Affairs could provide to the flagship programmes was increased. In the V-NAMA initiative, the steering committee provides strategic input and a specific task team dedicated to actively steering the V-NAMA on a daily basis and coordinating efforts between the three departments at the operational level. While all three departments had been involved in the initiative since 2012, once the capacity of the Department of Environmental Affairs increased, and personnel were dedicated to the flagship programmes, the results - in terms of improved coordination - started to show. One major beneficiary of this initiative has been the relationship between Department of Energy and Department of Environmental Affairs. Both departments traditionally found it difficult to coordinate their policy positions (Masters, 2013), but in preparing the V-NAMA, their relationship seems to be becoming

more harmonious [...] because everybody understands that the focus has got benefits for everybody, both energy and environmental affairs. Nobody's leadership is being undermined. ${ }^{47}$

Initial NAMA developments in South Africa were hampered due to a lack of coordination and oversight that precipitated overreach by government departments. The limited capacity of the Department of Environmental Affairs also constricted its ability to draw linkages between individual NAMAs and flagship programmes defined in the White Paper. Its international commitments were also made conditional on the availability of international support, further making it difficult to use the NAMA terminology without any assurance of international support. This only changed after the Department of Environmental Affairs - with support from GIZ-South Africa - enhanced its capacity to provide coordination and support to implementation of the flagship programmes. It established new institutional arrangements, in the form of; a steering committee to coordinate overall flagship programmes and a V-NAMA specific task team comprising representatives from relevant line departments. Thus, it was able to support both vertical and horizontal integration efforts, by investing in its coordination and institutional functions. The process was definitely demanding and required a more handson approach to coordination, but it seems to be providing results not only in terms of consolidating V-NAMA and enhancing institutional capacity, but also in terms of enhanced trust and understanding amongst departments.

\footnotetext{
${ }^{46}$ SA21.

${ }^{47} \mathrm{SA} 21$.
} 


\section{DISCUSSION}

Based on my findings, this chapter will summarise IBSA's NAMA engagements using a comparative approach. This chapter compares NAMA engagements in IBSA to identify and account for the variations in institutional approaches that have been made visible in chapter 5 . In doing so, the section 6.1 will tease out the variations and similarities visible in these engagements. In doing so, it speaks to the first part of the overarching objective (Section 1.1), how domestic institutional responses to climate change mitigation in emerging economies get influenced by international climate policy frameworks. Drawing further on these variations and similarities, section 6.2 will draw inferences that will be of relevance for broader climate governance literature and address the second part of the objective; how the domestic institutions determine the utility of these international climate policy frameworks.

\subsection{Comparing NAMAs in IBSA}

NAMA engagement and development in IBSA have progressed at different paces and in different directions. This thesis has identified instances where IBSA's NAMA engagement varies internationally and more importantly, domestically. Beginning with the submission of their Copenhagen pledges, IBSA's domestic approaches to NAMA have differed. In their Copenhagen pledges, India did not refer to NAMAs, Brazil not only referred to NAMAs in its submissions but also provided specific details on them, and South Africa referred to a NAMA in the singular only. By the end of 2015, although all three countries had submitted INDCs without referring to NAMAs, they maintained differences in their domestic engagement with NAMAs. Some of these differences are discussed below. Although actively engaged in the past, NAMAs in Brazil have given way to NDCs, South Africa continues to engage with NAMAs through some specific initiatives, whereas in India, after initially being sidelined, NAMAs are witnessing a surprising return to the policy cycle. Based on these engagements, this section details out how the domestic institutional responses in IBSA have been influenced by the international climate policy framework of NAMAs.

\subsubsection{Nature of Emerging NAMAs}

At the beginning of this thesis, I highlighted the implications of taking different interpretations of NAMAs as the starting point for studying NAMA engagements in IBSA. Within a given country context, the national government, as represented by its environment department, has the biggest say in influencing what could qualify for a NAMA. This is often provided for by the national climate policy. For example, while referring to the experience of NAMA development in South Africa, one of the interviewees emphasised that:

NAMAs cannot really exist without the flagship programmes because the flagship [programmes] represent the priority areas and NAMAs are typically 
the sub-component - that is more manageable. So, there should be a limited number of implementing partners. ${ }^{48}$

This interaction highlights two important points. First, NAMAs are defined within the ambit of the country's climate policy. For South Africa, this implies that NAMAs have to find avenues to support its flagship programmes (Paper I). Similarly, for India, this implies supporting the national missions and, for Brazil, supporting the overall target through the plans that the country has set for itself. While Brazil decided not to make any distinction between NAMAs and its domestic mitigation actions, by not using NAMA terminology in government documents, India and South Africa have maintained a distinction between the two. At the same time, actors do see similarities between the two. This is reflected in the second point, as made visible by the assertion in the Indian context, "it will be incorrect to view NAMAs separately from what is happening in the [national] missions" ${ }^{49}$ As discussed above, the nature of NAMAs will be heavily influenced by the nation's climate policy, but more crucially, unlike CDM projects which were predominately driven by market resources and in which the national governments played largely passive roles, NAMAs will be driven by national governments and involve public resources. It is tempting to refer to NAMAs as government CDM but on a conceptual level, there are fundamental differences between the two, particularly regarding how they are supported. ${ }^{50}$ But since the national government will play a more active role in implementing NAMAs, the institutional capacity and ability to ensure coordination amongst various government departments becomes crucial. Third, a NAMA should have a manageable number of ministries involved in the form of implementing partners. Beyond a point, it becomes practically difficult to bring different ministries on board. In words of a non-state actor it is akin to a miracle "to get right decision makers' diaries to align for [a] meeting, maybe the stars will align twice a year."

Another important aspect that seems to be common across NAMAs is that they are based in sectors that are dispersed in nature. The Forestry NAMA and Waste NAMA in India, SSF and V-NAMA in South Africa, and most NAMAs mentioned in Brazil's Copenhagen pledges involve nonpoint - i.e. spread over a large geographic area - sources of GHG emissions or energy consumption. Even SARi would have been spread over a large geographic area but, unlike other NAMAs explored in detail here, it aims to reduce supply-side emissions. In emerging economies, NAMAs seem to be witnessing greater state involvement, at a sectoral level, particularly in demand-side management.

\subsubsection{NAMA Development Along the Policy Cycle}

Understanding NAMA development using the policy cycle as a heuristic device helps us disentangle the policy process (Paper III), such that it is possible to identify the key institutions, contexts, and actors at play in different stages of the policy cycle (Howlett et al., 2009; Jordan \& Adelle, 2013). Amongst these three aspects, I chose to further focus on

\footnotetext{
${ }^{48} \mathrm{SA} 21$.

49 IN3.

${ }^{50}$ Ibid. 20.

${ }^{51}$ SA04.
} 
institutions because of the importance attributed to institutional aspects in the NAMA literature (Section 3.3, also see Paper IV).

The policy cycle helps us understand how agendas come to be influenced. In India, mitigating climate change is seen as the primary responsibility of developed countries, whereas Brazilian actors perceive that all countries need to take mitigation. This difference in approach towards climate change, clubbed with two important events in 2009-10, the Copenhagen climate conference and presidential elections, provided an avenue to strike bargains in Brazil, making it easier to use NAMA terminology. In Brazil, this provided an opportunity to align its NAMAs and mitigation actions. The national climate policies in India and South Africa have set the template for their NAMA engagements, making the availability of commensurate support an important precondition for using the NAMA terminology. NAMA engagements in India and South Africa also confirm that it is misguided to approach the policy cycle as a single iterative loop. Instead, as NAMA development indicates, it comprises multiple smaller loops (Howlett et al., 2009, p. 13) that go back and forth across stages, even at the same level of governance, before the defined agenda gets anywhere closer to getting implemented. For example, in India, the decision to undertake NAMA in forestry and waste sector was followed by formulation of policy options in the sector, which then led to the decision to submit these potential NAMAs to NAMA Facility. The decision defined the sectors where (agenda-setting, Paper III) the action shall be taken. In South Africa, the rejection of SSF provided an important lesson to the Department of Environmental Affairs, namely, that to improve the chances of a NAMA getting support, relevant line departments need to be involved from the outset. This subsequently has led to much closer collaboration in the development of VNAMA initiative. This lesson seemed to be missing in India where, although the Ministry of Urban Development did come on board the Waste sector NAMA, it was not clear "until the last minute [... whether or not to] bring the two ministries [Ministry of Climate Change and Ministry of Urban Development] together". ${ }^{2}$

An important stage in the NAMA policy cycle has been the decision-making stage, which can be demanding in terms of time but is also an important juncture in ensuring ownership. In Brazil, the government committed to actions simultaneously at the domestic and international levels, increasing the stakes to ensure positive outcomes for its NAMAs; whereas for South Africa ownership suffered as various actors rushed to access international sources of support without taking relevant line departments on board (Chandrashekeran et al., 2014; Held et al., 2013a). It is also possible that these failures were evaluated and accounted for in V-NAMA development, indicating that one policy cycle can feed into another, but also that the policy cycle can be halted due to external factors such as unavailability of international support. Paradoxically, studying NAMA engagements confirms that translating a policy into implementation does not always follow a neat model of successive stages. A policy can be evaluated without being implemented, as was the case with SSF. In India, the non-decision regarding NAMAs role in supporting domestic policy was witnessed for a long time, which affirms that the decision-making travels back and forth. The next step of analysing NAMA

\footnotetext{
52 IN16.
} 
development could be to apply specific theories to delve deeper into the specific aspects of the policy cycle (Weible, 2014).

\subsubsection{Role of Support Expectations and Norms}

For both India and South Africa, international support remains a prerequisite for using NAMA terminology to refer to their domestic mitigation efforts. Before making a decisive move on NAMAs, India waited for the future international climate governance architecture to emerge. At the UNFCCC level, it indicates that when it comes to striking an agreement on and ensuring adherence to norms related to responsibility distribution, India perceived the international climate governance architecture's institutional capacity to be suspect. In the meantime, some South African actors attempted to secure international support and recognition for proposed domestic actions by means of NAMAs. On the other hand, Brazil was explicit that its actions were not dependent on the availability of international support. Although its actions solely relied on domestic capacity, it continued to welcome support from developed countries under the provisions of the UNFCCC (Government of Brazil, 2010).

The difference in processing the possibility of getting support is influenced by the domestic norms prevalent in each country context. By 2009, Brazil had started to accept that not all developing countries could lay claim to international support. This is also reflected in its recent submission to the UNFCCC negotiating process in which it has proposed a "concentric circles" approach wherein, barring least-developed countries, all countries are expected to make some sort of quantified, economy-wide emission limitation or reduction targets (Government of Brazil, 2014b). This makes its actions not contingent on international support.

India continues to take mitigation action domestically but is only open to international scrutiny if international support is commensurate with its mitigation actions. At the national average, consumption patterns in India are consistently reported to be the most environmentally sustainable amongst the 18 countries surveyed. ${ }^{53}$ At the same time, it continues to maintain a high rate of growth. The contradiction between having a high rate of growth and sustainable consumption patterns gets balanced out due to its "tradition of sustainability, in terms of traditional practices, [...] cultural practices like [...] recycling everything that can be recycled, frugality in terms of consumption. " 54 Norms of sustainable consumption are emphasised regularly. Furthermore, unlike Brazil, India still needs to make electricity accessible to a large proportion of its population (Table 2), making poverty reduction and energy security its major priorities. This is reflected in the development agenda that forms the broader context of its INDC (Government of India, 2015). Meeting the needs of its domestic constituency continues to be the benchmark against which India measures its responsibility to act on global climate change (Atteridge et al., 2012). The principle of common but differentiated responsibilities underscoring the responsibility of the global North to take the lead in addressing climate change remains central to India.

\footnotetext{
${ }^{53}$ The Greendex survey, referred to earlier in the thesis, ranks Indian consumers as the top-scoring consumers. Brazilian consumers are ranked fourth and South African consumers ninth. All ranks from 10 to 18 are taken by developed country consumers (National Geographic \& GlobeScan, 2014).

${ }^{54}$ IN 10 .
} 
South Africa, on account of its relatively recent incorporation into international society, has the ambition to affirm its commitment to international society and the transnational norms it shares (Death, 2011). As a result, a section of South African society wants to contribute to global efforts to address climate change. However, due to its persistent domestic challenges of poverty, inequality, and unemployment (Republic of South Africa, 2012), these contributions are set within a developmental framework. While there is an acknowledgement that these three challenges could not be addressed without "breaking the links between economic activity, environmental degradation and carbon-intensive energy consumption" (The Presidency, 2014, p. 124), there is little explicit reference to norms catering to responsibility distribution by the interviewees, making it difficult to assess if the country's norms are decisively pointing towards any particular direction.

\subsubsection{Role of Actors}

Actors' roles have also varied between IBSA's NAMA engagements. While government actors have the most prominent role in all three countries, Brazilian and Indian NAMA engagements are particularly state driven with a very limited role for non-state actors. With the initiation of the Forestry and Waste NAMAs in India, non-state actors are being involved in the process during the policy formulation stage. ${ }^{55}$ In South Africa, non-state actors, in general, have been actively engaged in NAMA development.

While non-state actors formulated the SSF NAMA in South Africa, its fate was decided by the inability (or unwillingness) of the relevant government department to commit to its implementation. In the V-NAMA case, the Department of Environmental Affairs was able to influence the National Business Initiative and the Carbon Trust to let go of their NAMA so as to reduce competition for the V-NAMA. Similarly, the Ministry of Climate Change in India selected the forestry and waste sectors to develop NAMAs. Within the ambit of these sectors, the non-state actors were tasked with presenting various options for the Ministry to choose from. The NAMAs in both sectors were submitted to the NAMA Facility only once the decision was made by a senior bureaucrat involved in the process. In Brazil, the Mato Grasso initiative was not acknowledged as a NAMA by the Brazilian Ministry of the Environment representative. All these examples highlight an important aspect - the limited and state defined role of non-state actors in the NAMA processes, particularly at the agenda-setting stage. The national governments, represented by their Ministry of the Environment and relevant line ministries determine the ambit of non-state actors' role in NAMA development. National climate policy will determine the nature of NAMAs and because the government will decide on the sectors in which NAMAs should be utilised, the ability of non-state actors to influence the policy process may be limited to the policy formulation and implementation stages of the policy cycle. In the former, non-state actors can provide options from which the government can select NAMAs, and in the latter, they may or may not be part of implementing and even evaluating NAMAs. This is contrary to normally understood policy cycle model, that indicates that agenda-setting (where to take action) tends to involve a large number of actors (Howlett et al., 2009). Instead, at least in India, it seems to follow an

\footnotetext{
55 IN01.
} 
hourglass model, with more actors being involved during the policy formulation and implementation stages. It is still too early to comment on the evaluation stage. However, the global stocktake exercise can provide opportunities for the non-state actors to influence the agenda on regular basis.

At the same time, individual actors embedded in institutional structures will still have avenues to influence NAMA development. The role of the then additional secretary in influencing the fate of the NAMAs in India has already been highlighted. In South Africa, individuals behind the SSF and SARi initiatives were unable to make headway because there was no institutional structure in place to connect with. Ministers Silva and Minc were crucial to increase institutional capacity and thus influence NAMA engagements in Brazil. Therefore, individual actors can influence NAMA engagements provided they are operating within the institutional structures made available by national climate policy. This then keeps an avenue open for nonstate actors to influence NAMA development, by influencing the key decision makers.

\subsubsection{Institutional Experiments and Innovations}

While Brazil referred to its domestic mitigation actions as NAMAs in its Copenhagen submissions, South Africa referred to its broader target as a NAMA, and India did not refer to its actions and goal as a NAMA. Instead, in developing NAMAs from scratch, both India and South Africa are trying new models of institutional experimentation (Jordan et al., 2015; Jordan \& Huitema, 2014a) that can be important in three respects. First, these experimentations are attempts to develop linkages between the international NAMA terminology and the domestic terminology prevalent in each country contexts. Second, they are bringing together different national government departments in pursuit of overlapping objectives. This new layer of connection seems to be overcoming the institutional silos to which national climate policies had become tied to (Dubash \& Joseph, 2015; Worthington, 2014). Third, and most importantly, these initiatives are providing new and innovative models of climate governance that not only link government departments horizontally and vertically, but also simultaneously link them across to non-state actors.

Government entities in developing countries are generally trapped in institutional silos. While experiments take time, they can have far-reaching benefits. One such benefit is already being acknowledged in South Africa, where the Department of Environmental Affairs and Department of Energy have started to develop mutual trust and understanding. In Brazil, where existing institutional arrangements were already well established, NAMAs have been unable to contribute to institutional experiments. The Amazon NAMA, which was already highly successful, falls within the direct ambit of the Ministry of the Environment. Other NAMAs have not matched its level of success. Could it be that by simply accepting the NAMA label, Brazil has missed out on an opportunity to experiment with new institutional models that provide incentives to overcome existing institutional silos? Or maybe Brazil had already developed these institutional arrangements, as evidenced by its Brazilian Forum on Climate Change which acts as a bridge between the government and society. But based on the Indian and South African experiences, it could be argued that these experiments are important as they try to find ways around the strong framework established by their respective formal 
institutions in addressing cross-sectoral challenges. This could facilitate a culture of innovation that draws on the core competencies of different stakeholders.

\subsection{NAMAs and Climate Governance}

NAMAs are important from climate governance perspective because they marked an important point in the role of developing countries with respect to mitigation. They represented a delicate balance between encouraging developing countries to undertake mitigation and making provisions for supporting their efforts. Understanding how they have panned out in different country contexts can provide important lessons for the broader climate governance literature. This section expands on the influence of domestic institutions on the utility of NAMA as an international climate policy framework and responds to the second part of the overarching objective.

\subsubsection{Emergence of National Climate Policy}

Most of the emerging economies, including those of IBSA, currently have climate policies in place (Nachmany et al., 2015). Provisions for undertaking mitigation actions are built into each of these climate policy documents, albeit to varying degrees. However, these climate policies emerged at different times (Paper I) and followed very different stakeholder processes. As is evident from the deeper analysis of NAMA engagements in IBSA, national climate policy plays an important role in influencing its utility as an international climate policy framework (Paper II-IV).

Of the IBSA countries, India was the first off the block and launched its Action Plan in 2008. The Action Plan provided an institutional framework coordinated by the Indian Ministry of Climate Change and constituted eight national missions to be implemented by various line departments. When submissions were made to the UNFCCC after COP15, India drew linkages with the Action Plan by emphasising the voluntary nature of the domestic actions and the provisions related to providing support for mitigation in developing countries, as defined under the Convention. For NAMAs to be of use to Indian policymakers, it had to serve the objectives as defined by the Action Plan. However, due to its limited capacity (Dubash \& Joseph, 2015), the Indian Ministry of Climate Change could not develop linkages between NAMAs and various missions, and as a result, NAMAs were relegated to the sidelines. Climate policy development in Brazil coincided with preparations for COP15 and benefitted from the heightened environmental awareness at the time. The NAMAs communicated to the UNFCCC in Brazil's submissions were seamlessly integrated with its ongoing process to develop national climate policy. Once the President promulgated the climate policy into National Law, the NAMAs gained legal status and became part of the domestic policy lexicon. However, with the coming of INDCs, it seemed that NAMAs would not be of any use in either of these countries. While this perception is strong in Brazil, linkages between NAMAs and climate policy are now being made in India.

In contrast, the South African climate policy process was much more consultative and deliberative in nature. While South Africa established the centrality of international support for undertaking NAMAs in its Copenhagen submission, its climate policy did not refer to NAMAs. Although seven of its eight flagship programmes were relevant from a mitigation 
perspective, as in Indian case, no linkage was made between flagships programmes and NAMAs, creating confusion amongst South African actors about NAMAs' utility. This brought the South African NAMAs to a terrain similar to that of their Indian counterparts, which also lacked clear direction on establishing linkages between NAMAs and their national missions. This situation has only now started to show signs of a reversal in both the countries, possibly attributable to increased institutional capacity of Department of Environmental Affairs in South Africa and increased involvement of non-state actors during policy formulation stage - and possibly during implementation in future - of the NAMA policy process in India.

As it becomes evident from the analysis, the emergence of national policy can both facilitate as well as hamper the creation of links between domestic mitigation actions and international climate policy frameworks. Climate policy in itself does not guarantee the synchronisation of ongoing mitigation efforts with international climate policy frameworks. It needs, support from norms favouring engagements with such international frameworks, and investment to increase institutional capacity - either directly or indirectly (Paper IV).

\subsubsection{Varied Responses to Transnational Norms}

Acharya (2004) identifies three local responses to transnational norms: resistance, norm localization, and norm displacement. NAMA engagements in IBSA display traces of these three responses. A range of relevant transnational norms, but also some country specific norms can be identified in the three countries (Paper IV). Since IBSA have established domestic frameworks to undertake mitigation, a basic minimum of mitigation efforts can be taken as a given - indicating their willingness to take on greater responsibility. The scalingup, speed and nature of these actions, however, are contingent on the availability of international support. The bigger question - less so in the case of Brazil but more so in South Africa and India - is whether or not these voluntary domestic efforts will be commensurately supported by developed countries.

If NAMA development is approached from the UNFCCC perspective, then NAMAs can be seen as a means to influence agenda setting in favour of taking mitigation actions in developing countries, particularly emerging economies. From this perspective, NAMAs could be approached as the precursor of NDCs, as they introduced the notion of voluntary mitigation action for developing countries in the short term. This has subsequently managed to weaken the developed-developing country categorisation in the Paris Agreement. How does this stack up against the existing local norms? In Brazil, this speaks to the "concentric circles" proposal (Government of Brazil, 2014b), which is used to argue "that every country has the obligation of putting forward its mitigation plan", 56 indicating a case of norm localization. In India, this is contested by strongly invoking the sovereignty aspects to argue that

once you submit something as a NAMA, you are opening yourself up for ... reporting ... submitting the domestic MRV to international consultation and analysis. What does the international consultation and analysis actually

\footnotetext{
${ }^{56} \mathrm{BR} 1$.
} 
involve? Nobody knows. And developing countries have very strong apprehensions that the process of international consultation and analysis is essentially meant to try and second-guess their policies to drive the level of ambitions and to try and impose certain policies, so there are potential perceived costs in submitting an action as a NAMA, without significant international support. ${ }^{57}$

The notion of international oversight, in the absence of commensurate support, is therefore strongly resisted in India. This resistance shifted to positive engagement with NAMAs once there was some clarity on the availability of international support. Making NAMA engagement contingent on international support in South Africa, as well as recently in India, indicates that this resistance is giving way to a sort of norm localization, in which both countries are willing to take on more responsibility to tackle climate change provided developed countries make the international support available. This perception then makes it pertinent for NAMAs to deliver on the support function and in doing so, address the climate justice aspects and meet the provisions of Article 4.7 of the Convention (Paper IV). Failing to deliver on NAMA support will only confirm the concerns voiced in the reasoning above. Based on the fact that the national climate policy in IBSA has provisions for mitigation and substantiated by NAMA engagements in IBSA, one can argue that the notion of mitigation in emerging economies is not resisted. At the same time, existing local norms have ensured that framings of responsibility distribution that argue for increased mitigation in emerging economies are resisted to the extent, that development gets privileged as the key objective of NAMAs and mitigation as the co-benefit. The norm of mitigation gets localized to an extent once there is more clarity on how the international support will be provided to pursue these mitigation efforts.

\subsubsection{Institutional Capacity and Coordination}

The institutional capacity of the respective Ministry of the Environment plays an influential role in shaping NAMA engagements in IBSA. In all three countries, the Ministry of the Environment provides coordination for the implementation of climate policy. In Brazil, the Ministry of the Environment benefitted from civil society's high capacity to influence the climate change agenda before Copenhagen. In addition, its institutional structures in the form of the Inter-Ministerial Committee on Climate Change and the Brazilian Forum on Climate Change received top-down guidance. The President of Brazil was also the Chair of the Brazilian Forum, whereas the President's Chief of Staff coordinated the Inter-Ministerial Committee. In addition, the institutional capacity of the Ministry of the Environment increased considerably under the leadership of ministers Silva and Minc. The concentration of authority was channelled by the ministers to address deforestation in the Amazon and improve implementation (Carvalho, 2012; Viola \& Franchini, 2014). However, the same level of success has not been witnessed in other sectors. Although a number of actors are involved in the planning phase, the same cannot yet be confirmed at the implementation stage. Based on the outcomes of the Amazon NAMA, it seems that although the Ministry of the Environment has high capacity, its authority remains diffused on the horizontal level, limiting

\footnotetext{
${ }^{57}$ IN10.
} 
its ability to influence NAMA implementation in non-forestry sectors. Its institutional capacity and coordination ability along the vertical dimension are also perceived to be limited. This is reflected in its unwillingness to acknowledge sub-national initiatives as NAMAs and in the stakeholder perception that "there is not enough infrastructure or institutional capacity at the local level" ${ }^{58}$ This, however, seems to be in contradiction with the steps taken to reduce deforestation in Amazon forests.

In India and South Africa, new and dedicated institutional structures proved crucial for NAMA development. These institutional structures were key in helping NAMAs overcome resistance at the agenda-setting and decision-making stages by improving the coordination and capacity functions of the Ministry of the Environment. Increased coordination between participating departments at the policy formulation stage was also crucial for the V-NAMA in South Africa and the Waste NAMA in India. In their own different ways, Indian NAMAs and the South African V-NAMA are striving to link multiple layers of governance. There was a major difference, however, in how institutional capacity was shored up in the two countries (Prado, 2013). In South Africa's case, personnel were hired and dedicated to improving coordination of the implementation of flagship programmes. This enabled the Department of Environmental Affairs to set up a dedicated task team for V-NAMA at the operational level, which helped it to improve coordination with other government departments and to reach out to non-state actors in support of the V-NAMA initiative. For preparing V-NAMA, the Department of Environmental Affairs identified common areas of collaboration with two other ministries, and also increased its own capacity. By sharing authority with the other departments and actively involving non-state actors, the Department of Environmental Affairs seems to have consolidated its functioning along both the horizontal and vertical axes. In contrast, the Indian NAMAs do not yet seem to have increased the capacity of the Ministry of Climate Change, which has instead involved various non-state actors in overcoming its capacity deficit by contracting out the development of initial options in each sector (Braithwaite, 2006). By providing support for developing NAMA options, GIZ, as the implementing agency for the NAMAs, undertakes "the project activities in coordination and in alignment with [the Ministry of Climate Change]". ${ }^{59}$ In doing so, GIZ seems to have cushioned the pressure that NAMA development demands from the coordinating department, while at the same time letting the Ministry make the decisions.

\subsubsection{Mainstreaming or Alignment?}

By complementing the existence of national climate policy with developing horizontal and vertical linkages, institutional experiments and innovations indicate that although certain basic tenets of climate policy integration are being fulfilled, at the same time, such integration has not reached a stage at which climate policy is incorporated into "all stages of policymaking in other policy sectors" (Mickwitz et al., 2009, p. 19). Some developed countries have also gone back to dismantle their formal domestic responses to climate change (Paper I). This indicates that policy integration is not always a unidirectional process but one consisting of

\footnotetext{
${ }^{58} \mathrm{BR} 4$.

${ }^{59}$ IN 16.
} 
integration as well as disintegration (Candel \& Biesbroek, 2016). On the other hand, achieving climate policy integration (van Asselt et al., 2015), as understood in a developed country context wherein climate policy is central to policymaking, seems premature, especially in the Indian and South African contexts. Rather mainstreaming and alignment may be better placed to understand the policy dynamics prevailing in emerging countries.

By formally institutionalizing efforts to address climate policy, IBSA has - to an extent managed to mainstream climate change in domestic public policy debate. Climate change is seen as a relevant policy problem in all three countries but the importance it receives in comparison to other policy objectives, varies. In India and South Africa, it is still a secondorder challenge compared with the economic and social challenges facing the countries - at least in the near term - subordinating alignment possibilities to the availability of institutional capacity and clarity on international support. In Brazil, there has been considerable overlap between the Amazon NAMA and domestic priorities, so one can argue that not only climate policy has been mainstreamed but alignment between climate policy and other national objectives also occurred. However, in light of the ongoing governance crisis, climate policy may again take a backseat. This is also reflected in these countries' NAMA engagements, which by themselves do not set the current dispensation's agenda. Particularly in India, but also in South Africa, mitigation is seen as a co-benefit of development activities. Hence, a better approach would be to study whether and to what extent the climate policy is aligned with existing priorities or, better still, helps to align conflicting interests and priorities of various government departments. Approached from this perspective, it seems that NAMA initiatives in India and South Africa are being geared up to link government departments as well as non-state actors. Although the involvement of non-state actors is limited, NAMA initiatives are being designed to align the organizational structures and are providing positive externalities in form of improved understanding and trust among different government departments.

To conclude, domestic institutions, whether they be formal, informal or organizational in nature play important role in determining the utility of international climate policy frameworks (Paper IV). Although institutional capacity is important for the implementation of NAMAs in IBSA, its success hinges on a combination of domestic norms and perceptions of material base, as reflected in the formal institutions designed to address the socio-economic parameters (Table 2) prevalent in given country context. Since influencing formal and informal institutions could be a long drawn process, strengthening the organizational context by investing in institutional capacity, can be a way forward for the international climate policy frameworks to engage emerging economies to pursue mitigation while meeting domestic goals and objectives. 


\section{$7 \quad$ CONCLUSIONS}

'I wish I were a chess player. Do you play chess, Daintry?'

'No, bridge is my game.'

'The Russians don't play bridge, or so I understand.'

'Is that important?'

'We are playing games, Daintry, games, all of us. It's important not to take a game too seriously or we may lose it. We have to keep flexible, but it's important, naturally, to play the same game.

'I'm sorry, sir, 'Daintry said, 'I don't understand what you are talking about.' Graham Greene (1978), The Human Factor.

The overarching objective of this thesis has been to shed light on how the domestic institutional responses to climate change mitigation in emerging economies are influenced by engagements with international climate policy frameworks, and how, in turn, these engagements, domestically influence the utility of such frameworks. More specifically, the thesis aimed to identify and account for variations in institutional approaches to addressing GHG emissions through NAMAs, in IBSA.

To fulfil the aim of this thesis, I applied a sequential explanatory research design. Paper I in the thesis was based on a survey of climate policy across all UN member states in two time periods, 2007 and 2012. Although the paper develops and analyses a large-N study, it does not utilise statistical analysis to draw inferences. Instead, it maps the presence of climate policy in all UN member states during the two time periods to make pertinent observations. The paper provides a broad dataset that could be used to study all UN member states or any other relevant sub-group of countries. It helped me to establish the broader context of climate policy development in emerging economies, and to identify that the IBSA countries formalised their efforts to enhance climate mitigation by means of climate policy between 2007 and 2012. Paper I is followed by three papers that are different but complementary, in the approach they undertake to study climate policy development in IBSA. The Paper II, based on document analysis and interviews undertakes a case-study based approach to delve deeper into NAMA engagements in South Africa. It brings forth the tension visible in aligning climate policy with broader national interest. The paper explicitly focuses on coalitions of ideas and interests in pursuing mitigation in South Africa but also provides a rich tapestry of institutions and actors involved in its climate policy processes. It provided me with important pieces of the puzzle that are further pursued in paper III and IV. Paper III compares IBSA's NAMA engagement along different stages of the policy cycle, whereas paper IV focuses on the institutional dimensions of these engagements. By studying NAMA engagements in IBSA based on document analysis and interviews, the three papers add depth to the broad overview provided in Paper I. The mixed-method approach that I utilised thus helped me establish the broad context in which I situated both the case specific and comparative country studies. 
I used the policy cycle as a heuristic device when studying NAMA engagements in IBSA. While the policy cycle provides a useful approach to studying the policy process, the policy process field is replete with theories that examine various aspects of the policy process. The policy cycle model has been criticised by policy process scholars as it presents a simplified, linear representation of a complex process. However, as a heuristic device, I found the policy cycle's approach of breaking down the policy process into five stages - agenda-setting, policy formulation, decision-making, implementation, and evaluation - to be a good entry point for engagement with the broader policy process literature. This is not to say that the policy process literature does not have alternative approaches and theories. The policy process literature is brimming over with some very exciting theories, but I felt that the questions that I wanted to address were not the focus of these theories. Bearing in mind that the stages as defined in the policy cycle are not distinct, it still helped me to analytically dissect the process when examining the interviews. The policy cycle also helped me identify particular stages in which NAMA processes can become stuck, for example, the decision-making stage in the case of South African Renewable Initiative (SARi) and Sustainable Settlement Facility (SSF) NAMAs. This heuristic helped me identify how far along the policy process had different NAMAs in IBSA advanced.

To shed light on the domestic institutional responses to climate change mitigation in emerging economies, I first looked at the historical developments of national climate policy responses. Of the nine emerging economies, as defined here, four had initiated domestic policy responses to mitigate climate change by the end of 2007. By the end of 2012, except for Saudi Arabia, all the emerging economies had formal institutions, i.e. legislation or strategies in place to mitigate climate change. Both the legislative as well as strategic approaches to formulating climate policy were equally favoured by these emerging economies.

However, not all of them used NAMA terminology to refer to these mitigation actions. To begin with, their NAMA engagements have been quite varied at the international level itself. China, India, and South Korea did not use NAMA terminology in their submissions made after COP15. Argentina, Brazil, Indonesia, Mexico, and South Africa referred to NAMAs in their submissions in a variety of ways. Brazil referred to its actions as NAMAs along sectoral lines but did not make them conditional on availability of international support. In contrast, South Africa and Argentina tied the implementation of NAMAs on the availability of international support under the provision of the UNFCCC. The former provided an overall NAMA whereas the latter indicated the sectors in which it was developing NAMAs. Mexico and Indonesia also emphasised the importance of international support in implementing NAMAs. Unlike other seven emerging economies, both Mexico and Indonesia have also voluntarily shared information about their NAMAs on the NAMA Registry. Indonesia has submitted NAMAs that seek support for implementation, whereas Mexico seeks support for both preparing and implementing NAMAs.

While NAMAs provide indications of both pre- and post-2020 mitigation actions, INDCs are limited to actions post-2020. In their respective INDCs, none of the emerging economies refers to NAMAs. From the information available at the UNFCCC level, two inferences seem plausible: first, emerging economies are taking policy measures to undertake climate change mitigation, but NAMAs apparently have a negligible role in facilitating these measures and, 
second, within IBSA, Brazil comes across as the most receptive to and actively engaged with NAMAs, to an extent that it did not link their implementation to availability of international support. An in-depth investigation of IBSA's engagements with the international climate policy framework of NAMAs nuances these inferences.

NAMA development has varied considerably in IBSA. Brazil's NAMAs were neither dependent on international support nor submitted to the NAMA Registry to seek recognition. This created an avenue whereby aligning NAMAs and the National Law was done independently of the international dynamics. In Brazil, all national-level mitigation actions were labelled NAMAs as early as 2009, before the National Law was even passed. There was little or no time lag between the NAMA framework arriving at the agenda-setting stage and getting a favourable response at the decision-making stage. All planned actions were labelled NAMAs and made it past the decision-making stage. Differences started to emerge at the implementation stage, however. Some interviewees indicated that except for the Amazon NAMA, other Brazilian NAMAs have not yet, in terms of their stated goals, been satisfactorily implemented. As a concept, NAMAs were understood as a label to refer to actions being undertaken to achieve targets defined in a pre-2020 context; in the current context, going beyond 2020, they have been replaced by NDCs.

In India, NAMAs have faced considerable resistance and struggled to make it to the agendasetting stage for a long time. Most of the interviewees further indicated that with the emergence of INDCs, NAMAs no longer made much sense. This sentiment was echoed in interviews conducted in 2015. In parallel, the Indian Ministry of Climate Change, supported by GIZ-India had initiated a NAMA feasibility study in the forestry and waste sectors. In June 2015, reports making suggestions for NAMA developments in both these sectors were submitted to the Ministry of Climate Change, and in July 2016, a decision was made to submit one NAMA each from the two sectors to the NAMA Facility. This development indicates that NAMAs are starting to be seen as a relevant policy framework for facilitating mitigation actions in the Indian context. While this is an encouraging development, my research also indicates that only a handful of domestic stakeholders were aware of this development.

Throughout this period, South Africa engaged with NAMAs, but repeatedly faced problems at the decision-making stage, primarily due to a lack of effective institutional coordination mechanism. Two initiatives that could not be implemented due to lack of coordination were SSF and SARi (Paper II). However, unlike Brazil, which framed NAMAs as sectoral targets without seeking international support, South African actors developed much more specific NAMAs - conditional on the availability of international support - to implement national climate policy goals. Finally, through GIZ's V-NAMA initiative, one of South Africa's NAMA proposals, in its third submission to the NAMA Facility, has now reached the appraisal stage. The implementation of this NAMA, subject to the approval of finance, is expected to begin in 2017.

NAMA development along the policy cycle does not occur in a single iterative policy loop in IBSA. Instead, it comprises multiple smaller loops that provide feedback and enhance learning about the process (Howlett et al., 2009). These loops can help refine decisions. For 
example, in India, process to develop concrete NAMA proposals was only taken after a decision to develop NAMA proposals in Waste and Forestry sector was taken by the Ministry of Climate Change. This was then followed by development of policy proposals for the government to consider, which in turn was followed by the decision to submit NAMAs to the NAMA Facility. At the same time, NAMA development faces obstacles at different stages of the policy cycle. The amount of time taken to go from one stage to another is highly variable and depends on the country context. As has been the case in India, NAMAs may get stuck at the agenda-setting stage for a long time or, as in the South African examples, may suffer from a lack of coordination at the decision-making stage. The opposite is also possible, as is evident in the Brazilian approach to NAMA engagement where the decision to label its domestic mitigation actions as NAMAs was taken as soon as NAMAs appeared on the agenda-setting stage.

It is too early, however, to comment on the implementation of NAMAs as there are not enough examples from IBSA to draw inferences from and the Brazilian NAMAs are given targets for the year 2020. Once a NAMA becomes stuck at any stage of the policy cycle, it can become difficult for it to complete the process. This is especially true if the institutional structures that can create space for actors and individuals to collaborate or intervene are missing. Instances in which such institutional structures are created, for example, the VNAMA-specific task team in South Africa and the bilateral project steering committee in India, obstacles can be overcome given sufficient time.

So, why do we see variances across the IBSA countries? The thesis has particularly focused on three institutional factors that can help us understand the variance in NAMA engagements: climate policy, norms related to responsibility distribution, and institutional capacity. Climate policy can create both positive and negative incentives for engaging with international climate policy frameworks. Transnational norms can be resisted by local norms, become localized to serve local needs, or replace existing norms, resulting in norm displacement. Institutional capacity influenced whether or not government actors chose to engage with NAMAs and make such engagements conditional on external support or not; it can also determine whether these engagements will lead to institutional experiments and innovation.

The countries' climate policy, both legislative and strategic approaches, provides a reference point for NAMA development; at the same time, there are instances in which terminology used in national climate policy makes the NAMA concept redundant. This creates a paradox, as national climate policy creates a reference point for international climate policy frameworks, a reference point that also gets used to questioning the very utility of and the need for such frameworks.

By establishing a shared language of understanding amongst stakeholders, national climate policy can make NAMAs relevant as well as redundant. In India, the mitigation avenues were captured by the national missions as defined by the Action Plan (Upadhyaya, 2010). Compared with the mitigation-relevant national missions, the NAMA concept was very vague. As a result, it was crowded out as a potential policy option for major sectors. This situation only changed once the lead ministry's institutional capacity constraints were addressed by involving non-state actors in developing concrete NAMA proposals. 
South Africa initiated a process of developing climate policy in 2005 that culminated with the publication of the White Paper in 2011. But South Africa also did not use NAMA terminology - available from 2007 onwards - in the White Paper, as South African policymakers were unsure about the implications of using NAMAs in the White Paper. However, on account of the country's high capacity to formulate policies, some actors did try to find synergies between NAMAs and the flagship programmes. The fate of these initiatives was determined by the ability to provide effective institutional coordination. NAMA proposals and national climate policy were developed simultaneously in Brazil, which did not seek international support to implement the former. Instead, the government used them to shore up legitimacy for the National Law and itself, both internationally and domestically.

Domestically driven policy approaches to addressing climate change in IBSA vary in terms of their legal obligations, interactions across governance levels and policy instruments deployed. While India and South Africa have undertaken a strategic approach to national climate policy, Brazil has undertaken a legislative approach. Mitigation efforts in India are largely nationally driven with sub national action plans focusing on adaptation aspects. Various sub-national climate policies in Brazil have indicated their intentions to reduce GHG emissions but NAMAs are seen to be developed at national level. In South Africa, some of the provinces have also developed climate strategies, but here too progress remains uneven. Like India, mitigation seems to be driven by the White Paper at the national level.

Norms were also important in facilitating or refraining from NAMA engagements. In Brazil, norms shifted decidedly in favour of emerging economies taking action on climate change, seen as a common concern for humanity, with every country having the responsibility to mitigate climate change, although in a differentiated manner. In India, norms giving precedence to pressing domestic priorities were at the forefront of the discussions, and responsibility to act to mitigate climate change was understood as belonging to the North. As policymakers realised that India is highly vulnerable to climate change and the country could contribute to avoiding adverse impacts of climate change by undertaking mitigation, they came to favour domestic actions that provide for mitigation as a co-benefit. In South Africa, as in India, norms underpinning views of the distribution of responsibilities to mitigate climate change stressed the importance of getting international support for domestic mitigation actions. However, unlike India, which considered the support available to be inadequate, in South Africa, support was assessed by at least some actors as worthwhile enough to justify attempting to secure parts of it to enhance mitigation actions.

Institutional capacity is crucial for the uptake of NAMAs as a concept in emerging economies. In Brazil, institutional capacity to take mitigation actions was relatively high when the concept of NAMAs was first agreed on in 2007, as evidenced by its success in controlling deforestation in the Amazon. In contrast, both India and South Africa only started to favour the use of NAMA terminology after efforts were made to address the institutional capacity limitations of their respective Ministry of the Environment. In South Africa, institutional investment is increasing trust and understanding amongst key departments and is expected to engender collaboration at multiple levels. In India, while there has been limited involvement of national ministries other than the Ministry of Climate Change in NAMA 
development, sub-national and non-state actors are being involved during the policy formulation stage.

By providing new modes of engagement, investment in institutional capacity is providing novel examples of institutional experimentation. Based on NAMA engagements in IBSA, three important observations related to institutional capacity can be made. First, the South African cases show that institutions can play a decisive role in supporting new coalitions of ideas and interests in overcoming the resistance that mitigation actions face from existing ideas and interests. Dedicating institutional capacity for enhancing coordination was an important factor in ensuring that V-NAMA did not share the fate of SSF and SARi. Second, and linked to the first observation, the fact that emerging economies such as India and South Africa are also seeking international support from external partners to facilitate institutional capacity for NAMA development indicates that it is seen as a demanding process that strains both time and resources. It only underlines the level of support needed by developing countries as a whole. Other than Amazon NAMA, that was already showing results before it was labelled as a NAMA, we are yet to see NAMA implementation in IBSA. Finally, by synchronising NAMAs with the legal structure provided by its climate policy, Brazil may be missing out on the opportunity to experiment with novel modes of engagement between different ministries and across non-state actors. But it is also possible that in addressing deforestation from Amazon forests, Brazil already undertook institutional experimentation, much before other emerging economies started setting up relevant institutional arrangements.

Based on IBSA's NAMA engagements, it can be argued that emerging economies have so far not benefitted from each other's experiences. This is evident from the fact that stakeholders involved in the Indian NAMA development project were unaware of the fate of the SSF NAMA in South Africa. There is a need to provide more information about such initiatives to potential NAMA developers. At the moment, IBSA stakeholders are largely unaware of NAMA developments in other IBSA countries, and even less aware of NAMA developments in other country contexts. One way to overcome this barrier would be to have a network of the environment ministries that could benefit from sharing both their positive and negative experiences of NAMA development. There are some initiatives that operate along these lines, but they focus on the existence of domestic legislation (for e.g. GLOBE International, 2017) and not necessarily on its implementation. The network of environment ministries suggested above could focus on sharing information and experiences about implementing national climate policy. Similarly, the NAMA Facility provides information about NAMAs selected for appraisal or implementation, but no information about why NAMAs have failed to make the cut has been made publicly available. It may, however, be tricky for support providers to publicly comment on why a proposal was not selected.

\subsection{Lessons for Nationally Determined Contributions}

While all three countries participated in the NAMA negotiations under the UNFCCC, they have taken different approaches to engaging with the NAMA concept in their domestic settings. With the emergence of NDCs, it is pertinent to consider NAMAs' continuing role and relevance. With the consolidation of NDCs, four trends can be anticipated: variance in the 
implementation of mitigation actions; the domestic determination of mitigation actions; the central role of national government in providing oversight, ensuring coordination, and facilitating implementation; and varied interpretation of and interaction between domestic mitigation efforts and international climate policy frameworks. Since NAMAs also emphasised these functions by shifting the locus of decision-making to the state, I argue that studying NAMA engagements provides an opportunity to better anticipate NDC engagements as well. Based on the study of NAMA engagements in IBSA, I make some observations that can be of relevance to NDC engagements.

The experience with NAMA engagement in IBSA indicates: First, beginning at international level, lack of clarity undermines engagements with international climate policy frameworks. NAMAs were poorly defined to begin with, could never provide strong signal on availability of international support and took long time to be of any practical use to serve its long-term goal. As a result, IBSA countries interpretation of and engagements with NAMAs were quite distinct to each other. Whether or not a country seeks international support will be an important factor in determining these interpretations and engagements. Brazil did not see the availability of international support as a determining factor for its mitigation actions and was able to use NAMAs as a means to communicate domestic actions to the international audience. For both South Africa and India, international support was seen as a crucial element for NAMA engagements. Once there was some clarity on international support both countries started to gear up for NAMA engagement but in slightly different ways. In South Africa, NAMAs are being positioned to strengthen institutional structures and enhance institutional capacity, whereas in India they serve as a means to shore up the limited institutional capacity by increasing non-state actors' involvement in policy formulation and implementation. Therefore, clarity on international climate policy frameworks, including on sources of support will be important in determining how the country engages with the NDC framework.

Second, domestic priorities will increasingly determine the nature of mitigation efforts. NAMAs in IBSA are driven largely by their respective national climate policy, which in turn is driven by overriding domestic priorities. While sectors that directly come within the ambit of the Ministry of the Environment can provide a good starting point for undertaking mitigation actions such as NAMAs, improving coordination with key ministries can help align climate policy goals and other pressing domestic priorities such as energy security. NAMAs can be used to align national climate policy and NDCs by establishing linkages between NDCs and the avenues defined in the national climate policy.

Third, the speed and scale at which NAMAs have been utilised vary considerably in IBSA. Within a small subset of emerging economies, I have illustrated how various institutional factors have influenced NAMA engagements along the policy cycle. The biggest challenge during agenda-setting is to balance norms regarding responsibility distribution with the need to address socio-economic parameters. During policy formulation, decision-making and implementation stages, institutional capacity, particularly that of the Ministry of the Environment, surfaces in my analysis as the most important factor. Institutional capacity determines the ability to, either take on the active coordination of inter-sectoral mitigation actions or to engage non-state actors in making up for the limited capacity. NAMA engagement in India and South Africa only picked up once investments were made in 
strengthening institutional capacity. Brazil changed its stance on deforestation once the investments in improving the institutional capacity of its Ministry of the Environment started to show results. Arrangements to support NDC implementation will be better served to take note of these institutional differences.

Fourthly, NAMA development is a protracted process in which two to three years are needed to get a NAMA from its inception to the stage at which it is considered mature enough for investment. It is even possible that a NAMA may only begin to be implemented in its fourth or fifth year. In Amazon NAMA, the results started to show around the same time horizon (Held et al., 2013b). What does this mean for emerging economies' NDCs, which are expected to be more ambitious than NAMAs? In order to reduce the implementation gap and time lag between policy formulation and actual policy implementation, it is crucial to prioritise investments in the institutional dimension. The pilot project approach, whereby short-term projects are prioritised to show quick results cannot serve the demands of the climate challenge. As the NAMA experience shows, without clarity and assurance on the delivery of international support, implementing many NDCs at the scale and speed desired, will suffer.

Finally, by setting the agenda - as was largely expected - the state played decisive role in defining the nature of NAMAs in IBSA. Beyond defining the overall agenda for mitigation through formal institutions, and deciding on the sectors in which NAMAs can be explored, the state has also been important in providing oversight and coordination of NAMA engagement. It is difficult to draw concrete conclusions concerning NAMA implementation, as other NAMAs have not been so successfully implemented. Yet, based on NAMA engagements in other stages of policy cycle an observation on non-state actors' involvement needs to be flagged. In playing a decisive role in defining NAMAs, deciding the sectors for NAMA uptake, providing oversight and coordination, the state also defines the boundaries within which non-state actors need to operate. The NAMA engagements in IBSA include non-state actors to address the priority areas identified by the state. This may be the limits of the hybrid architecture in emerging economies. The experience from NAMA indicates that the aims of involving non-state actors may be limited to policy formulation and implementation stage of the policy cycle. At the same time, IBSA did consult non-state actors while developing their iNDCs. Therefore, it is possible that the state may not take the same approach to defining NDC as it took to defining NAMAs.

In summary, the NDC implementation can benefit from NAMA engagements by factoring in five interlinked learnings. Firstly, it will be crucial for NDCs to provide clarity as an international climate policy framework. Support functions also need to be clarified on a priority basis. Secondly, establish and strengthen linkages with avenues defined in the countries' national climate policy as well as with broader priorities of the government so as to ensure alignment with overall domestic objectives. Third, it will be beneficial for arrangements to support NDC implementation to take into account the institutional differences in different country contexts. Fourthly, to implement NDCs at the scale and speed desired, the pilot project approaches are ill-suited. Institutional investments are needed enhance the institutional capacity, particularly of the Environment Ministries to reduce the 
time taken to travel from policy formulation to actual policy implementation. Finally, more clarity is needed on the role of non-state actors' involvement in NDC development.

\subsection{Future research areas}

As shown in this study, NAMA engagement varies in many ways in IBSA. A next step would be to continue the comparative effort of this thesis in various directions, first by studying NAMA engagements in other emerging economies as well, which could help test and sharpen the conclusions reached here. To increase the number of cases under observation, qualitative comparative analysis as a potential mixed-method approach should be employed, as it is also better suited for theory generation than the sequential explanatory research design adopted here. While such an approach would increase the breadth of the study, it is also possible to further increase the depth of the present analysis. This could be done by continuing with the comparative approach used here, and extending it to study the actual implementation of the Forestry NAMA and Waste NAMA in India and the V-NAMA in South Africa. Such a study would not only highlight the challenges faced in translating NAMAs into reality but also test the dependability of the increased institutional capacity of the relevant government departments. The study could also establish linkages with the role of support providers and could be extended to examine and compare different support models that are available to countries that want to continue using NAMAs as a useful climate policy framework. The third strand - assuming that the NAMA Facility supports the NAMAs studied here - would be to assess whether or not the prevalent negative perception amongst developing countries' stakeholders regarding the efficacy and intent of support providers, is changed or not. It is also possible to revisit Paper I to update the dataset from 2012 onwards. It would, therefore, be possible to undertake case studies, small-N studies, as well as Large-N studies as a way to consolidate the findings, arrived at here.

Although fusing the policy cycle with institutional perspectives has helped me understand the NAMA engagements in IBSA, there are many avenues that remain unstudied. To understand the dynamics in other emerging economies and in developing countries broadly, better empirical understanding needs to be developed. This demands to increase the depth as well as the breadth of the analysis that I have undertaken in this thesis. To further the policy process analysis, a next step could be to apply and compare various theories in studying specific NAMAs in a given country context or to apply a single policy process theory in studying several NAMAs across different country contexts (Gupta, 2012). This retains the comparative perspective that I have found to be very useful. I think that policy feedback theory, due to its attention to institutionalised policies, the institutional analysis and development framework on account of the prominence given to institutions (although it has not been used for the national level studies), and the social construction framework, on account of the eminence it gives to interpretations, would be useful theories to explore.

Another research direction would be to draw on the comparative politics literature to bring together ideas, interests, and institutions (Purdon, 2015), in order to consider how these three important aspects come together to influence the policy process. It might be complicated to bring together all three traditions of comparative politics in a single comparative study but 
using case study approach might be the way forward to untangle the complex ways in which ideas, interests, and institutions influence policy processes. 


\section{REFERENCES}

Acharya, A. (2004). How Ideas Spread: Whose Norms Matter? Norm Localization and Institutional Change in Asian Regionalism. International Organization, 58(02), 239275.

Adelle, C., \& Russel, D. (2013). Climate Policy Integration: A Case of Déjà Vu? Environmental Policy and Governance, 23(1), 1-12.

Amars, L., Fridahl, M., Hagemann, M., Röser, F., \& Linnér, B.-O. (2016). The transformational potential of Nationally Appropriate Mitigation Actions in Tanzania: assessing the concept's cultural legitimacy among stakeholders in the solar energy sector. Local Environment, 1-20.

ANC. (2007). 52nd National Conference: Adopted Strategy and Tactics of the ANC. ANC.

Retrieved from http://www.anc.org.za/content/52nd-national-conference-adoptedstrategy-and-tactics-anc

Atteridge, A. (2013). The Evolution of Climate Policy in India: Poverty and Global Ambition in Tension. In D. Held, C. Roger, \& E.-M. Nag (Eds.), Climate Governance in the Developing World (pp. 53-71). Cambridge: Polity Press.

Atteridge, A., Shrivastava, M., Pahuja, N., \& Upadhyay, H. (2012). Climate policy in India: what shapes international, national and state policy? AMBIO: A Journal of the Human Environment, 41, 68-77.

Bäckstrand, K., Kuyper, J. W., Linnér, B.-O., \& Lövbrand, E. (Forthcoming). Non-State Actors in the New Landscape of International Climate Cooperation. Environmental Politics.

Bailey, I., \& Compston, H. (Eds.). (2012). Feeling the Heat: The politics of Climate Policy in Rapidly Industrializing Countries. Palgrave Macmillan.

Bang, G., Underdal, A., \& Andresen, S. (Eds.). (2015). The Domestic Politics of Global Climate Change: Key Actors in International Climate Cooperation. Cheltenham, UK: Edward Elgar Publishing.

Barbi, F., \& Ferreira, L. D. C. (2016). Governing Climate Change Risks: Subnational Climate Policies in Brazil. Preprints, 12.

Baumgartner, F. R., \& Jones, B. D. (1993). Agendas and Instability in American Politics. Chicago: University of Chicago Press.

Baumgartner, F. R., Jones, B. D., \& Mortensen, P. B. (2014). Punctuated Equilibrium Theory: Explaining Stability and Change in Public Policymaking. In P. A. Sabatier \& C. M. Weible (Eds.), Theories of the Policy Process (3rd ed., pp. 59-103). Boulder: Westview Press.

Bennett, C. J., \& Howlett, M. (1992). The Lessons of Learning: Reconciling Theories of Policy Learning and Policy Change. Policy Sciences, 25(3), 275-294.

Bernstein, S. (2000). Ideas, Social Structure and the Compromise of Liberal Environmentalism. European Journal of International Relations, 6(4), 464-512. 
Betsill, M., Dubash, N. K., Paterson, M., van Asselt, H., Vihma, A., \& Winkler, H. (2015). Building Productive Links between the UNFCCC and the Broader Global Climate Governance Landscape. Global Environmental Politics, 15(2), 1-10.

Biesenbender, S., \& Tosun, J. (2014). Domestic politics and the diffusion of international policy innovations: How does accommodation happen? Global Environmental Change, 29, 424-433.

Biniaz, S. (2016). Comma But Differentiated Responsibilities: Punctuations and 30 other ways Negotiators have resolved issues in the International Climate Change Regime. New York. Retrieved from https://web.law.columbia.edu/sites/default/files/microsites/climatechange/files/Publications/biniaz_2016_june_comma_diff_responsibilities.pdf

Birkland, T. A. (2007). Agenda Setting in Public Policy. In F. Fischer, G. J. Miller, \& M. S. Sidney (Eds.), Handbook of Public Policy Analysis: Theory, Politics, and Methods. (pp. 63-78). Florida: CRC Press.

Bloomberg. (2009, December 18). "Famous comma" slows climate talks. The Economic TImes. Copenhagen. Retrieved from http://articles.economictimes.indiatimes.com/2009-1218/news/27648464_1_comma-climate-talks-climate-deal

Bodansky, D. (2007, December 19). Bali High? Retrieved from http://opiniojuris.org/2007/12/19/bali-high/

Bodansky, D., \& Diringer, E. (2014). Alternative Models for the 2015 Climate Change Agreement (13). Lysaker, Norway: Fridtjof Nansen Institute. Retrieved from http://www.fni.no/climatepolicyperspectives/FNICPP-13.html

Bodansky, D., Hoedl, S. A., Metcalf, G. E., \& Stavins, R. N. (2016). Facilitating linkage of climate policies through the Paris outcome. Climate Policy, 16(8), 956-972.

Borghesi, S., Montini, M., \& Barreca, A. (2016). The European Emission Trading System and Its Followers: Comparative Analysis and Linking Perspectives (1st ed.). Springer.

Boyd, A., Coetzee, K., \& Boulle, M. (2014). What does the current NAMA-space in South Africa look like? (A TERI-NFA NAMA country report on South Africa.). Cape Town: Energy Research Centre, University of Cape Town.

Brady, H. E., \& Collier, D. (Eds.). (2010). Rethinking Social Inquiry: Diverse Tools, Shared Standards (2nd ed.). Plymouth: Rowman and Littlefield publishers.

Braithwaite, J. (2006). Responsive regulation and developing economies. World Development, 34(5), 884-898.

Brouwer, S., Rayner, T., \& Huitema, D. (2013). Mainstreaming Climate Policy: The Case of Climate Adaptation and the Implementation of EU Water Policy. Environment and Planning C: Government and Policy, 31(1), 134-153.

Bueno de Mesquita, B., \& Smith, A. (2012). Domestic Explanations of International Relations. Annual Review of Political Science, 15(1), 161-181.

Busby, J. W. (2007). Bono Made Jesse Helms Cry: Jubilee 2000, Debt Relief, and Moral Action in International Politics. International Studies Quarterly, 51(2), 247-275. 
Cairney, P., \& Heikkila. (2014). A Comparison of Theories of the Policy Process. In P. A. Sabatier \& C. M. Weible (Eds.), Theories of the Policy Process (Third, pp. 363-390). Boulder: Westview Press.

Candel, J. J. L., \& Biesbroek, R. (2016). Toward a processual understanding of policy integration. Policy Sciences, 1-21. https://doi.org/10.1007/s11077-016-9248-y

Carvalho, F. V. de. (2012). The Brazilian position on forests and climate change from 1997 to 2012: from veto to proposition. Revista Brasileira de Política Internacional, 55(SPE), 144-169.

CAT. (2016). Rating countries - Climate Action Tracker. Retrieved October 25, 2016, from http://climateactiontracker.org/countries.html

CCAP. (2012). Overview of NAMA Financial Mechanisms. CCAP. Retrieved from http://www.ccap.org/docs/resources/1135/CCAP\%20NAMAs\%20and\%20Financial\%2 0Mechanisms\%20final.pdf

CDKN. (2017). The Policy Cycle Stages. Retrieved February 15, 2017, from /content/policycycle-stages

Chandrashekeran, S., Morgan, B., Coetzee, K., \& Baker, L. (2014). From statements of intent to institutionalised practice: What makes climate change policies stick? CPR. Retrieved from http://ssrn.com/abstract=2538294

Chapman, A., McLellan, B., \& Tezuka, T. (2016). Strengthening the Energy Policy Making Process and Sustainability Outcomes in the OECD through Policy Design. Administrative Sciences, 6(3).

Checkel, J. T. (1998). The Constructive Turn in International Relations Theory. World Politics, 50(02), 324-348.

Cheng, C. C. (2010). A new NAMA framework for dispresed energy end-use sectors. Energy Policy, 38, 5614-5624.

Coetzee, K., \& Winkler, H. (2014). The international policy context for mitigation actions. Climate and Development, 6(S1), 4-11.

Compston, H., \& Bailey, I. (2008). Turning Down the Heat: The politics of Climate Policy in Affluent Democracies. Palgrave Macmillan.

Cortell, A. P., \& Davis, J. W. (2005). When norms clash: international norms, domestic practices, and Japan's internalisation of the GATT/WTO. Review of International Studies, 31(1), 3-25.

Dang, T. K. P., Visseren-Hamakers, I. J., \& Arts, B. (2016). A framework for assessing governance capacity: An illustration from Vietnam's forestry reforms. Environment and Planning C: Government and Policy, 34(6), 1154-1174.

Death, C. (2011). Leading by Example: South African Foreign Policy and Global Environmental Politics. International Relations, 25(4), 455-478.

deLeon. (1999). The Stages Approach to the Policy Process: What has it done? Where is it going? In P. A. Sabatier (Ed.), Theories of the Policy Process (1st ed., pp. 19-32). Boulder: Westview Press.

Dente, B. (2014). Understanding Policy Decisions. Heidelberg: Springer. 
Dimitrov, R. S. (2005). Hostage to Norms: States, Institutions and Global Forest Politics. Global Environmental Politics, 5(4), 1-24.

Doody, O., \& Noonan, M. (2013). Preparing and conducting interviews to collect data. Nurse Researcher, 20(5), 28-32.

Dubash, N. K. (2013). The politics of climate change in India: narratives of equity and cobenefits. Wiley Interdisciplinary Reviews: Climate Change, 4(3), 191-201.

Dubash, N. K., Hagemann, M., Höhne, N., \& Upadhyaya, P. (2013). Developments in national climate change mitigation legislation and strategy. Climate Policy, 13(6), 649-664.

Dubash, N. K., \& Jogesh, A. (2014). From Margins to Mainstream? State Climate Change planning in India. Economic \& Political Weekly, XLIX(48), 86-95.

Dubash, N. K., \& Joseph, N. B. (2015). The Institutionalisation of Climate Policy in India: Designing a Development-Focused, Co-Benefits Based Approach. Working Paper, New Delhi.

Dubash, N. K., \& Morgan, B. (Eds.). (2013). The Rise of the Regulatory State of the South: Infrastructure and Development in Emerging Economies (First). Oxford: Oxford University Press.

Duit, A. (Ed.). (2014). State and Environment: The Comparative Study of Environmental Governance. Massachusetts: MIT Press.

Duit, A. (2016). The four faces of the environmental state: environmental governance regimes in 28 countries. Environmental Politics, 25(1), 69-91.

Ebbinghaus, B. (2005). When Less is More: Selection Problems in Large- N and Small- N Cross-National Comparisons. International Sociology, 20(2), 133-152.

Ecofys. (2016, November). NAMA Database. Retrieved January 25, 2017, from http://www.nama-database.org/index.php/Main_Page

Ecofys, \& ECN. (2012). Ecofys - Annual Status Report on NAMAs 2012. Retrieved from http://www.ecofys.com/en/publication/annual-status-report-on-namas-2012/

Ellerman, A. D., \& Buchner, B. K. (2007). The European Union Emissions Trading Scheme: Origins, Allocation, and Early Results. Review of Environmental Economics and Policy, 1(1), 66-87.

Estache, A., \& Wren-Lewis, L. (2009). Toward a Theory of Regulation for Developing Countries: Following Jean-Jacques Laffont's Lead. Journal of Economic Literature, 47(3), 729-70.

Estache, A., \& Wren-Lewis, L. (2010). On the Theory and Evidence on Regulation of Network Industries in Developing Countries. In R. Baldwin, M. Cave, \& M. Lodge (Eds.), The Oxford Handbook of Regulation (pp. 371-406). Oxford University Press.

Evans, P. (1995). Embedded Autonomy: States and Industrial Transformation. New Jersey: Princeton University Press.

Fine, B., \& Rustomjee, Z. (1996). The Political Economy of South Africa: From Minerals-Energy Complex to Industrialisation. Boulder: Westview Press.

Finnemore, M. (1996). National Interests in International Society. Ithaca: Cornell University Press. 
Finnemore, M., \& Sikkink, K. (1998). International Norm Dynamics and Political Change. International Organization, 52(04), 887-917.

Fischer, F., Miller, G. J., \& Sidney, M. S. (Eds.). (2007). Handbook of Public Policy Analysis: Theory, Politics, and Methods. Florida: CRC Press.

Fisher, S. (2012). Policy storylines in Indian climate politics: opening new political spaces? Environment and Planning C: Government and Policy, 30(1), 109-127.

Fridahl, M., Hagemann, M., Röser, F., \& Amars, L. (2015). A Comparison of Design and Support Priorities of Nationally Appropriate Mitigation Actions. The Journal of Environment \& Development, 24(2), 237-264.

Fridahl, M., \& Johansson, L. (2016). An assessment of the potential for spurring transformational change through Nationally Appropriate Mitigation Actions (NAMAs). Environmental Innovation and Societal Transitions.

Fridahl, M., Upadhyaya, P., \& Linnér, B.-O. (2014). Supporting Nationally Appropriate Mitigation Actions through the Green Climate Fund: Governance Capacities and Challenges. Carbon and Climate Law Review, 4, 257-269.

Friedman, B. L. (2006). Policy Analysis as Organizational Analysis. In M. Moran, M. Rein, \& R. E. Goodin (Eds.), The Oxford Handbook of Public Policy (1st ed., pp. 482-495). New York: Oxford University Press.

Friman, M. (2013). Historical responsibility: Assessing the past in international climate negotiations. Linköping University, Linköping. Retrieved from http://liu.divaportal.org/smash/searchref.jsf;jsessionid=a4bce84dbebba44340fa80ff160e?pid=diva 2:583947\&searchld=null

Friman, M. (2016). Consensus rationales in negotiating historical responsibility for climate change. International Environmental Agreements: Politics, Law and Economics, 16(2), 285-305.

Fuhr, H., \& Lederer, M. (2009). Varieties of Carbon Governance in Newly Industrializing Countries. The Journal of Environment \& Development, 18(4), 327-345.

Fukuda, K., \& Tamura, K. (2012). From NAMAs to Low Carbon Development in Southeast Asia: Technical, Mainstreaming, and Institutional Dimensions. IGES. Retrieved from https://pub.iges.or.jp/pub/namas-low-carbon-development-southeast-asia

Garibaldi, J. A., Winkler, H., La Rovere, E. L., Cadena, A., Palma, R., Sanhueza, J. E., ... Torres Gunfaus, M. (2013). Comparative analysis of five case studies: commonalities and differences in approaches to mitigation actions in five developing countries. Climate and Development, 6(sup1), 59-70.

George, A. L., \& Bennett, A. (2005). Case Studies and Theory Development in the Social Sciences. Massachusetts: The MIT Press.

GIZ. (2013). Sub-national involvement in NAMA development: Current and emerging practice towards vertical integration. Eschborn: GIZ. Retrieved from https://mitigationpartnership.net/giz-2013-sub-national-involvement-namadevelopment 
GIZ. (2014). Building Energy Efficiency V-NAMA in South Africa. Deutsche Gesellschaft fur Internationale Zusammenarbeit (GIZ) GmbH.

Glemarec, Y. (2010). Financing the transition to a low-carbon society. Journal of Renewable and Sustainable Energy, 2(031013), 1-12.

GLOBE International. (2016a). Countries | The Global Climate Legislation Study. Retrieved November 17, 2016, from http://www.Ise.ac.uk/GranthamInstitute/legislation/countries/

GLOBE International. (2016b, November). The Global Climate Legislation Study - Summary of key trends 2016. Grantham Research Institute on climate change and the environment.

GLOBE International. (2017). GLOBE International Home. Retrieved February 21, 2017, from http://globelegislators.org/

Government of Brazil. (2009). Public Law, No. 12.187, 29 December 2009.

http://www2.camara.leg.br/legin/fed/lei/2009/lei-12187-29-dezembro-2009-

599441-publicacaooriginal-121756-pl.html. Accessed 6 May 2016.

Government of Brazil. (2010, January 29). Brazil's Copenhagen pledges including NAMAs.

Retrieved from

https://unfccc.int/files/meetings/cop_15/copenhagen_accord/application/pdf/brazil cphaccord_app2.pdf

Government of Brazil. (2014a). Views of Brazil on accelerating the Implementation of Enhanced Climate Action. UNFCCC.

Government of Brazil. (2014b). Views of Brazil on the elements of the New Agreement under the Convention Applicable to all Parties. UNFCCC. Retrieved from http://www4.unfccc.int/submissions/Lists/OSPSubmissionUpload/73_99_130602104 651393682-BRAZIL\%20ADP\%20Elements.pdf

Government of Brazil. (2015). Brazil iNDC. Federative Republic of Brazil. Retrieved from http://www4.unfccc.int/submissions/INDC/Published\%20Documents/Brazil/1/BRAZI L\%20iNDC\%20english\%20FINAL.pdf

Government of India. (2008). National Action Plan on Climate Change. Ministry of Environment and Forest, Government of India. Retrieved from http://pmindia.nic.in/climate_change.htm

Government of India. (2009). Climate Change Negotiations: India's submissions to the United Nations Framework Convention on Climate Change. New Delhi: Ministry of Environment and Forests (MoEF), Government of India. Retrieved from http://moef.nic.in/downloads/home/UNFCCC-final.pdf

Government of India. (2012). Increasing Ambition Level under Durban Platform for Enhanced Actions. UNFCCC. Retrieved from https://unfccc.int/files/documentation/submissions_from_parties/adp/application/p df/adp_india_28022012.pdf

Government of India. (2015). India's INDC: Working towards Climate Justice. Government of India. Retrieved from 
http://www4.unfccc.int/submissions/INDC/Published\%20Documents/India/1/INDIA \%20INDC\%20TO\%20UNFCCC.pdf

Green, J. F., Sterner, T., \& Wagner, G. (2014). A balance of bottom-up and top-down in linking climate policies. Nature Climate Change, 4(12), 1064-1067.

Guest, G., MacQueen, K. M., \& Namey, E. E. (2012). Applied Thematic Analysis / SAGE Publications Ltd. California: SAGE Publications.

Gupta, K. (2012). Comparative Public Policy: Using the Comparative Method to Advance Our Understanding of the Policy Process. Policy Studies Journal, 40, 11-26.

Halsnæs, K., Garg, A., Christensen, J., Føyn, H., Karavai, M., La Rovere, E., ... Segafredo, L. (2014). Climate change mitigation policy paradigms - national objectives and alignments. Mitigation and Adaptation Strategies for Global Change, 19(1), 45-71.

Hanna, P. (2012). Using internet technologies (such as Skype) as a research medium: a research note. Qualitative Research, 12(2), 239-242.

Harrison, K. (2007). The Road not Taken: Climate Change Policy in Canada and the United States. Global Environmental Politics, 7(4), 92-117.

Harrison, K., \& Sundstrom, L. M. (Eds.). (2010). Global Commons, Domestic Decisions: The comparative Politics of Climate Change. MIT Press.

Harvey, W. S. (2011). Strategies for conducting elite interviews. Qualitative Research, 11(4), 431-441.

Held, D., Roger, C., \& Nag, E.-M. (Eds.). (2013a). Climate Governance in the Developing World. Cambridge: Polity Press.

Held, D., Roger, C., \& Nag, E.-M. (2013b). Controlling the Amazon: Brazil's Evolving Response to Climate Change. In D. Held, C. Roger, \& E.-M. Nag (Eds.), Climate Governance in the Developing World (pp. 134-154). Cambridge: Polity Press.

Helme, N. (2009). The Bali Roadmap: Nationally Appropriate Mitigation Action and Sectoral Approaches (pp. 1-17). Beijing: Center for Clean Air Policy.

Heywood, A. (2013). Key Concepts in politics. Hampshire and New York: Palgrave Macmillan. Hill, M. (2014). The Public Policy Process (6th ed.). Abingdon, Oxon; New York, NY:

Routledge.

Hochstetler, K., \& Viola, E. (2012). Brazil and the Politics of Climate Change: Beyond the Global Commons. Environmental Politics, 21(5).

Hofferberth, M., \& Weber, C. (2015). Lost in translation: a critique of constructivist norm research. J Int Relat Dev, 18(1), 75-103.

Hogwood, B. W., \& Peters, B. G. (1982). The dynamics of policy change: Policy succession. Policy Sciences, 14(3), 225-245.

Howlett, M., \& Giest. (2015). The policy-making process. In E. Araral, S. Fritzen, M. Howlett, M. Ramesh, \& X. Wu (Eds.), Routledge Handbook of Public Policy (pp. 17-28). New York: Routledge.

Howlett, M., McConnell, A., \& Perl, A. (2016). Moving Policy Theory Forward: Connecting Multiple Stream and Advocacy Coalition Frameworks to Policy Cycle Models of Analysis. Australian Journal of Public Administration, 1-15. 
Howlett, M., Ramesh, M., \& Perl, A. (2009). Studying Public Policy - Policy Cycles and Policy Subsystems. (3rd ed.). Canada: Oxford University Press.

ICAP. (2016). Emissions Trading Worldwide: Status Report 2016 (p. 72). Berlin: ICAP. Retrieved from https://icapcarbonaction.com

ILO. (2014). Global Employment Trends 2014: The risk of a jobless recovery. Geneva: International Labour Organization. Retrieved from http://www.ilo.org/global/research/global-reports/global-employmenttrends/2014/WCMS_233953/lang--en/index.htm

ILO. (2017). World Employment and Social Outlook: Trends 2017 (Report). Geneva: International Labour Organization. Retrieved from http://www.ilo.org/global/research/global-reports/weso/2017/WCMS_541211/lang-en/index.htm

IRENA. (2012). Nationally Appropriate Mitigation Actions (NAMAs) with Renewable Energy: Handbook for Policy Makers and Project Developers. International Renewable Energy Agency. Retrieved from http://www.irena.org/DocumentDownloads/Publications/Handbook_RE_NAMAs.pdf Irvine, A., Drew, P., \& Sainsbury, R. (2013). "Am I not answering your questions properly?" Clarification, adequacy and responsiveness in semi-structured telephone and face-toface interviews. Qualitative Research, 13(1), 87-106.

Ivankova, N. V., Creswell, J. W., \& Stick, S. L. (2006). Using Mixed-Methods Sequential Explanatory Design: From Theory to Practice. Field Methods, 18(1), 3-20.

Jann, W., \& Wegrich, K. (2007). Theories of the Policy Cycle. In F. Fischer, G. J. Miller, \& M. S. Sidney (Eds.), Handbook of Public Policy Analysis: Theory, Politics, and Methods. (pp. 43-62). CRC Press.

Jayaraman, T., Kanitkar, T., \& D'souza, M. (2011a). Equitable access to sustainable development: An Indian approach (Scientific paper). Experts from BASIC countries. Jayaraman, T., Kanitkar, T., \& D'souza, M. (2011b). Equity and burden sharing in emission scenarios: A carbon budget approach. In N. K. Dubash (Ed.), Handbook of Climate Change and India: Development, Politics and Governance (pp. 130-146). Routledge. Jenkins-Smith, H. C., Nohrstedt, D., Weible, C. M., \& Sabatier, P. A. (2014). The Advocacy Coalition Framework: Foundations, Evolution, and Ongoing Research. In P. A. Sabatier \& C. M. Weible (Eds.), Theories of the Policy Process (3rd ed., pp. 183-223). Boulder: Westview Press.

Jordan, A., \& Adelle, C. (2013). EU Environmental policy at 40: Retrospect and prospect. In A. Jordan \& C. Adelle (Eds.), Environmental Policy in the EU: Actors, Institutions and Processes. (3rd edition, pp. 369-386). Oxon: Routledge.

Jordan, A., \& Huitema, D. (2014a). Innovations in climate policy: the politics of invention, diffusion, and evaluation. Environmental Politics, 23(5), 715-734.

Jordan, A., \& Huitema, D. (2014b). Policy innovation in a changing climate: Sources, patterns and effects. Global Environmental Change, 29, 387-394. 
Jordan, A., Huitema, D., Hilden, M., van Asselt, H., Rayner, T. J., Schoenefeld, J. J., ... Boasson, E. L. (2015). Emergence of polycentric climate governance and its future prospects. Nature Clim. Change, 5(11), 977-982.

Jordan, A., \& Matt, E. (2014). Designing policies that intentionally stick: policy feedback in a changing climate. Policy Sciences, 47(3), 227-247.

Jörgens, H., Lenschow, A., \& Liefferink, D. (2014). Understanding Environmental Policy Convergence - The Power of Words, Rules and Money. Croydon: Cambridge University Press.

Jung, M., Vieweg, M., Eisbrenner, K., Höhne, N., Ellermann, C., Schimschar, S., \& Beyer, C. (2010). Nationally Appropriate Mitigation Actions: Insights from example development.

Katzenstein, P. J. (Ed.). (1996). The Culture of National Security. New York: Columbia University Press.

Keohane, R. O. (2015). The Global Politics of Climate Change: Challenge for Political Science. PS: Political Science \& Politics, 48(1), 19-26.

Kim, J. A., Corfee-Morlot, J., \& de T'Serclaes, P. (2009). Linking mitigation actions in developing countries with mitigation support: A conceptual framework. Paris: OECD.

King, G., Keohane, R. O., \& Verba, S. (1994). Designing Social Inquiry: Scientific Inference in Qualitative Research. Princeton University Press.

Kingdon, J. W. (2011). Agendas, Alternatives, and Public Policies (Updated 2nd). Longman. Kiser, L. L., \& Ostrom, E. (1982). The Three Worlds of Action: A Metatheoretical Synthesis of Institutional Arrangements. In E. Ostrom (Ed.), Strategies of Political Inquiry (pp. 179222). Beverly Hills: CA: Sage.

Klotz, A. (1995). Norms Reconstituting Interests: Global Racial Equality and U.S. Sanctions Against South Africa. International Organization, 49(3), 451-478.

La Rovere, E. L., Pereira, A. O., Dubeux, C. B. S., \& Wills, W. (2014). Climate change mitigation actions in Brazil. Climate and Development, 6(sup1), 25-33.

Lachapelle, E., \& Paterson, M. (2013). Drivers of national climate policy. Climate Policy, 13(5), 547-571.

Laffont, J. J. (2005). Regulation and Development. Cambridge: Cambridge University Press.

Landman, T. (2008). Issues and Methods in Comparative Politics: An INtroduction (3rd ed.). Abingdon, Oxon ; New York, NY: Routledge.

Landolt, L. K. (2004). (Mis)Constructing the Third World? Constructivist Analysis of Norm Diffusion. Third World Quarterly, 25(3), 579-591.

Lasswell, H. D. (1956). The Decision Process: Seven Categories of Functional Analysis. College Park, Maryland: University of Maryland Press.

Lasswell, H. D. (1971). A Pre-View of Policy Sciences. New York: American Elsevier.

Legro, J. W. (1997). Which norms matter? Revisiting the "failure" of internationalism. International Organization, 51(01), 31-63. 
Levina, E., \& Helme, N. (2009). Nationally Appropriate Mitigation Actions by Developing Countries: Architecture and Key Issues. Washington: Centre for Clean Air and Policy (CCA).

Lieberman, E. S. (2005). Nested Analysis as a Mixed-Method Strategy for Comparative Research. American Political Science Review, 99(03), 435-452.

Lijphart, A. (1971). Comparative Politics and the Comparative Method. The American Political Science Review, 65(3), 682-693.

Linnér, B.-O., Mickwitz, P., \& Román, M. (2012). Reducing greenhouse gas emissions through development policies: a framework for analysing policy interventions. Climate and Development, 4(3), 175-186.

Linnér, B.-O., \& Pahuja, N. (2012). A Registry of Nationally Appropriate Mitigation Actions: Goals, Outcomes, and Institutional Requisites. AMBIO: A Journal of the Human Environment, 41(1), 56-67.

Lütken, S., Aalders, E., Peters, N., Pretlove, B., \& Trexler, M. (2011). Measuring Reporting Verifying: A primer on MRV for Nationally Appropriate Mitigation Actions. Roskilde: UNEP Ris $\varnothing$ Centre. Retrieved from http://namapipeline.org/Publications/MRV_PrimerNationallyAppropriateMitigationA ctions.pdf

Mahoney, J., \& Goertz, G. (2006). A tale of two cultures: Contrasting Quantitative and Qualitative research. Political Analysis, 14, 227-249.

Malets, O. (2014). When Transnational Standards Hit the Ground: Domestic Regulations, Compliance Assessment and Forest Certification in Russia. Journal of Environmental Policy \& Planning, 17(3), 332-359.

March, J. G., \& Olsen, J. P. (2009). Elaborating the "New institutionalism." In R. E. Goodin (Ed.), The Oxford Handbook of Political Science (pp. 159-175). Oxford: Oxford University Press.

Masters, L. (2013). Reaching the Crossroads: The Development of Climate Governance in South Africa. In D. Held, C. Roger, \& E.-M. Nag (Eds.), Climate Governance in the Developing World (pp. 258-276). Cambridge: Polity Press.

Mcallister, L. K. (2010). Dimensions of Enforcement Style: Factoring in Regulatory Autonomy and Capacity. Law \& Policy, 32(1), 61-78.

McBeth, M. M., Jones, M. D., \& Shanahan. (2014). The Narrative Policy Framework. In P. A. Sabatier \& C. M. Weible (Eds.), Theories of the Policy Process (Third, pp. 225-266). Boulder: Westview Press.

Meadowcroft, J. (2012). Greening the State? In P. F. Steinberg \& S. D. VanDeever (Eds.), Comparative Environmental Politics: Theory, Practice, and Prospects (pp. 63-87). Massachusetts: MIT Press.

Michaelowa, K., \& Michaelowa, A. (2012). India as an emerging power in international climate negotiations. Climate Policy, 12(5), 575-590.

Mickwitz, P., Aix, F., Beck, S., Carss, D., Ferrand, N., Görg, C., ... van Bommel, S. (2009). Climate Policy Integration, Coherence and Governance (PEER No. 2). Helsinki: 
Partnership for European Environmenral Research. Retrieved from

http://www.peer.eu/publications/climate-policy-integration-coherence-andgovernance/

Milner, H. V. (1997). Interests, Institutions, and Information. New Jersey: Princeton University Press.

Mobjörk, M., \& Linnér, B.-O. (2006). Sustainable funding? How funding agencies frame science for sustainable development. Environmental Science \& Policy, 9(1), 67-77.

Morris, M., \& Martin, L. (2015). Political Economy of Climate-relevant Policies: the Case of Renewable Energy in South Africa. (Evidence Report No. 128). Cape Town: Institute of Development Studies. Retrieved from

http://opendocs.ids.ac.uk/opendocs/bitstream/handle/123456789/5986/ER128_Poli ticalEconomyofClimaterelevantChangePoliciestheCaseofRenewableEnergyinSouthAfr ica.pdf?sequence $=6$

Nachmany, M., Fankhauser, S., Davidova, J., Kingsmill, N., Landesman, T., Roppongi, H., ... Townshend, T. (2015). The 2015 Global Climate Legislation Study: Summary for Policy-makers. UK: The Globe Legislators Organisation. Retrieved from http://www.Ise.ac.uk/GranthamInstitute/wpcontent/uploads/2015/05/Global_climate_legislation_study_20151.pdf

NAMA Registry. (2017). Public NAMA: Information on Support. Retrieved August 23, 2016, from http://www4.unfccc.int/sites/nama/SitePages/InformationOnSupport.aspx

Narasimha, R. (2011). Equity in climate change: the range of metrics and views. In N. K. Dubash (Ed.), Handbook of Climate Change and India: Development, Politics and Governance (pp. 147-156). Routledge.

Nasiritousi, N. (2016). Shapers, Brokers and Doers: The Dynamic Roles of Non-State Actors in Global Climate Change Governance. Linköping University, Linköping. Retrieved from https://liu.diva-portal.org/smash/get/diva2:881212/FULLTEXT01.pdf

National Geographic, \& GlobeScan. (2014). Greendex 2014: Consumer Choice and the Environment: A Worldwide Tracking Survey (p. 172). Ontorio: National Geographic and GlobeScan. Retrieved from http://images.nationalgeographic.com/wpf/mediacontent/file/2014_Global_Report-cb1411689801.pdf

National Planning Commission. (2011, October 11). National Development Plan. National Planning Commission.

Never, B., \& Betz, J. (2014). Comparing the Climate Policy Performance of Emerging Economies. World Development, 59, 1-15.

Newell, P. (2009). Varieties of CDM Governance: Some Reflections. The Journal of Environment \& Development, 18(4), 425-435.

Newell, P., \& Phillips, J. (2011). Governing Clean Development: What Have We Learnt? (Policy brief). Norwich: University of East Anglia.

North, D. (1990). Institutions, Institutional Change and Economic Performance. Cambridge: Cambridge University Press. 
Nunes, J., \& Peña, A. M. (2015). Marina Silva and the rise of sustainability in Brazil. Environmental Politics, 24(3), 506-511.

Okubo, Y., Hayashi, D., \& Michaelowa, A. (2011). NAMA crediting: how to assess offsets from and additionality of policy-based mitigation actions in developing countries. Greenhouse Gas Measurement and Management, 1(1), 37-46.

Ostrom, E. (2011). Background on the Institutional Analysis and Development Framework. Policy Studies Journal, 39(1), 7-27.

Ostrom, E., Cox, M., \& Schlager, E. (2014). An Assessment of the Institutional Analysis and Development Framework and Introduction of the Social-Ecological Systems Framework. In P. A. Sabatier \& C. M. Weible (Eds.), Theories of the Policy Process (Third pp. 267-306). Boulder: Westview Press.

Oxford Poverty and Human Development Initiative. (2016). Global Multidimentional Poverty Index Databank. Retrieved February 15, 2017, from http://www.dataforall.org/dashboard/ophi/index.php/

Pennings, P., Keman, H., \& Kleinnijenhuis, J. (1999). The comparative approach: theory and method. In Doing research in political science: an introduction to comparative methods and statistics (pp. 21-40). London: SAGE Publications.

Prado, M. M. (2013). Bureaucratic Resistance to Regulatory Reforms: Contrasting Experiences in Electricity and Telecommunications in Brazil. In N. K. Dubash \& B. Morgan (Eds.), The Rise of the Regulatory State of the South: Infrastructure and Development in Emerging Economies (First pp. 75-97). Oxford: Oxford University Press.

Preston, B. L., Mustelin, J., \& Maloney, M. C. (2015). Climate adaptation heuristics and the science/policy divide. Mitigation and Adaptation Strategies for Global Change, 20(3), 467-497.

Purdon, M. (2015). Advancing Comparative Climate Change Politics: Theory and Method. Global Environmental Politics, 15(3), 1-26.

Putnam, R. D. (1988). Diplomacy and Domestic Politics: The Logic of Two-Level Games. International Organization, 42(3), 427-460.

Raghunandan, D. (2012). India's Climate Policy: Squaring the Circle. IDS Bulletin, 43, 122129.

Ragin, C. C. (1987). The Comparative Method: Moving Beyond Qualitative and Quantitative Strategies. Berkeley: University of California Press.

Rajamani, L. (2009). India and Climate Change: What India Wants, Needs, and Needs to Do. India Review, 8(3), 340-374.

Rajan, S., \& Byravan, S. (2011). Developmental Benefits from a Low-Carbon Pathway. Retrieved from http://papers.ssrn.com/sol3/papers.cfm?abstract_id=1946701

Republic of South Africa. (2006, October 20). Sustainable Development - Policies and Measures. UNFCCC.

Republic of South Africa. (2008). Proposal by South Africa: Register of nationally-appropriate mitigation actions by developing countries, including Sustainable Development 
Policies and Measures (Submission by South Africa No. 15B). UNFCCC. Retrieved from http://unfccc.int/files/kyoto_protocol/application/pdf/southafricamitigationbap3009 08.pdf

Republic of South Africa. (2010, January 29). South Africa: Copenhagen Pledge to UNFCCC. Republic of South Africa. (2011a). National Climate Change Response White Paper.

Department of Environmental Affairs. Retrieved from

https://www.environment.gov.za/sites/default/files/legislations/national_climatecha nge_response_whitepaper.pdf

Republic of South Africa. (2011b). The launch of the SARi in Durban during the UNFCCC COP

17 climate change conference. Government of South Africa. Retrieved from

https://sarenewablesinitiative.files.wordpress.com/2011/12/sa-renewablesinitiative-launch-7-december-2011.pdf

Republic of South Africa. (2012). National Development Plan 2030: Our future - make it work. National Planning Commission, The Presidency. Retrieved from http://www.africaportal.org/sites/default/files/ndp2030_cover_overview.pdf

Republic of South Africa. (2014). South Africa's 1st Biennial Update Report (pp. 1-160). Pretoria: Department of Environmental Affairs.

Reus-Smit, C. (2005). Constructivism. In Theories of International Relations (3rd ed., p. 188212). Hampshire and New York: Palgrave Macmillan.

Risse, T., Ropp, S. C., \& Sikkink, K. (Eds.). (1999). The power of Human Rights: International Norms and Domestic Change (1st ed.). Cambridge: Cambridge University Press.

Roger, C., Hale, T., \& Andonova, L. (2017). The Comparative Politics of Transnational Climate Governance. International Interactions, 43(1), 1-25.

Röser, F., Van Tilburg, X., Davis, S., \& Höhne, N. (2011). Annual Status Report on Nationally Appropriate Mitigation Actions (NAMAs) (Annual report). Ecofys, ECN and CCAP.

Rothkopf, D. (2009, July 9). The world's best foreign minister. Foreign Policy. Retrieved from https://foreignpolicy.com/2009/10/07/the-worlds-best-foreign-minister/

Sabatier, P. A. (Ed.). (1999). Theories of the Policy Process (First). Boulder: Westview Press.

Sabatier, P. A., \& Jenkins-Smith, H. C. (1993). Policy Change and Learning: An Advocacy Coalition Approach. Boulder: Westview Press.

Sabatier, P. A., \& Weible, C. M. (Eds.). (2014). Theories of the Policy Process (3rd ed.). Boulder: Westview Press.

Sabatier, P., \& Mazmanian, D. (1980). The Implementation of Public Policy: A Framework of Analysis. Policy Studies Journal, 8(4), 538-560.

Sandberg, J., \& Alvesson, M. (2011). Ways of constructing research questions: gap-spotting or problematization? Organization, 18(1), 23-44.

Sartori, G. (1991). Comparing and Miscomparing. Journal of Theoretical Politics, 3(3), 243257.

Schlager, E. (1999). A comparison of Frameworks, Theories and Models of Policy Processes. In P. A. Sabatier (Ed.), Theories of the Policy Process (First, pp. 233-260). Boulder: Westview Press. 
Schlager, E., \& Weible, C. M. (2013). New Theories of the Policy Process. Policy Studies Journal, 41(3), 389-396.

Schmitt, S. (2015). Comparative approaches to the study of public policy-making. In E. Araral, S. Fritzen, M. Howlett, M. Ramesh, \& X. Wu (Eds.), Routledge Handbook of Public Policy (pp. 29-43). New York: Routledge.

Schrodt, P. A. (2006). Beyond the Linear Frequentist Orthodoxy. Political Analysis, 14(3), 335-339. https://doi.org/10.1093/pan/mpj013

Scott, W. R. (2014). Institutions and Organizations: Ideas, Interests, and Identities (4th ed.). Stanford: SAGE Publications.

Scrieciu, S. Ş., Belton, V., Chalabi, Z., Mechler, R., \& Puig, D. (2014). Advancing methodological thinking and practice for development-compatible climate policy planning. Mitigation and Adaptation Strategies for Global Change, 19(3), 261-288.

Selin, H., \& VanDeever, S. D. (2009). Changing Climates in North American Politics. Cambridge, MA: MIT Press.

Setzer, J. (2014). How Subnational Governments are Rescaling Environmental Governance: The Case of the Brazilian State of São Paulo. Journal of Environmental Policy \& Planning, 1-17.

Shrivastava, A., \& Kothari, A. (2012). Churning the Earth: The Making of Global India. New Delhi: Penguin Books.

Shrivastava, M. K., Pahuja, N., Tewari, R., Pandey, N., \& Agarwal, S. (2014). Mainstreaming development imperatives into NAMAs: An approach. In M. Jooste, E. Tyler, K. Coetzee, A. Boyd, \& M. Boulle (Eds.), Internalising mitigation activities into the development priorities and approaches of developing countries (pp. 22-38). Cape Town: Energy Research Centre, University of Cape Town.

Shrivastava, M. K., \& Upadhyaya, P. (2014). Whither multilateralism? Implications of bilateral NAMA finance for development and sovereignty concerns of developing countries. In M. Jooste, E. Tyler, K. Coetzee, A. Boyd, \& M. Boulle (Eds.), Internalising mitigation activities into the development priorities and approaches of developing countries (pp. 78-89). Cape Town: Energy Research Centre, University of Cape Town.

Sidney, M. S. (2007). Policy Formulation: Design and Tools. In F. Fischer, G. J. Miller, \& M. S. Sidney (Eds.), Handbook of Public Policy Analysis: Theory, Politics, and Methods. (pp. 79-87). Florida: CRC Press.

Silverman, D. (2006). Interpreting Qualitative Data (3rd ed.). SAGE Publications.

Singh, A. (2009). Climate co-benefit policies for the Indian power sector: domestic drivers and North-South cooperation. Climate Policy, 9(5), 529-543.

Small, M. L. (2011). How to Conduct a Mixed Methods Study: Recent Trends in a Rapidly Growing Literature. Annual Review of Sociology, 37(1), 57-86.

Smismans, S. (2015). Policy Evaluation in the EU: The Challenges of Linking Ex Ante and Ex Post Appraisal. European Journal of Risk Regulation, 6(1), 6-26. 
Stålgren, P. (2006). Worlds of Water: Worlds Apart. How targeted domestic actors transform international regimes. Göteborg: University of Gothenburg. Retrieved from https://gupea.ub.gu.se/handle/2077/16750

Steinberg, P. F. (2012). Welcome to the Jungle: Political Theory and Political Instability. In Comparative Environmental Politics: Theory, Practice and Prospects. (pp. 255-284). The USA: The MIT Press.

Steinberg, P. F., \& Vandeveer, S. D. (2012). Comparative Environmental Politics. The MIT Press.

Sterk, W. (2010a). Nationally Appropriate Mitigation Actions: Definitions, Issues and Options (JIKO Policy Paper No. 2). Wuppertal: Wuppertal Institute for Climate, Environment and Energy.

Sterk, W. (2010b). New mechanisms for the carbon market? Sectoral Crediting, sectoral Trading, and Crediting Nationally Appropriate Mitigation Actions. (JIKO Policy Paper). Wuppertal: Wuppertal Institute for Climate, Environment and Energy. Retrieved from http://jiko-

bmu.de/files/basisinformationen/application/pdf/pp_nmbm_submissions.pdf

Stevenson, H. (2015). Contemporary Discourses of Green Political Economy: A Q Method Analysis. Journal of Environmental Policy \& Planning, 0(0), 1-21.

Stokes, B., Wike, R., \& Carle, J. (2015). Global Concern about Climate Change, Broad Support for Limiting Emissions. (Numbers, Facts and Trends shaping the World). Pew Research Centre. Retrieved from http://www.pewglobal.org/files/2015/11/PewResearch-Center-Climate-Change-Report-FINAL-November-5-2015.pdf

Sugiyama, N., \& Takeuchi, T. (2008). Local Policies for Climate Change in Japan. The Journal of Environment \& Development, 17(4), 424-441.

Tarrow, S. (2010). Bridging the Qualitative-Quantitative Divide. In Rethinking Social Inquiry: Diverse Tools, Shared Standards. (2nd ed., pp. 101-110). Plymouth: Rowman and Littlefield publishers.

The Presidency. (2014). Twenty Year Review: South Africa 1994-2014 (p. 175). The Presidency. Retrieved from http://www.thepresidency-dpme.gov.za/news/Pages/20Year-Review.aspx

Tollefson, J. (2016). Political upheaval threatens Brazil's environmental protections. Nature News, 539(7628), 147-148.

Tuerk, A., Mehling, M., Flachsland, C., \& Sterk, W. (2009). Linking carbon markets: concepts, case studies amd pathways. Climate Policy, 9(4), 341-357.

Tyler, E. (2011). Aligning South African energy and climate change mitigation policy. Climate Policy, 10(5), 575-588.

Tyler, E., Boyd, A., Coetzee, K., Torres Gunfaus, M., \& Winkler, H. (2013). Developing country perspectives on "mitigation actions", "NAMAs", and "LCDS." Climate Policy, 1-7.

Tyler, E., Boyd, A. S., Coetzee, K., \& Winkler, H. (2014). A case study of South African mitigation actions (For the special issue on mitigation actions in five developing countries). Climate and Development, 6(sup1), 49-58. 
Tyler, E., \& Gunfaus, M. T. (2015). What was the contribution of the Long Term Mitigation

Scenario process to South African climate mitigation policy? Cape Town: MAPS.

UN. (1992). The Framework Convention on Climate Change (No. A/AC.327/18 (Part II)/Add.

1.). Retrieved from http://unfccc.int/resource/docs/convkp/conveng.pdf

UNDP. (2013). Income Gini coefficient. Retrieved February 15, 2017, from

http://hdr.undp.org/en/content/income-gini-coefficient

UNDP. (2017). Human Development Index and its components. Retrieved February 15, 2017, from http://hdr.undp.org/en/composite/HDI

UNEP DTU. (2016, January 11). NAMA Pipeline Analysis and Database. Retrieved July 11, 2016, from

UNEP RIS $\varnothing$ Centre. (2016, December). UNEP Risoe CDM/JI Pipeline Analysis and Database.

Retrieved from http://www.cdmpipeline.org/

UNFCCC. (2007). COP13: Addendum 1 to report (including the Bali Action Plan) (No.

FCCC/CP/2007/6/Add.1). Bali: UNFCCC.

UNFCCC. (2008). Report of the Conference of the Parties on its thirteenth session, held in Bali from 3 to 15 December 2007. (Decisions adopted by the Conference of the Parties No. FCCC/CP/2007/6/Add.1). Bali: UNFCCC. Retrieved from

http://unfccc.int/documentation/documents/advanced_search/items/6911.php?prir ef $=600004671$

UNFCCC. (2009a). Ideas and proposals on the elements contained in paragraph 1 of the Bali Action Plan. Submission from Parties: Part II. (Submissions from Parties: Part II. No. FCCC/AWGLCA/2009/MISC.4 (Part II)). UNFCCC. Retrieved from http://unfccc.int/resource/docs/2009/awglca6/eng/misc04p02.pdf

UNFCCC. (2009b, May 19). FCCC/AWGLCA/2009/MISC.4 (Part II) - misc04p02_Ideas and proposals on the elements contained in paragrpah 1 of the Bali Action Plan.pdf. UNFCCC. Retrieved from http://unfccc.int/resource/docs/2009/awglca6/eng/misc04p02.pdf

UNFCCC. (2010). COP 16. Retrieved December 17, 2012, from http://unfccc.int/meetings/cancun_nov_2010/session/6254/php/view/decisions.php UNFCCC. (2011a). Compilation of information on nationally appropriate mitigation actions to be implemented by Parties not included in Annex I to the Convention (No. FCCC/AWGLCA/2011/INF.1). UNFCCC. Retrieved from http://unfccc.int/resource/docs/2011/awglca14/eng/inf01.pdf

UNFCCC. (2011b). Report of the Conference of the Parties on its sixteenth session, held in Cancun from 29 November to 10 December 2010 (1/CP.16 No. FCCC/CP/2010/7/Add.1). Bonn: UNFCCC. Retrieved from https://unfccc.int/resource/docs/2010/cop16/eng/07a01.pdf

UNFCCC. (2012). Workshop to further the understanding of the diversity of nationally appropriate mitigation actions by developing country Parties, underlying assumptions, and any support needed for implementation of these action (AWG-LCA 15). Bonn: Plenary, Hotel Maritim. Retrieved from http://unfccc4.meta- 
fusion.com/kongresse/sb36/templ/play.php?id_kongresssession=5086\&theme=unfc CC

UNFCCC. (2014). FCCC/SBI/2014/INF.11 Report on the second workshop under the work programme to further the understanding of the diversity of NAMAs by developing country parties. UNFCCC. Retrieved from http://unfccc.int/resource/docs/2014/sbi/eng/inf11.pdf

UNFCCC. Paris Agreement (2015). Retrieved from http://unfccc.int/files/essential_background/convention/application/pdf/english_par is_agreement.pdf

Upadhyaya, P. (2010). Is emission trading a possible policy option for India? Climate Policy, 10(5), 560-574.

Upadhyaya, P. (2016). Aligning Climate Policy with National Interest: Disengagements with Nationally Appropriate Mitigation Actions in South Africa. Journal of Environmental Policy \& Planning, 18(4), 463-481.

Upadhyaya, P., Friman, M., \& Linnér, B.-O. (2012). Financing Nationally Appropriate Mitigation Actions: A phased approach (Working Paper). Norrköping: Centre for Climate Science and Policy Research. Retrieved from http://www.cspr.se/nytt-francspr/1.421656/1.423482/Finalversion12120309.32.pdf

van Asselt, H., Berseus, J., Gupta, J., \& Haug, C. (2010). Nationally appropriate mitigation actions (NAMAs) in developing countries: challenges and opportunities. (Scientific Assessment and Policy Analysis No. 500102 035). Amsterdam: Institute for Environmental Studies (IVM), Vrije Universiteit Amsterdam.

van Asselt, H., Rayner, T., \& Persson, Å. (2015). Climate Policy Integration. In K. Bäckstrand \& E. Lövbrand (Eds.), Research Handbook on Climate Governance (pp. 388-399). Edward Elgar Publishing.

Van Tilburg, X., Cameron, L., Würtenberger, L., \& Bakker, S. J. A. (2011). On developing a NAMA proposal: Discussion paper. The Energy research Centre of the Netherlands (ECN).

Van Tilburg, X., Würtenberger, L., de Coninck, H., \& Bakker, S. (2011). Paving the way for low-carbon development strategies. Policy Study ECN-E-11-059. Energy Research Centre of the Netherlands: Petten, Netherlands. Available Online at: Http://Www. Ecn. NI/Publications/ECN-E-11-059.

Viola, E., \& Franchini, M. (2014). Brazilian climate politics 2005-2012: ambivalence and paradox. Wiley Interdisciplinary Reviews: Climate Change, 5(5), 677-688.

Vogel, B., \& Henstra, D. (2015). Studying local climate adaptation: A heuristic research framework for comparative policy analysis. Global Environmental Change, 31, 110120.

Vogel, S. K. (1997). International Games With National Rules: How Regulation Shapes Competition in "Global" Markets. Journal of Public Policy, 17(02), 169-193.

Wang-Helmreich, H., Sterk, W., Wehnert, T., \& Arens, C. (2011). Current developments in Pilot Nationally Appropriate Mitigation Actions of Developing Countris (NAMAs) 
(Policy paper No. 01/2011). Wuppertal: Wuppertal Institute for Climate, Environment and Energy.

Weible, C. M. (2014). Introducing the Scope and Focus of the Policy Process Research and Theory. In P. A. Sabatier \& C. M. Weible (Eds.), Theories of the Policy Process (Third, pp. 3-21). Boulder: Westview Press.

Wellstead, A., \& Stedman, R. (2015). Mainstreaming and Beyond: Policy Capacity and Climate Change Decision-Making. Michigan Journal of Sustainability, 3, 47-63.

Williamson, O. E. (1975). Markets and Hierarchies: Analysis and Antitrust Implications. Free Press.

Winkler, H., \& Dubash, N. K. (2015). Who determines transformational change in development and climate finance? Climate Policy, 1-9.

Wlokas, H., Rennkamp, B., Torres, M., Winkler, H., Boyd, A., Tyler, E., \& Fedorsky, C. (2012). MAPS: Low Carbon Development and Poverty Exploring poverty alleviating mitigation action in developing countries (pp. 1-48). Cape Town: University of Cape Town.

World Bank. (2013). Population living in areas where elevation is below 5 meters (percentage of total population) | Data. Retrieved February 15, 2017, from http://data.worldbank.org/indicator/EN.POP.EL5M.ZS

World Bank. (2016a). Access to electricity (percentage of population) | Data. Retrieved February 15, 2017, from http://data.worldbank.org/indicator/EG.ELC.ACCS.ZS

World Bank. (2016b). GDP per capita, PPP (constant USD) | Data. Retrieved February 15, 2017, from http://data.worldbank.org/indicator/NY.GDP.PCAP.PP.KD

World Bank. (2016c). GDP, PPP (constant 2011 USD) | Data. Retrieved February 15, 2017, from http://data.worldbank.org/indicator/NY.GDP.MKTP.PP.KD

World Bank. (2016d). Population, total | Data. Retrieved February 15, 2017, from http://data.worldbank.org/indicator/SP.POP.TOTL

World Bank. (2016e). Urban population (percentage of total) | Data. Retrieved February 15, 2017, from http://data.worldbank.org/indicator/SP.URB.TOTL.IN.ZS

World Bank. (2016f). Proportion of seats held by women in national parliaments (Percentage) | Data. Retrieved February 15, 2017, from http://data.worldbank.org/indicator/SG.GEN.PARL.ZS

World Bank, \& Ecofys. (2016). Carbon Pricing Watch 2016. World Bank and Ecofys. Worthington, R. (2014). Report on a Review of Implementation of South Africa's National Climate Change Response White Paper (NCCRWP). Electricity Governance Initiative South Africa, Project 90 by 2030 and EnAct International.

WRI. (2016). Climate Analysis Indicator Tool (CAIT) Climate Data Explorer. Retrieved February 15, 2017, from http://www.wri.org/our-work/project/cait-climate-dataexplorer

Wurzel, R., \& Connelly, J. (2010). The European Union as a Leader in International Climate Change Politics (Hardback) - Routledge. Oxon: Routledge. 
WWF. (2010, November). Emerging Economies: How the developing world is starting a new era of climate change leadership. Retrieved October 26, 2012, from http://awsassets.panda.org/downloads/emerging_economies_report_nov_2010.pdf Zahariadis, N. (2014). Ambiguity and Multiple Streams. In P. A. Sabatier \& C. M. Weible (Eds.), Theories of the Policy Process (Third, pp. 25-58). Boulder: Westview Press. Zimmermann, L. (2016). Same Same or Different? Norm Diffusion Between Resistance, Compliance, and Localization in Post-conflict States. International Studies Perspectives, 17(1), 98-115.

Zohlnhöfer, R., Herweg, N., \& Huß, C. (2015). Bringing Formal Political Institutions into the Multiple Streams Framework: An Analytical Proposal for Comparative Policy Analysis. Journal of Comparative Policy Analysis: Research and Practice, 18(3), 1-14.

Zuma, J. (2009, December 18). Address by President Jacob Zuma at UN Climate Change Conference. The Presidency. Retrieved from http://www.thepresidency.gov.za/pebble.asp?relid=555. 


\section{APPENDICES}

\section{Appendix I: Interview Guide}

\section{Section I: For all the respondents (20-25 Minutes)}

The first section of the interview guide applies to all respondents. Questions are presented to understand national priorities.

\section{Understanding the Individual and country context}

1. Briefly elaborate on your professional affiliations and your role in your country's climate and/or development policy.

2. What are the development challenges and opportunities facing your country?

3. What are the interventions being planned or already implemented by your government to address the development policy goals identified above? (How is your country dealing with these challenges and opportunities?)

\section{Development and climate change}

1. To what extent and in what ways has the concept of sustainable development informed the debate and policy-making in your country/ your country's development priorities?

2. To what extent has climate change been linked to development initiatives in your country? How has it evolved over time?

3. How relevant is climate change a policy problem in your country and how is it being dealt with?

\section{National climate policy initiatives}

1. What are the key policy initiatives undertaken in your country to address climate change?

2. How were these climate policy initiatives developed and formulated?

3. Who are the key actors involved in climate policy process in your country? To what extent and how are non-governmental actors involved in these processes?

4. To what extent are these climate policy measures linked to your country's development objectives? Do you see any trade-offs or synergies thereof?

5. Have you heard about Nationally Appropriate Mitigation Actions (NAMAs)? If so, can you briefly describe what they imply?

\section{With which statement do you identify more?}

A) I am familiar with the concept of NAMAs and engage with it either on a conceptual or at implementation level. B) I am not familiar with the concept of NAMAs or have only come across this concept in passing and do not engage with it actively.

If statement A then go to section II, If statement B then go to section III. 


\section{Section II: Respondents familiar with NAMAs (25-35 Minutes)}

Questions are presented to understand the reasons behind and mode of NAMA engagement or lack thereof.

\section{National objectives}

1. What would you consider as nationally appropriate climate action in your country?

2. What are the key objectives that can be achieved by means of NAMAs?

\section{NAMA process}

1. To what extent does your government support NAMA formulation and development?

2. How are NAMAs identified and defined in your country? Kindly elaborate.

3. At what level of government are NAMAs being developed? Which sectors do they address?

4. Which factors motivate or impede NAMA proposals in your country?

5. Which actors are involved in the NAMA process in your country? How are they involved?

\section{International context of NAMAs}

1. Has international support been instrumental for NAMA development in your country? If so, then in what ways?

2. To what extent should your country seek international support for NAMAs?

3. Do you consider your country's Copenhagen pledges as NAMAs? Why/Why not?

4. What in your eyes should NAMAs do for your country?

5. Do you consider NAMA a useful or a redundant formulation?

\section{Section III: Respondents unfamiliar with NAMAs (20-25 Minutes)}

Questions are presented to understand the initial reactions to the concept of NAMAs.

\section{Objectives}

1. How familiar are you with the United Nations climate negotiations? What is your personal view of these negotiations?

2. What are your initial reactions to the term NAMAs?

3. What do you see as nationally appropriate climate action in your country context?

\section{Implementation}

1. How is your organization involved in climate action?

2. How useful is the NAMA concept for dealing with the challenges and opportunities highlighted by you?

3. What in your eyes should NAMAs do for your country? 
Appendix II: Interviewee Descriptions

\section{South African Interviewees:}

SA1. Senior Researcher, Energy Research Centre (ERC) in University of Cape Town (UCT), May 2014.

SA2. Senior Researcher, ERC, May 2014.

SA3. Consultant, The Green House, May 2014.

SA4. Employee, SouthSouthNorth, May 2014.

SA5. Manager, Sustainable Energy Africa, May 2014.

SA6. Independent Consultant 1, May 2014.

SA7. Corporate Consultant, Eskom, May 2014.

SA8. Independent Consultant 2, May 2014.

SA9. Manager, South Africa Centre for Carbon Capture and Storage, May 2014.

SA10. Official, Department of Environmental Affairs, May 2014.

SA11. Researcher, South Africa Institute of International Affairs, May 2014.

SA12. Senior Researcher, ERC, May 2014.

SA13. Independent Consultant 3, June 2014.

SA14. Senior Staff, World Wildlife Fund - South Africa, June 2014.

SA15. Official, National Treasury, June 2014.

SA16. Official 2, Department of Environmental Affairs, June 2014.

SA17. Senior Staff, ENSAfrica, June 2014.

SA18. Manager, Council for Scientific and Industrial Research, June 2014.

SA19. Senior Researcher, Institute for Global Dialogue, June 2014.

SA20. Advisor, South African - German Energy Programme (SAGEN), GIZ, June 2016.

SA21. Official 2, Department of Environmental Affairs, June 2016.

\section{Indian Interviewees:}

IN1. Advisor 1, GIZ India, April 2015.

IN2. Member, Climate Action Network South Asia, April 2015.

IN3. Independent consultant, Ex-Govt. Official, April 2015.

IN4. Researcher, The Energy and Resources Institute (TERI), April 2015.

IN5. Associate, Climate and Development Advice, April 2015.

IN6. Senior Staff, Intercooperation Social Development, April 2015.

IN7. Official, Bureau of Energy Efficiency (BEE), April 2015.

IN8. Senior Manager, IORA Ecological Solutions Pvt. Ltd, April 2015.

IN9. Senior Staff, Vasudha Foundation, May 2015.

IN10. Senior Staff, TERI, May 2015.

IN11. Senior Manager, Emergent Ventures India, May 2015.

IN12. Senior Staff, Shakti Sustainable Energy Foundation, May 2015.

IN13. Senior Fellow, Centre for Policy Research, May 2015.

IN14. Senior Advisor, Norwegian Embassy, May 2015.

IN15. Official, Ministry of New and Renewable Energy (MNRE), May 2015.

IN16. Advisor 2, GIZ India, November 2016. 


\section{Brazilian Interviewees:}

BR1. Ex-Chairman, Climate Change Commission, October 2015.

BR2. Senior Staff, University of Rio de Janerio, November 2015.

BR3. Senior Staff, COPPE, Universidade Federal do Rio de Janeiro, November 2015.

BR4. Senior Staff, University of Brasilia, November 2015.

BR5. Facilitator, United Nations Environment Programme, January 2016.

BR6. Senior Staff, System Study Greenhouse Gas Emissions Estimates (SEEG) Brazil, February 2016.

BR7. Official, Ministry of the Environment, March 2016. 
